\title{
WestVirginiaUniversity
}

THE RESEARCH REPOSITORY @ WVU

Graduate Theses, Dissertations, and Problem Reports

2005

\section{Effect of moisture and temperature on the mechanical properties of concrete}

\author{
Brian Downie \\ West Virginia University
}

Follow this and additional works at: https://researchrepository.wvu.edu/etd

\section{Recommended Citation}

Downie, Brian, "Effect of moisture and temperature on the mechanical properties of concrete" (2005). Graduate Theses, Dissertations, and Problem Reports. 1625.

https://researchrepository.wvu.edu/etd/1625

This Thesis is protected by copyright and/or related rights. It has been brought to you by the The Research Repository @ WVU with permission from the rights-holder(s). You are free to use this Thesis in any way that is permitted by the copyright and related rights legislation that applies to your use. For other uses you must obtain permission from the rights-holder(s) directly, unless additional rights are indicated by a Creative Commons license in the record and/ or on the work itself. This Thesis has been accepted for inclusion in WVU Graduate Theses, Dissertations, and Problem Reports collection by an authorized administrator of The Research Repository @ WVU. For more information, please contact researchrepository@mail.wvu.edu. 


\title{
Effect of Moisture and Temperature on the Mechanical Properties of Concrete
}

\author{
Brian Downie
}

Thesis submitted to the College of Engineering and Mineral Resources at West Virginia University in partial fulfillment of the requirements for the degree of

\author{
Master of Science \\ in \\ Mechanical Engineering
}

Samir Shoukry, Ph.D., Chair

Larry Banta, Ph.D.

Gergis William, Ph.D.

Mourad Riad, M.S.

Department of Mechanical and Aerospace Engineering

Morgantown, West Virginia

2005 


\title{
Abstract \\ Effect of Moisture and Temperature on the Mechanical Properties of Concrete
}

\author{
Brian Downie
}

Concrete is one of the most widely used building materials. Extensive research was accomplished testing concrete properties including but not limited to modulus of elasticity, compressive strength, tensile strength, and Poisson's ratio using modulus of elasticity and strength testing. The research was done under laboratory conditions. The ideal air temperature in the laboratory was between 68 and $71^{\circ} \mathrm{F}$, and the ideal air relative humidity in a laboratory was between 40 and 60 percent. Research was accomplished on properties of concrete during the curing process at extreme temperatures experienced in the developed world, but little on concrete that is already cured in the temperature range of $-4^{\circ} \mathrm{F}$ and $122^{\circ} \mathrm{F}$. There has also been some research of cured concrete at very high temperatures to simulate the strength properties of concrete in a fire. Virtually no research has been accomplished on the properties of concrete relating to moisture either during or after the curing process, thus there is a need for research on this topic.

Modulus of elasticity, compressive strength, and split tensile strength testing were conducted here at varying temperatures and degrees of saturation to examine what the effect is on normal concrete. The simulation was done with the aid of an environmental chamber constructed of widely available materials in the laboratory. The chamber works in conjunction with a freezer to provide chilled air and a heat gun to provide hot air. The chamber heating and cooling functions were controlled via a microcontroller. The degree of saturation in the specimens was controlled by massing the specimens. According to the compression and modulus of elasticity, testing concrete strength and modulus of elasticity of elasticity are inversely related to temperature as well as concrete water saturation. Concrete modulus of elasticity was directly related to concrete compressive strength in both temperature and moisture testing. Mathematical formulas were developed for modulus of elasticity, compressive strength, tensile strength, and Poisson's ratio.

Keywords: Temperature Controlled Testing Chamber, Modulus of Elasticity Test, Compressive Test, Split Tensile Test, Microcontroller, Temperature Variation, Degrees of Saturation 


\section{Acknowledgements}

This Thesis would not have been possible without the help of my advisor Dr. Shoukry and his research staff. Dr. Shoukry provided the ideas needed and support with his research staff to execute the project. Mourad Riad provided the most assistance with designing the experiments as well as the experimental setup including the multiplexer and data logger. Dr. Banta and Musat Crihalmeanu helped with the design of the control system needed to control the temperature of the testing chamber. Dr. Banta primarily aided with the microcontroller programming and Musat Crihalmeanu primarily aided with the wiring. Dr. Shoukry presented the idea to use a temperature controlled testing chamber for modulus of elasticity testing, which was designed and constructed with minimal help. Dr. William helped with the experimental setup and primarily report organization. 


\section{TABLE OF CONTENTS}

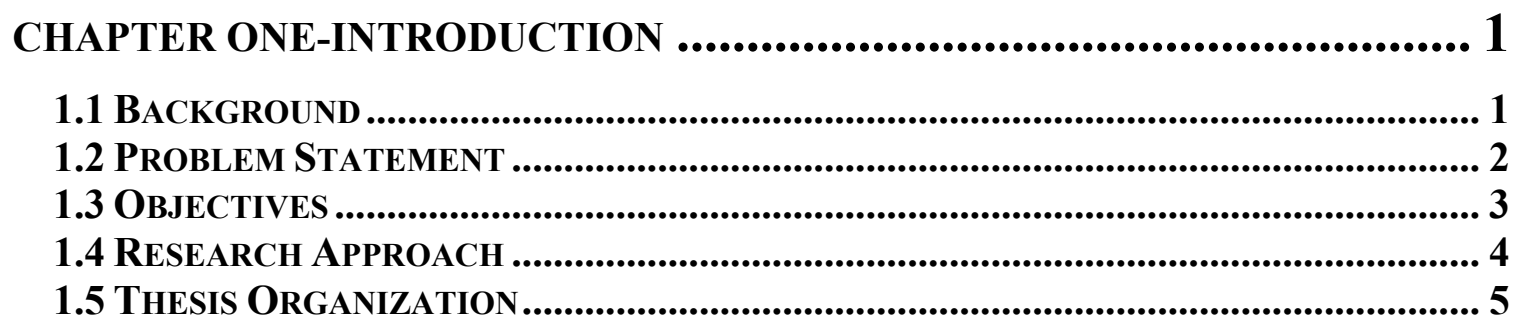

CHAPTER TWO-LITERATURE REVIEW............................................ 6

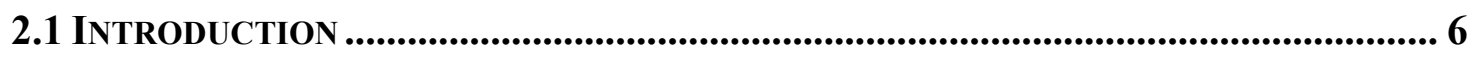

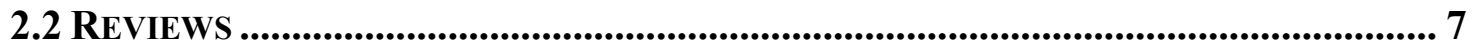

2.2.1 Effect of Varying Temperature on Concrete Properties.............................. 7

2.2.2 Concrete Testing Under High Temperatures................................................ 9

2.2.3 Concrete Testing Under Low Temperatures.................................................. 12

2.2.4 High Strength vs. Normal Strength Concrete at High Temperature........ 16

2.2.5 Effect of Temperature Variations on Concrete Creep ............................... 17

2.2.6 Effect of Degree of Saturation ............................................................................. 18

2.3 CONCLUSION.......................................................................................................... 18

CHAPTER THREE-SPECIMEN PRODUCTION ................................... 20

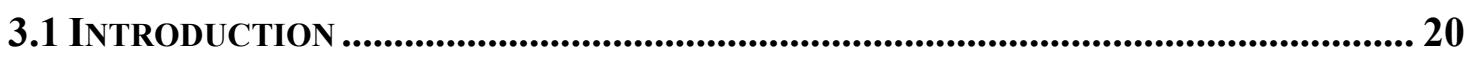

3.2 PREPARATION OF CONCRETE SPECIMENS............................................................ 21

3.2.1 Mold Preparation................................................................................................ 21

3.2.2 Concrete Curing........................................................................................... 22

3.2.3 Specimen Preparation for Temperature Testing ....................................... 22

3.2.4 Specimen Preparation for Moisture Testing ................................................ 25

CHAPTER FOUR-EXPERIMENTAL TESTING ..................................... 31

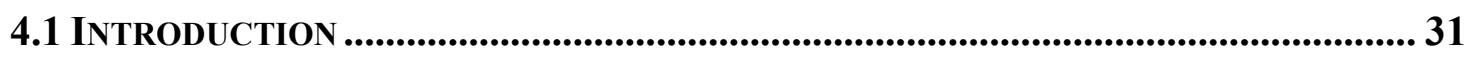

4.2 Specimen Temperature Controlling AND TeSting CHAMber ................... 31

4.2.1 Hydraulic Actuators .......................................................................................... 31

4.2.2 Microcontroller ........................................................................................ 32

4.2.3 Specimen Storage Container................................................................................. 34

4.2.4 Heat Gun..................................................................................................................... 37

4.2.5 Computer Fan and Air Ducts ................................................................................ 38

4.2.6 Computer Fan Power Supply ....................................................................... 38

4.2.7 Thermocouple.................................................................................................................. 39

4.2.8 Data Acquisition System.................................................................................. 39

4.2.9 Data Logger ............................................................................................................. 40

4.2.10 Vibrating Wire Strain Gages .......................................................................... 40

4.2.11 Temperature Controlled Chamber .............................................................. 42 


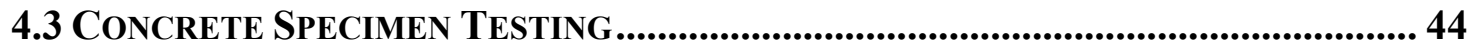

4.3.1 Modulus Test and Calculations ................................................................ 44

4.3.2 Compression Test and Calculations................................................................. 51

4.3.3 Tensile Strength Test (Modulus of Rupture) and Calculations................... 52

CHAPTER FIVE-RESULTS ....................................................... 53

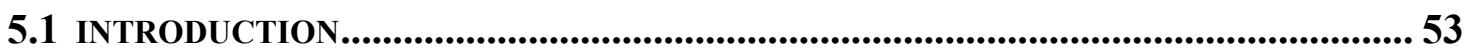

5.2 ERROR ANALYSIS....................................................................................................... 53

5.3 CONCRETE STRENGTH WHILE CURING............................................................ 55

5.4 EFFECT OF TEMPERATURE ON CONCRETE STRENGTH ........................................ 58

5.5 EFFECT OF DEGREE OF SATURATION ON CONCRETE STRENGTH ........................... 61

5.6 EFFECT OF TEMPERATURE ON MODULUS OF ELASTICITY ..................................... 64

5.7 EFFECT OF DEGREE OF SATURATION ON MODULUS OF ElASTICITY..................... 71

5.8 EFFECT OF TeMPerature AND MoISTURe ON Poisson's Ratio........................ 74

5.9 EFFeCT OF CURING Time ON THE THERMAL COEFFICIENT OF CONCRETE ....... 78

5.10 EXAMPLE PROBLEM .................................................................................................. 88

CHAPTER SIX-CONCLUSION.................................................... 90

REFERENCES .......................................................................... 93

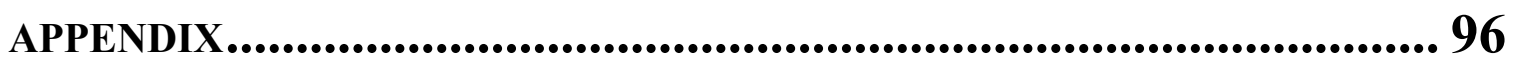

A.1 Modulus of Elasticity TeSTING Data ......................................................96

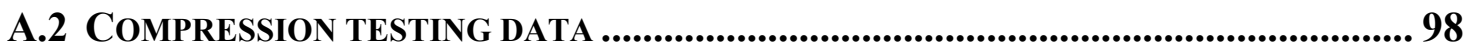

A.3 SPLIT TENSILE TESTING DATA................................................................................ 101

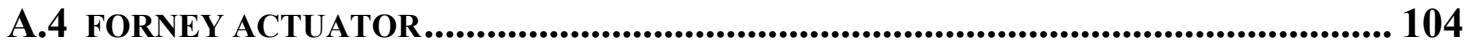

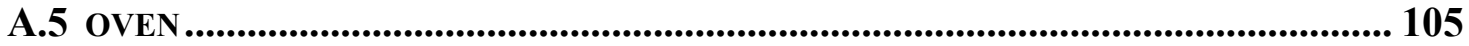

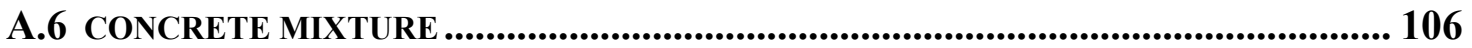




\section{List of Figures}

Figure 3.1 Specimen Dimensions............................................................... page 20

Figure 3.2 Specimen Preparation............................................................. page 21

Figure 4.1 Control System Schematic.......................................................... page 33

Figure 4.2 Microprocessor Based Controller.......................................... page 34

Figure 4.3 Specimen Storage Container Dimensions...............................page 36

Figure 4.4 Specimen Storage Container.................................................... page 37

Figure 4.5 Fan and Duct Dimensions...................................................... page 38

Figure 4.6 Vibrating Wire Strain Gage Dimensions..................................page 41

Figure 4.7 Temperature Controlled Chamber Dimensions...................... page 43

Figure 4.8 Temperature Controlled Chamber...........................................page 43

Figure 4.9 Modulus Testing System Layout............................................... page 49

Figure 4.10 Modulus Test.................................................................................page 50

Figure 4.11 Compression Test............................................................... page 51

Figure 4.12 Split Tensile Test..................................................................page 52

Figure 5.1 Effect of Curing on Compressive Strength.............................. page 56

Figure 5.2 Effect of Curing on Tensile Strength...................................... page 57

Figure 5.3 Effect of Temperature on Compressive Strength................... page 59

Figure 5.4 Effect of Temperature on Tensile Strength............................page 60

Figure 5.5 Effect of Degree of Saturation on Compressive Strength...... page 62

Figure 5.6 Effect of Degree of Saturation on Tensile Strength.............. page 63

Figure 5.7 Effect of Temperature on Modulus of Elasticity Day 3........ page 65

Figure 5.8 Effect of Temperature on Modulus of Elasticity Day 7........ page 66

Figure 5.9 Effect of Temperature on Modulus of Elasticity Day 14....... page 67

Figure 5.10 Effect of Temperature on Modulus of Elasticity Day 21.... page 69

Figure 5.11 Effect of Temperature on Modulus of Elasticity Day 28..... page 71

Figure 5.12 Effect of Degree of Saturation on Modulus of Elasticity.... page 73

Figure 5.13 Effect of Temperature on Poisson's Ratio..............................page 76

Figure 5.14 Effect of Degree of Saturation on Poisson's Ratio.............. page 77

Figure 5.15 Effect of Age on the Thermal Coefficient of Concrete......... page 79

Figure 5.16 Coefficient of Thermal Expansion V. Time (C. Test)...........page 82

Figure 5.17 Strain V. Time...................................................................page 83

Figure 5.18 Strain V. Time (C. Test)...................................................... page 84

Figure 5.19 Strain V. Temperature............................................................... page 85

Figure 5.20 Strain V. Temperature (C. Test)............................................ page 86

Figure 5.21 Temperature V. Time...............................................................page 87

Figure 5.22 Temperature V. Time (C. Test)..............................................page 88 


\section{List of Tables}

Table 3.1 Number of Concrete Specimens used for Temperature

Testing. page 23

Table 3.2 Uninstrumented Concrete Specimens used for Compression and

Tensile Strength Tests During the Curing Process. page 23

Table 3.3 Uninstrumented Cured Concrete Specimens used for Compressive and Split Tensile Strength Tests at Variable Temperature. page 24

Table 3.4 Instrumented Concrete Specimens for Modulus Testing at Variable Temperatures Before and After Curing. page 24

Table 3.5 Quantity of Concrete Specimens Used for Degrees of Saturation

Testing. page 27

Table 3.6 Uninstrumented Cured Concrete Specimens used for Compressive and Split Tensile Strength Tests at Variable Degrees of Saturation.......page 27 Table 3.7 Instrumented Concrete Specimens for Modulus Testing at Varying Degrees of Saturation After Curing. .page 27

Table 3.8 Concrete Specimen Mass for Variable Degrees of Saturation (Compressive Test). page 28

Table 3.9 Concrete Specimen Mass for Variable Degrees of Saturation (Split

Tensile Test) page 29

Table 3.10 Concrete Specimen Mass for Variable Degrees of Saturation (Modulus

Test) page 30

Table 4.1 Geokon Data Logger Specifications page 40

Table 4.2 Geokon Strain Gage Specifications page 41

Table 5.1 Effect of Curing on Compressive Strength..............................page 56

Table 5.2 Effect of Curing on Tensile Strength...................................... page 57

Table 5.3 Effect of Temperature on Compressive Strength.................... page 59

Table 5.4 Effect of Temperature on Tensile Strength............................... page 60

Table 5.5 Effect of Degree of Saturation on Compressive Strength...... page 62

Table 5.6 Effect of Degree of Saturation on Tensile Strength................ page 63

Table 5.7 Effect of Temperature on Modulus of Elasticity Day 3........... page 65

Table 5.8 Effect of Temperature on Modulus of Elasticity Day 7........... page 66

Table 5.9 Effect of Temperature on Modulus of Elasticity Day 14......... page 67

Table 5.10 Effect of Temperature on Modulus of Elasticity Day 21...... page 69

Table 5.11 Effect of Temperature on Modulus of Elasticity Day 28....... page 71 Table 5.12 Effect of Degree of Saturation on Modulus of Elasticity Day 180 page 73

Table 5.13 Effect of Temperature on Poisson's Ratio............................ page 76

Table 5.14 Effect of Degree of Saturation on Poisson's Ratio................ page 77

Table 5.15 Effect of Curing Time on the Thermal Coefficient of

Concrete page 79 
Table 5.16 Effect of Curing Time on the Thermal Coefficient of Concrete (C. Test)..................................................................................................................... page 81

Table 6.1 Material Model Equations...................................................... page 92

Table A.1 Modulus of Elasticity Test $+20^{\circ} \mathrm{C}$ day 28 specimen 1 ........... page 96 Table A.2 Modulus of Elasticity Test at $40 \%$ degrees saturation and $20^{\circ} \mathrm{C}$ day 180 specimen 2................................................................................. page 97 Table A.3 Compression Results During the Curing Process at Room Temperature. page 98

Table A.4 Compression Results of Cured Concrete At Varying Temperatures......................................................................................... page 99

Table A.5 Compression Results at Varying Degrees of Saturation.........page 100 Table A.6 Tension Results During the Curing Process at Room Temperature page 101

Table A.7 Tension Results of Cured Concrete At Varying

Temperatures.......................................................................................... page 102

Table A.8 Tensile Results at Varying Degrees of Saturation...................page 103

Table A.9 Forney Actuator Specifications..............................................page 104

Table A.10 Oven Specifications.......................................................................... page 105

Table A.11 Concrete Mixture....................................................................... page 106 


\section{Chapter One \\ Introduction}

\subsection{Background}

Concrete is a construction material that is widely used in many different structures including houses, commercial buildings, roadways, bridges, underground structures, and waterfront structures. These structures are dynamic systems subjected to continuous changes in moisture content and temperature. More importantly, parts of these structures are exposed to extreme environmental conditions such as with bridge piers, dams, and waterfront structures. They experience variations in the tidal zone, hence continuous changes in the moisture content as well as temperature. Temperature and moisture variations affect the strains induced in concrete structures and mechanical properties of the concrete as well.

Concrete properties are usually determined at standard laboratory conditions where air is at $68^{\circ} \mathrm{F}$ and 50 percent relative humidity. There has been enormous research on the curing of concrete during extreme cold and dry conditions, cool and damp conditions, warm and humid conditions, as well as extreme hot and dry conditions [7, 8, and 9]. The environmental conditions when concrete is poured and cured have an impact on the properties of the final product. Therefore, in extreme weather conditions such as extreme cold or hot, construction may be delayed until the environment improves unless precautions are taken for concrete curing. For example, normal concrete can be poured in sub-freezing temperatures if the surfaces are heated and the concrete is covered. Normal concrete can also be poured in hot dry conditions if the surface is wetted periodically and covered. The concern is what happens after the concrete has cured. There is little research on the mechanical properties of cured concrete in outside temperature conditions. It would be impractical, due to high-energy costs, to heat or cool the concrete surface during extreme weather conditions to room temperature.

Previous studies indicated that concrete exhibits change in its compressive strength and its modulus of elasticity as environmental conditions change $[\mathbf{1}, \mathbf{2}, \mathbf{3}, \mathbf{1 2}$, and 13]. Therefore, to design a long lasting concrete structure, it is necessary for the 
structural designer to know the range of the mechanical properties of concrete corresponding to temperature and humidity levels expected to be present at the construction site so that appropriate safety factors can be considered.

The objective of this research was to examine the effect of temperature and moisture variations on the mechanical properties of concrete that has completely cured. The research was also aimed at developing relations that can be used to determine the properties of concrete at different temperatures and degrees of saturation that are normally experienced in outside conditions in most climates with the use of an environmental chamber.

\subsection{Problem Statement}

Concrete mechanical properties are usually evaluated at laboratory conditions. However, concrete structures are exposed to continuous variations in temperature and moisture content, which influences the mechanical properties of the concrete. Therefore, there is a need to develop a mathematical model that can be used by engineers to estimate concrete mechanical properties such as compressive strength and modulus of elasticity based on the standard condition properties and magnitude of temperature and degrees of saturation variations. Evaluating concrete strength at different temperatures enables the designer to check the factor of safety and the adequacy of the structure to sustain all applied loads safely. Previous studies [16] indicated that at a high temperature of $122^{\circ} \mathrm{F}$ and saturated moisture level concrete can lose up to 50 percent of its strength measured at standard conditions of $68{ }^{\circ} \mathrm{F}$ and $50 \%$ degrees of saturation.

In general the more that is known about material properties the more parameters can be used in determining a safety factor. A safety factor compensates for unknown factors. It ensures that the strength of a material is stronger than the stress applied to it and strain is within an acceptable range. The effect of temperature and moisture and the resulting uncertainty in concrete material properties are often ignored or more likely unknown. To offset this lack of knowledge, a large safety factor is currently used. This can cause several problems. If the safety factor is too large, a structure will cost more 
than needed. If the safety factor is too small, a structure could fail. In order to minimize risk of failure and cost it is important for the structural engineer to incorporate temperature and moisture into a model.

An environmental chamber was needed in order to measure the stress-strain relation of the concrete under different temperatures and degrees of saturation. This presented a number of challenges because concrete specimens have to be maintained at proper temperature for the duration of the testing. The chamber was required to be large enough to allow concrete specimens to properly fit inside, and the chamber had to properly fit under an MTS actuator in the laboratory.

\subsection{Objectives}

The main objective of this thesis is to measure the mechanical properties of concrete at different temperatures and degrees of saturation and establish a correlation between such properties and the concrete properties at standard laboratory conditions. In order to achieve the overall objective, supportive objectives have been identified as:

1. To design and build an environmentally controlled chamber that can fit the standard concrete specimen and properly fit under the MTS actuator to facilitate testing the concrete at different temperatures and degrees of saturation.

2. To measure the following properties: modulus of elasticity, Poisson's ratio, compressive strength, tensile strength, and coefficient of thermal expansion at various temperatures and degrees of saturation. Additionally, all the aforementioned properties were measured at different ages while curing in order to assess the gain in each property as the concrete ages. 
3. To develop a set of formulae that correlate the mechanical properties measured at different temperatures and degrees of saturation with their corresponding values at standard conditions.

4. To use the results of modulus of elasticity, compressive, and split tensile testing to examine the adequacy of the safety factors applied in designing concrete structures.

\subsection{Research Approach}

In order to find the compressive strength, tensile strength, modulus of elasticity, Poisson's Ratio, and thermal expansion coefficient of concrete a number of procedures were followed:

A total of 89 standard concrete cylindrical specimens were made for temperature testing, 47 were 6 inches in diameter and 12 inches high. They were produced for testing under axial compressive loads in the compression and modulus of elasticity tests, the rest (4 inches in diameter and 8 inches high) were made exclusively for split tensile testing. Five out the 89 cylinders were fitted with a $90^{\circ}$ strain gage rosette mounted at the specimen center such that one strain gage is mounted along its vertical axis, while the other one is mounted horizontally. The strain rosette is fitted with a thermistor that enables measuring the actual concrete temperature inside the specimen near its core. An additional 24 specimens 6 inches in diameter and 12 inches high were produced for compression testing and an additional 24 specimens 4 inches in diameter and 8 inches high were made for split tensile testing at variable degrees of saturation.

The modulus of elasticity testing was completed using an MTS actuator supported by a large steel frame. The steel frame is 20 feet high and takes up over 400 square feet of area. This was much too large to fit inside of a freezer. It was too expensive and difficult to cool and heat the entire lab to the temperature needed $\left(-4^{\circ} \mathrm{F}\right.$ to $\left.122^{\circ} \mathrm{F}\right)$. The simplest and least expensive solution was to design and build a small environmental chamber that was situated under the actuator. The chamber is cubic with an exterior 
volume nearly 8 cubic feet. The specimen was positioned in the environmental chamber and loaded axially with the actuator. Vertical and horizontal strains were recorded together with applied loads. This enables calculating both the concrete modulus of elasticity and Poisson's ratio.

In order to measure the compressive strength and tensile strength of concrete at different temperatures and degrees of saturation, the uninstrumented concrete specimens were tested. Since the compressive and tensile tests only last about a minute and require a much larger force than the modulus of elasticity testing, the Forney compressive machine was used. The temperature controlled testing chamber was not designed to be used with the Forney actuator nor was it needed since the compression and tensile tests were so short. The uninstrumented specimens were pre-chilled or pre-heated to a uniform temperature and then tested right away. During the moisture testing the specimens were tested once they reached a proper degrees of saturation.

\subsection{Thesis Organization}

In order to accomplish the desired on the pertinent research work done in the past to measure concrete properties at different temperatures. In order to find the properties of concrete an experimental plan was developed. The plan first included the types of tests needed to be conducted in order to obtain the need properties. The four tests included the compressive strength test, the modulus of elasticity test, the coefficient of thermal expansion test, and the split tensile test. To do testing at varying concrete temperatures and degrees of saturation a temperature and moisture range was developed. The next step was to design the experiments including how many concrete specimens would need to be produced. After that, a temperature controlled temperature chamber was designed and produced so the concrete could be exposed to varying temperatures and degrees of saturation. The degrees of saturation was varied with the use of an oven preceding the compression and split tensile tests, time was allowed for the specimens to cool to $68^{\circ} \mathrm{F}$. The next step was to make the specimens and test them. After that, the results were analyzed and mathematical models were developed. 


\section{Chapter Two \\ Literature Review}

\subsection{Introduction}

A significant amount of research work has been conducted on the curing of concrete at different temperatures. However, there is little literature on temperature effects of cured concrete and most of that is at very high temperatures $[2, \mathbf{3}, \mathbf{6 , 1 4}, \mathbf{1 5}$, and 19], in order to evaluate the strength of concrete in a fire.

There is also a wealth of information on the freezing and thawing of water on concrete as well as creep and thermal stresses. It is important to eliminate cracks when pouring concrete. Cracks allow water to seep inside and then when the temperature drops below $0{ }^{\circ} \mathrm{C}$ the water freezes. Water unlike most molecules actually expands when it goes from the liquid to solid phase. The molecular expansion is stronger than what the concrete can resist, thus it will enlarge any existing cracks. In the review, there is some focus on the freezing and thawing of the ground, effect on concrete, as well as creep and thermal stresses on cured concrete. Temperature effects on curing concrete were also looked into, though the main topic consists of how different temperature and degrees of saturation effect cured concrete properties.

In the literature review, a number of topics were looked at in depth. Concrete property behaviors at high temperatures while curing and once cured were reviewed. The effect of creep was reviewed. The effect of freezing and thawing of concrete were reviewed. The effect of low temperature on curing and cured concrete was also reviewed. 


\subsection{Reviews}

\subsubsection{Effect of Varying Temperature on Concrete Properties}

Brewage and Starker [2] conducted tests on concrete prisms to examine how properties of normal concrete change with varying temperatures. The testing plan included:

- Thirty-five $3 \times 4 \times 12$ inch concrete prisms for measuring coefficient of thermal expansion.

- Thirty-six $3 \times 3 \times 12$ inch concrete prisms for measuring modulus of elasticity.

- Concrete cylinders with dimensions of 6 inches by 12 inches were used to test for compressive strength as well as static modulus of elasticity.

The temperatures of the tests varied from $-99^{\circ} \mathrm{F}$ to $151^{\circ} \mathrm{F}$. The specimens were divided into eighteen series of which each series included two of each type of concrete prisms and five of each type of control cylinders. Ten of the eighteen series were dry cured in a laboratory after curing in water at $70{ }^{\circ} \mathrm{F}$ for seven days. The temperatures were between $68^{\circ} \mathrm{F}$ and $72{ }^{\circ} \mathrm{F}$ with a relative humidity ranging from 65 to 75 percent in the laboratory. The other eight series were cured in water. The eight series were divided into four groups each with two series, which had water to cement ratios of $0.45,0.49$, 0.58 , and 0.67 . Tests were performed at 7,28 , and 84 days for specimens that had water to cement ratios of $0.67,0.58$, and 0.49 , while Testing was performed at 7 and 84 days for water to cement ratios of 0.45 . Testing was also done at one year for water to cement ratios of 0.43 and 0.71 . Type I Portland cement was used in all specimens. The concrete was mixed in a 3.5 cubic feet Eirich counter-rotary mixer. The concrete was then consolidated into steel moulds by the use of a pencil vibrator. The specimens were then cured under wet burlap for 16 hours. They were then demolded and stored in water. The dry cure specimens were removed from water after seven days. The strength of the concrete mixtures after curing for 28 days ranged from 4800 psi to 6340 psi [2]. 
To test the concrete specimens, an environmental chamber was designed. The chamber was capable of producing temperatures between -99 and $199^{\circ} \mathrm{F}$. The chamber operates with input controllers and cycling devices. Cooling is accomplished with a refrigeration cycle while heating is accomplished with resistors. The controllers were very basic. Since this experiment occurred in the 1970's microprocessor, based controllers had yet to be invented. The controller was essentially a thermostat similar to what one would find on an electric oven or refrigerator. The chamber was built much like an oven, thus it was very well insulated. It also had windows to allow the operator to see how the test is progressing [2].

Electrodynamic materials tester was used to determine the modulus of elasticity of the 3 inch by 3 inch by 12 -inch prism specimens. The tester works by exciting the prism in the longitudinal mode. This induces vibrations, which transmit voltages via a piezo-electric crystal in the pick-up. This turn activates an amplitude meter indicator. Knowing the amplitude of vibration and natural frequency of the material, the static modulus of elasticity can be calculated [2].

Optical extensometers were used to find the coefficient of thermal expansion of concrete prisms. The specimens rest vertically on the chambers floor. The unit measures any deformation in the shape of the specimen as temperature changes. Transducers are also used to measure deformation [2].

The results indicated that the static modulus of elasticity increases as the concrete cures. All other variables being equal, static modulus of elasticity increases faster for the specimens cured in water than the specimens cured in air. The strength of concrete is much greater for lower water to cement ratio specimens. There is linear ratio for water to cement between 0.49 and 0.67 for both 28 day old and 84 day old specimens. For concrete mixes with water to cement ratios less than 0.49 , the strength of concrete increases dramatically. Concrete with a higher water to cement ratio is more workable and less expensive, but it is not as strong. Concrete with lower water to cement ratios is more expensive and less workable, but it is stronger. Concrete with low water to cement ratios requires that the specimens are kept moist for longer periods for proper curing. The three variables along with other variables should be optimized to give the best combination for a particular use [2]. 
The dynamic modulus of concrete decreases as concrete ages, if it was not kept adequately moist and air-cured. The dynamic modulus of concrete will increase as the water to cement ratio decreases. The dynamic modulus increases with age of the watercured specimens until the water to cement ratio decreases to 0.6 then it starts to levels off. The water cured specimens start to lose dynamic modulus of elasticity when the water to cement ratio drops below 0.5 [2].

The results also indicated that dynamic modulus and temperatures are inversely related. The dynamic modulus of elasticity will increase with a decrease in temperature and decrease with an increase in temperature. The relation is not always linear however. In between temperatures of $151^{\circ} \mathrm{F}$ and $32^{\circ} \mathrm{F}$, the relation was found to be linear. Going below freezing there is a sharp increase in the modulus of elasticity caused by the freezing of moisture within the concrete. The relation is linear again between $32{ }^{\circ} \mathrm{F}$ and $-99^{\circ} \mathrm{F}[2]$.

\subsubsection{Concrete Testing Under High Temperatures}

Researchers at the National Institute of Standards and Technology evaluated concrete modulus of elasticity and compressive strength at extremely high temperatures. Lawson et al. [11] conducted compressive and modulus of elasticity tests on concrete specimens that were heated from $77^{\circ} \mathrm{F}$ to a steady state temperature of $212^{\circ} \mathrm{F}$. Then the test was repeated at temperatures of $392^{\circ} \mathrm{F}, 572{ }^{\circ} \mathrm{F}$, and finally at $842{ }^{\circ} \mathrm{F}$. The specimens were heated at a rate of $9{ }^{\circ} \mathrm{F}$ per minute up to their steady state temperature of 212,392 , 572 , or $842^{\circ} \mathrm{F}$ respectively. Three of the concrete types were high performance concrete and one type was conventional concrete. Before being exposed to extremely high temperatures, the average compressive strength of the four types of concrete varied from 6000 psi to 15,000 psi. The specimens were heated for a total period of six hours including both the steady state heating and the rise time. The four different mixtures all used Type I Portland Cement. The mixtures differed by the water to cement ratio and the amount of silica fume used. The specimens were stored for six months in water that was nominally $73^{\circ} \mathrm{F}$. The specimens were allowed to dry to 50 percent degrees of saturation at $73^{\circ} \mathrm{F}$ prior to testing. The results indicated that the concrete strength started to drop 
significantly, as its temperature exceeds $392^{\circ} \mathrm{F}$. It was also reported that modulus of elasticity generally decreased as the temperature rose.

Researchers at the National Institute of Standards and Technology [11] set out to determine how much strength is lost in concrete structure during a fire. The concrete specimens were made out of ASTM type I Portland cement mixed with aggregate consisting of crushed limestone as a coarse aggregate and crushed river stone as a fine aggregate. The cement and aggregate were mixed with water in four different mixtures:

- Mixture I has a water-cement ratio of 0.22 , contains $10 \%$ silica fume, and has 28 day compressive strength of $13.8 \mathrm{ksi}$.

- Mixture 2 has a water to cement ratio of 0.30 , contains $10 \%$ silica fume, and has 28-day compressive strength of $10.1 \mathrm{ksi}$.

- Mixture 3 contains a water to cement ratio of about 0.30 , contains $0 \%$ silica fume, and has 28-day compressive strength of $9.4 \mathrm{ksi}$.

- Mixture 4 contains a water to cement ratio of about 0.57 , contains $0 \%$ silica fume, and has 28-day compressive strength of $4.06 \mathrm{ksi}$.

A typical concrete mix consists of $6 \%$ air, $11 \%$ Portland cement, $41 \%$ crushed stone (course aggregate), 26\% sand (fine aggregate), and 16\% water though these can vary widely. The concrete specimens were allowed to cure for 28 days. There are many variables affecting the properties of concrete including the overall temperature difference, rate of temperature change, the surface area exposure at the highest temperatures, and the thermal mass of the concrete. When a concrete is subjected to a very high temperature, it does not mean the entire mass of concrete will be at that temperature. The time variable is very important when conducting tests on the stress of concrete. When there is a large temperature variation between the outer most shell and the core of a specimen, large thermal gradients and stresses will develop [11].

In the unstressed concrete test, the concrete samples were exposed to progressively higher temperatures without any restraint. After the steady state temperature is reached, the concrete samples are loaded to failure. In the stressed test, the specimens were heated to steady state with a pre-load of 40 percent of their compressive 
strength at room temperature. Once steady state temperature is reached, they are loaded to failure. It is important to remain at the steady state temperature long enough for the entire concrete sample to reach that temperature. If the tests are conducted with a large variation in temperature in the specimen, the results will be erroneous because of internal thermal stresses [11].

The stressed and unstressed tests results showed that concrete loses $50 \%$ of its strength for every $180{ }^{\circ} \mathrm{F}$ rise in temperature up to about $392{ }^{\circ} \mathrm{F}$. This temperature is much higher than what would ever be seen by light colored concrete in a roadbed. Interestingly the higher the compressive strength of concrete at room temperature, the more strength is lost at higher temperatures [11].

According to compression tests on cured concrete conducted by Phan and Carino [16], cured concrete loses up to 50 percent of its compressive strength for every $180{ }^{\circ} \mathrm{F}$ change in temperature. It was also found that concrete would permanently lose strength if exposed to repeated extreme temperatures. The authors attributed this behavior to several reasons. The first is due to shrinkage cracks that form when concrete was exposed to cool damp conditions then exposed to hot dry conditions. Secondly the concrete loses some of its strength when exposed to repeated high temperatures because concrete is porous. The porosity allows moisture to slowly infiltrate the concrete specimen. The water vapor expands faster than it can escape the sample, which creates vapor pressure inside the specimen. When this pressure becomes greater than strength of the concrete sample, the sample will start to crack internally. This may not be visible from the outside of the specimen and the entire specimen may not break for an extended period. This is because as cracks form the moisture is allowed to escape. This in turn puts more pressure on the outer shell of the specimen, which will eventually fail.

Carette and Malhotra [3] investigated the effects of sustained high heat on cured concrete properties. They investigated two types of concrete. The first type of concrete consisted of Portland cement, limestone as coarse aggregate, and natural sand as the fine aggregate. The second type of concrete consisted of Portland cement, dolostone as the coarse aggregate, and natural sand as the fine aggregate. The water to cement ratio ranged from 0.33 to 0.60 . The concretes were exposed to the following temperatures: $167,302,572,842,1112^{\circ} \mathrm{F}$. The durations of exposure were 2 days, 1 month, and 4 
months. The specimens to be tested were moist cured for 28 days then cured at standard room conditions for 26 days. For both aggregates, three mixes were made with water to concrete ratios of $0.33,0.45$, and 0.60 .

Forty-eight 4 inch by 8 inch concrete cylinders were produced for each mix for a grand total of 288 concrete specimens. The heating rate was about $68^{\circ} \mathrm{F}$ per hour until the correct temperature is reached. Moisture was allowed to flow freely out of the chamber. Visual examinations, weight determinations, pulse velocity measurements, resonant frequency measurements, and compression tests were all performed on the 288 concrete specimens. The tests were carried out at room temperature and humidity according to ASTM standards [3].

Both limestone and dolostone concrete lose strength as temperature increases. The tests at the different temperatures last for about 120 days. There is some leveling off or even strength increases around 30 days. Then shortly thereafter strength is lost again. Even at a stable high temperature, strength continually is lost even up to 120 days. More strength is lost at higher temperature than lower temperatures. More strength can be lost though at lower temperatures if the exposure time is very long. The concrete with dolostone aggregate becomes unstable when exposed to temperatures near $302{ }^{\circ} \mathrm{F}$ or greater for extended periods. The concrete rupture would catastrophically fail if dolostone aggregate was used. Most of the strength loss occurred during the first 30 days. The concrete with a higher water to cement ratio, in this case 0.60 , was slightly less affected by high temperatures than the 0.45 and 0.33 ratios [3].

\subsubsection{Concrete Testing Under Low Temperatures}

A study was done in Canada by Nasser and Evans [13] to find the effects of cold on hardened concrete. Three concrete mixes were used. They had water to cement ratios of $0.40,0.45$, and 0.50 and aggregate cement ratios of 4.0, 4.6, and 5.3. The maximum size of coarse aggregate was 0.75 inches in diameter, while the sand fineness modulus was around 2.5. The aggregate was from a glacier deposit near Saskatoon, Canada. Standard Type I Portland cement was used. Concrete cylinder and prism specimens were used. The cylindrical specimens were 3 inches in diameter and 9 inches long. The 
specimens were cast in steel molds on a vibrating table to allow air to escape the concrete mixture. The prism dimensions were either 3 inches by 3 inches by 11 inches or 1.5 inches by 2 inches by 8 inches. They were hand tamped and trowel finished. The large prisms were used in dynamic modulus tests, while the small prisms were used in impact tests. The concrete specimens were cured at laboratory conditions. Four different curing conditions were used. The first condition includes 7 days in water at $72{ }^{\circ} \mathrm{F}$, then 13 days in fog at the same temperature, and 8 days in air at the same temperature and 22 percent relative humidity. The second condition includes 28 days in water at $72^{\circ} \mathrm{F}$. The third condition includes 2 days at $261^{\circ} \mathrm{F}$ after being exposed to the first condition. The fourth condition includes 20 days exposure to steam at $129^{\circ} \mathrm{F}$ and 8 days exposure to air at 72 ${ }^{\circ} \mathrm{F}$ at 22 percent relative humidity. After the curing time had elapsed, the temperature was lowered $15^{\circ} \mathrm{F}$ per hour until the testing temperature was reached [13].

The results indicated that strength of concrete increases as temperature falls. The following generalized results are for water to concrete ratio of 0.50 and an aggregate to cement ratio of 5.3. The splitting strength of concrete increases as temperature falls. The results are most dramatic in the second curing condition and least dramatic in the third curing condition. In fact, in the third curing condition, there is almost no change in splitting strength with respect to temperature. Strain decreases most of the time as temperature decreases. This is true in the second and third curing conditions and in the first and fourth curing condition below freezing [13].

According to Johnson [5], roadway concrete temperature in general will not fall below the ambient air temperature, because of time constraints. Concrete itself has a large thermal mass. In addition, the thermal mass of the ground also plays a role in concrete temperature. Concrete in bridge roadways will fall to a much lower temperature than roadways on top of the ground. The lowest concrete temperature generally will not occur at the minimum ambient temperature. Since concrete has a large thermal mass and minimum temperatures occur for a short period, the concrete temperature will not fall fast enough within the four-hour period to get close to the ambient temperature. The concrete temperature can actually be lower during periods of temperatures much higher than the minimum seen for a particular region. 
Several tests were conducted by the National Bureau of Standards [1] concerning the use of concrete for tanks and other structures. Two concrete mixes were used. The first one was made by a commercial cement company. The second one was made in house. Both mixes used were Portland type I cement. An air-entraining agent was used. Elgin sand was used as the aggregate in mix 1, while Clear Creek sand was used in mix 2. The concrete mortars were both mixed in the following ratios by weight: water/cement $=$ 0.5 and aggregate/cement $=3.4$. The air content of mix 1 was $11.0 \%$ and $17.0 \%$ for mix 2 , both by volume. Mix 1 was allowed to cure normally for 10 days. After that, the samples were held at $32{ }^{\circ} \mathrm{F}$ to slow the hydration process. Mix 2 was created in two batches. The first batch was made 8 months prior to the second batch. They were tested at 215 days and 79 days respectively. Tests were then conducted at varying temperatures. In general the strength decreased as temperature increased. The testing results indicated that concrete is not suitable for structures that require high tensile loading. Concrete is excellent for use in compressive applications at cold temperatures. Its strength actually increases as the temperature decreases. There are a few drawbacks though. Concrete can crack from moisture expansion and becomes brittle which could lead to cracks if it is deformed. For mix 1 the compressive modulus of elasticity increased from room temperature to $-108{ }^{\circ} \mathrm{F}$. It decreased approximately 30 percent from $-108{ }^{\circ} \mathrm{F}$ to $-323{ }^{\circ} \mathrm{F}$ and then decreased another 30 percent from $-323{ }^{\circ} \mathrm{F}$ to $-452{ }^{\circ} \mathrm{F}$. The compressive strength increased as temperature decreased all the way down to $-452^{\circ} \mathrm{F}$. For mix 2, ultimate compressive strength, proportional limit, and compressive modulus all increased as the temperature decreased [1].

According to Korhonen [8], concrete's largest vulnerability lies in its resistance to freezing and thawing. Concrete with a low water to cement ratio, good aggregate, and air entrainment goes a long way to preventing damage from freezing and thawing. Concrete contains a complex structure of pores that form as it cures. The report focuses on the cement component of the concrete since this is where the pores form. Water reacts with Portland cement, a process called hydration, to form calcium silicate hydrate (C-S-H gel) and calcium hydroxide $(\mathrm{CH})$. C-S-H gel contributes to concrete's strength by bonding the aggregate together with van der Waals forces. More capillary pores are formed with concrete made with high water to cement ratios. Water will freeze in these pores causing 
damage to the concrete. Cured concrete regardless of its water to cement ratio and other properties is unaffected by freezing and thawing when the concrete is free from moisture. The freezing and thawing of concrete at high degrees of saturation can cause damage since water can freeze in the capillary pores. When water freezes, it expands by 9 percent, thus exerting pressure on the pore walls of the concrete. This alone does not explain damage done to concrete by repeated freezing and thawing cycles since the concrete pores contain large air voids. A more in depth explanation shows that when the water expands upon freezing it forces remaining liquid water out of the pore at a rapid rate causing erosion and cracks within the concrete, thus weakening it.

To maximize freezing and thawing resistance, the main consensus was to change the pore structure of the concrete. The easiest way to eliminate capillary pores was to use concrete with a lower water to cement ratio. This had have several drawbacks including workability and curability. Concrete with low water to cement ratios does have several advantages though including strength and freeze thaw resistance. Water in pores smaller than $0.0033 \mu \mathrm{m}$ can not freeze due to the ice crystal structure [8].

According to Charles J. Korhonen, Brian Charest, and Kurt Romisch [7] it is possible to increase the acceleration of the curing process and in effect have concrete that is stronger earlier. This is accomplished with low temperature admixtures for concrete. These admixtures accelerate the curing of concrete in cold conditions. In cold conditions, concrete without this admixture would take too long to cure. This makes placing concrete in cold conditions practical. Unfortunately, the additive does nothing to correct the freeze and thaw problem in cold temperatures of cured concrete. It also does not help to strengthen concrete when it is exposed to high temperatures. Cured concrete that is exposed to high temperatures is weaker than cured cold concrete.

According to Charles J. Korhonen and John W. Brook [9] there is a need for an admixture, which prevents concrete from freezing during the initial curing process. If the concrete freezes during the initial curing process it will crack and lose substantial strength. An admixture is needed that will prevent the concrete from freezing, but not affect its properties in a substantial way once it is cured. If concrete is placed during cold weather (below $32{ }^{\circ} \mathrm{F}$ ) without an admixture it must be heated and covered to prevent it form freezing, it should be heated if the temperature is below $50^{\circ} \mathrm{F}$ or it will take too long 
to cure. If concrete is placed in the 50-65 degree Fahrenheit range it should at least be covered. To protect concrete from the cold weather the construction industry spends 800 million USD annually. Pozzutec 20 was developed to accomplish the goal of depressing the freezing point of water. This allows for cold weather placement, along with an admixture to speed up the curing process. Pozzutec 20 has a negligible effect on the other properties of concrete.

\subsubsection{High Strength vs. Normal Strength Concrete at High Temperature}

According to Phan [17] and Ravindrarajah [19] higher strength concrete loses more strength in absolute terms and as a percentage of maximum strength than normal concrete at high temperatures, and it is more likely that a high strength specimen will explosively spall. This is not to say that higher strength concrete is weaker than normal strength concrete, just that the difference in strength between the two goes down as the temperature goes up. Even as the temperature approaches $932^{\circ} \mathrm{F}$, the high strength concrete will remain a little stronger. The high strength concrete will always fail at a higher load than normal strength concrete, though that difference lessons as the temperature increases. The high strength concrete will more likely fail suddenly with explosive force, so extra care must be taken when experimenting.

The reasoning for the sudden failure of high strength concrete has to do with vapor pressure that builds up in the core. According to Kodur [6] High strength concrete has a low permeability thus pressure builds up inside to the point where the internal

pressure exceeds the strength of the concrete, causing an explosion. Lightweight aggregate increases the chance of spalling. High strength concrete has a low water to cement ratio, which leaves fewer pores in the concrete. It is preferable to have concrete with a lower moisture content to prevent spalling. Moisture contents over 75 percent are considered too high. The size of a specimen will lead to more spalling, since it takes longer for the moisture to work its way out of a larger specimen. Thus, a larger beam would be more susceptible to spalling than a smaller beam. The rate at which heat increases will have an effect on spalling. If enough time is given, spalling will not occur. Even in low porous high strength concrete, the moisture will escape if given enough time, 
which generally is not the case in a fire. The moisture inside the concrete specimens is not water left over from when the concrete was poured. Moisture from the surrounding environment has gone through the pores of the concrete. A loaded high strength concrete specimen will fail earlier than a non-loaded specimen since the pressure caused by the external load is added to the pressure exerted by the vapor. This combined pressure will cause the specimen to spall when the combined pressure exceeds the strength of the specimen.

According to Phan [18], to avoid concrete spalling when exposing concrete to high heat such as in a fire, it is recommended that carbonate aggregate is used. Carbonate aggregate is made up primarily of crushed limestone, has a higher heat capacity and specific heat, thus it will take longer for spalling to occur if at all.. Siliceous aggregate, which is made up primarily of quartz, should be avoided. Fiber reinforcement can be used to prevent spalling. When the fiber melts, it creates channels for the moisture to escape.

\subsubsection{Effect of Temperature Variations on Concrete Creep}

Creep is a very important concrete property and is very much affected by changes in temperature [19]. Creep can be measured by recording small deformations under constant loading. Tests for Creep have been done on both High Performance Concrete and Normal Strength Concrete. Normal Strength Concrete is more susceptible to instantaneous deformation and Creep than High Strength Concrete. Younger concrete is more susceptible to creep than highly cured concrete. Creep occurs faster during periods of higher stress. More creep will occur if a load is applied for longer periods. A small constant load will cause more creep than a large load for a short period.

Concrete has negligible creep at room temperature. Concrete suffers from the most creep at high temperature and high load. Concrete experiences the least creep at low temperatures with no loading. Creep can occur with no load due to the shrinkage of concrete. Virtually all creep in concrete occurs in the cement paste and not in the aggregate. In general creep strains are linearly related to applied stress up to about 50 
percent of concrete's ultimate strength. Creep increases linear with temperature from 68 ${ }^{\circ} \mathrm{F}$ up to $176^{\circ} \mathrm{F}$. Above $176^{\circ} \mathrm{F}$ the rate of creep starts to accelerate with respect to temperature. Creep is reduced in dry conditions [20].

\subsubsection{Effect of Degree of Saturation}

According to the Shengxing $\mathrm{Wu}$ and Yunfeng Li [23] an artificial climatic environmental laboratory with auto control and multifunction needs to be designed in order to accurately simulate the effects of weather and other environmental factors on cured concrete. This laboratory not only exposes concrete to different temperatures and humidity levels, but it exposes concrete to sunlight, rain, ice, snow, loads, vibration, pollution, fast moving water, and wind. All of these conditions help to deteriorate concrete. Fast moving water over a dam causes erosion of the concrete. Freezing and thawing leads to concrete cracking. Rain followed by a dry sunny period can lead to shrinkage. The lab can be used to test other materials as well. Vibration can lead to concrete cracking. High contents of carbon dioxide can lead to chemical reactions within the concrete that weaken it.

High air humidity negatively impacts concrete in a number of ways. Concrete loses modulus of elasticity as it becomes more saturated with moisture. The concrete also loses compressive and tensile strength and becomes less brittle. Concrete, especially young concrete will permanently lose its ability to strengthen if exposed to low degrees of saturation. Most disturbing though is the fact that concrete will shrink when exposed to high humidity such as during rainfall then, and then exposed to low humidity and high temperature. The changes in concrete degrees of saturation will lead to shrinkage cracks. Those cracks will become larger as the cycle repeats itself. In the winter those cracks are excellent places for water to accumulate then freeze further expanding the crack [23].

\subsection{Conclusion}

The extensive literature review presented in this chapter indicates that temperature and moisture do play a role in affecting the properties of concrete. According to Tarun R. 
Naik [12], both concrete compressive and modulus of elasticity increases as concrete becomes colder, as it cures, and as its degrees of saturation decreases, although concrete becomes more brittle. The shrinkage strain in concrete becomes higher as concrete becomes warmer and its degrees of saturation increases; however it decreases as concrete cures. The worst condition for concrete is when it is very warm with very high degrees of saturation. For example, at a temperature of $122^{\circ} \mathrm{F}$ and 100 percent degrees of saturation, concrete is both weak in compression and tension. This is the condition where maximum load for a concrete structural member should be calculated.

Cold temperatures have negative impacts on cured concrete as well. Water unlike most molecules actually expands when it solidifies. Freezing and thawing can damage concrete even if there are no cracks large enough for a liquid water molecule to seep through and without rain. When the temperature is warm and the degrees of saturation is high moisture in the form of water vapor seeps through the pores of the concrete. When the temperature drops below the dew point the moisture inside the concrete condenses. When the temperature drops below the freezing point the water freezes and cracks the concrete. This process has to occur quickly though, if a cool dry air mass moves overhead then the dry air will infiltrate the concrete carrying the moisture away.

The negative effects from cold temperatures can be minimized in a number of ways. Adding air to concrete is one way to minimize micro-cracks. The air void allows space for the water to expand when it freezes. Adding air however weakens concrete. Concrete with a low water to cement ratio can be used to minimize voids that water will freeze in. This however makes the concrete difficult to work with and it may set up faster than desired especially during warm conditions. Silica Fume can be added to the concrete mixture in order to refine the pore system so that the water molecules will not freeze even below $32^{\circ} \mathrm{F}$.

Both heat and cold pose dangers to cured concrete. Heat reduces the strength of concrete due to several reasons including spalling. The cold indirectly causes cracks to form in the concrete, which reduce its strength. At the molecular level, assuming no moisture presence in the concrete, heat will always reduce concrete strength, while the cold will increase concrete strength. This is due to the fact that the molecules are packed more closely together when the concrete is cold. In all reality, moisture is the enemy of concrete, even more so then temperature. 


\section{Chapter Three \\ Specimen Production}

\subsection{Introduction}

In order to conduct modulus of elasticity testing instrumented specimens were constructed. This was done by pouring freshly mixed concrete into instrumented molds. Specimens made for compressive strength and tensile testing were made with uninstrumented molds. The instrumented molds contained a strain gage rosette that was used to measure horizontal and vertical strain. Two sizes of concrete specimens were used. The size used for the compression and modulus of elasticity testing were 6 inches in diameter by 12 inches in height. The size used for split tension testing was 4 inches in diameter by 8 inches in height. Concrete cylinder size will affect how much force is required to break the specimen but will not affect the strength if the concrete is uniform and of the same composition and shape. The only differences between the instrumented and uninstrumented molds were the strain gages in the instrumented molds.

Note: All Dimensions are in inches

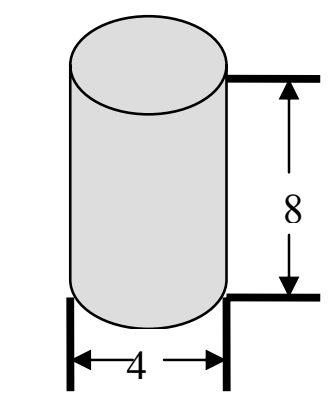

Figure 3.1a Specimen for Split Tensile Testing

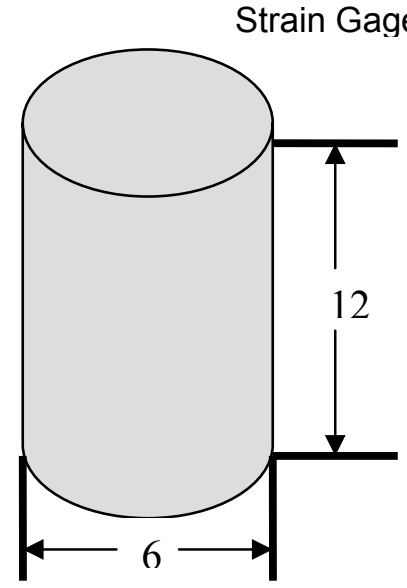

Figure 3.1b Specimen for Compression Testing

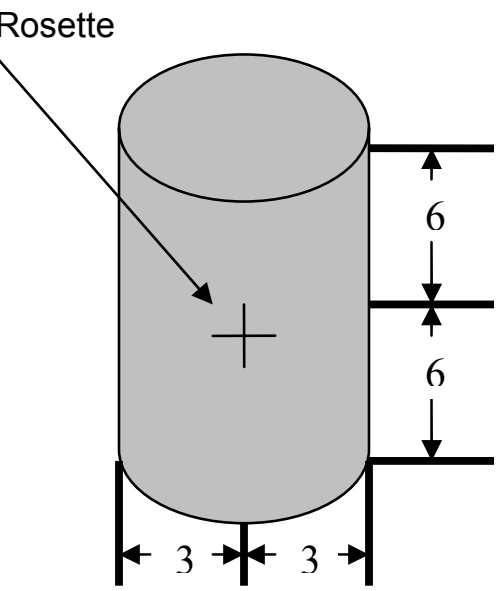

Figure 3.1c Specimen for Modulus of Elasticity Testing

Figure 3.1 Specimen Dimensions 


\subsection{Preparation of Concrete Specimens}

\subsubsection{Mold Preparation}

Standard concrete specimen molds were prepared according to ASTM standard C470. Each mold was thoroughly cleaned, dried, and then coated with a film of oil before any concrete was poured. The film of oil made it simpler to remove specimens from their molds once the curing process was complete. Greater care was used when working with the instrumented cylinder molds to make sure that the strain gages were kept properly oriented. The concrete specimens were set to cure about one day before the molds were removed. Special care was taken while removing the concrete specimens from their molds in order not to introduce any hairline cracks. Compressed air was used to remove the molds from all specimens while those fitted with strain gages had to be cut off in order to keep the lead wires intact. It is important to treat all of the specimens the same to ensure that they all cure at equal rates.

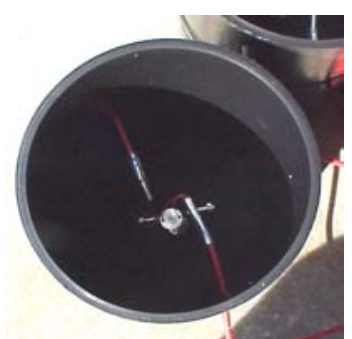

Figure 3.2a

Specimen Mold with strain gauge top view

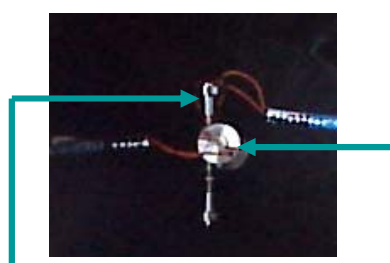

Figure 3.2d Strain Gage Rosette

Horizontal Strain Gauge

Vertical Strain Gauge

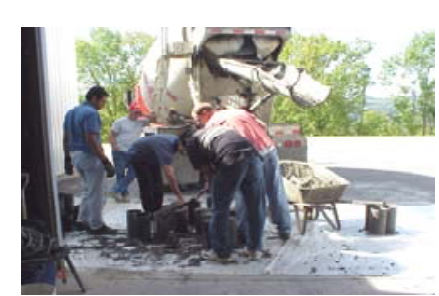

Figure 3.2b Pouring Uninstrumented Specimens

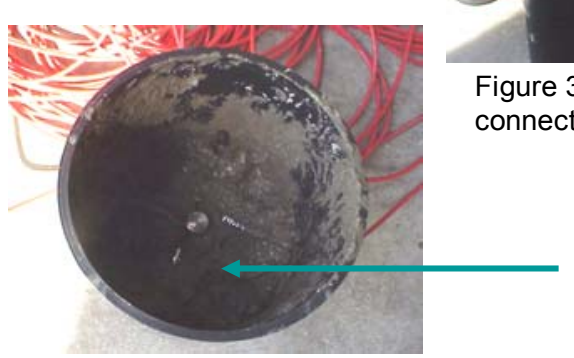

Figure 3.2e Specimen Mold with strain gauge top view partially filled with concrete

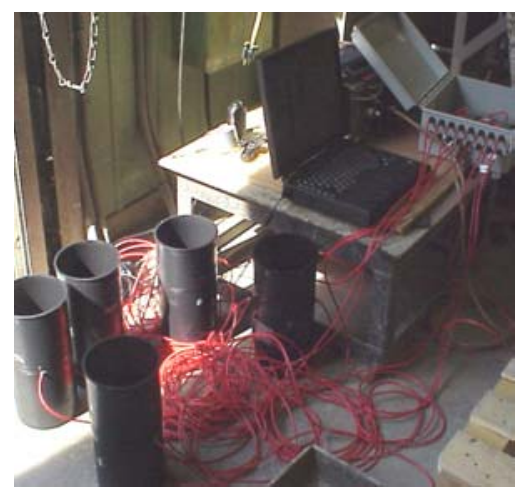

Figure 3.2c Instrumented Molds connected to multiplexer

Care was taken when adding concrete around the strain gauges

Figure 3.2 Specimen Preparation 


\subsubsection{Concrete Curing}

The concrete specimens were cured according to ASTM standard C192. Proper concrete curing is the most important step when making a concrete structure, in this case concrete cylinder specimens. When pouring the freshly mixed concrete into the concrete cylinder molds, they were filled a third of the way at first. The concrete was then compacted to ensure all of air was allowed to escape. The concrete was compacted with the use of a compacting rod. The procedure was repeated two more times filling the mold with concrete. Next the side of mold was tapped to ensure that all of the air escapes. The top surface was finished. The procedure was used for both sizes of specimens. After 1 hour the concrete specimens were covered and kept saturated with moisture for a period of 1 month with the exception of removing the molds and testing. In order to prevent the specimens from drying out, they were covered with burlap and plastic. They were also rewetted daily for 30 days. Concrete that is kept saturated and at room temperature achieves more than 99 percent of its maximum attainable strength. To gain nearly 100 percent strength the concrete would have to be kept damp for a period of a year or more which is impractical in most cases.

\subsubsection{Specimen Preparation for Temperature Testing}

The concrete was allowed to cure for 28 days in as close to ideal conditions as possible before the compression and tension tests were completed at varying temperatures. Three specimens were consumed during each compression and tensile test. There were periodic tests before the final test on day 28 to make sure the concrete cured properly. On days 1, 3, 7, and 14 after the concrete is poured, 3 compression tests were performed as well as 3 tension tests all at room temperature. The modulus of elasticity testing took place while the concrete was curing and after it cured. Each modulus of elasticity test consisted of 3 samples; that were tested every $9{ }^{\circ} \mathrm{F}$ between -4 degrees and 122 degrees on days 3 through 28 and 5 specimens including the previous 3 were tested on day 28. Five of the concrete cylinders were instrumented; they were reused in the non-destructive modulus of elasticity test. Tables 3.1 to 3.4 give detailed descriptions of 
the testing program and the number of tests carried out for each test relative to temperature changes. All temperature testing was completed with the concrete specimens completely saturated.

Table 3.1 Number of Concrete Specimens used for Temperature Testing

\begin{tabular}{|c|c|}
\hline Description & Number of Specimens \\
\hline Total Number of Concrete Cylinders Used & 89 \\
\hline (6in. X 12in.) Cylinders & 47 \\
\hline (4in. X 8in.) Cylinders & 42 \\
\hline Instrumented (6in. X 12in.) Cylinders & 5 \\
\hline Non-Instrumented (6in. X 12in.) Cylinders & 42 \\
\hline Total Number of Tests & 231 \\
\hline Total Number of Destructive Tests & 84 \\
\hline Total Number of Non-Destructive Tests & 147 \\
\hline
\end{tabular}

Table 3.2 Uninstrumented Concrete Specimens used for Compression and Tensile Strength Tests During the Curing Process

Temperature $=68^{\circ} \mathrm{F}$ Degree of Saturation $=100 \%$

\begin{tabular}{|c|c|c|c|c|c|c|}
\hline Age of Concrete (Days) & 1 & 3 & 7 & 14 & 21 & Total \\
\hline $\begin{array}{c}\text { Number of Compression } \\
\text { Tests }\end{array}$ & 3 & 3 & 3 & 3 & 3 & 15 \\
\hline $\begin{array}{c}\text { Number of Split Tensile } \\
\text { Tests }\end{array}$ & 3 & 3 & 3 & 3 & 3 & 15 \\
\hline
\end{tabular}


Table 3.3 Uninstrumented Cured Concrete Specimens used for Compressive and Split Tensile Strength Tests at Variable Temperature Degree of Saturation $=100 \%$

\begin{tabular}{|c|c|c|c|c|c|c|}
\hline Day & 3 & 7 & 14 & 21 & 28 & Total \\
\hline $\begin{array}{c}\text { Number of } \\
\text { Modulus of } \\
\text { Elasticity Tests }\end{array}$ & 12 & 14 & 18 & 27 & 76 & 147 \\
\hline
\end{tabular}

Table 3.4 Instrumented Concrete Specimens for Modulus Testing at Variable Temperatures Before and After Curing Degree of Saturation $=\mathbf{1 0 0 \%}$

\begin{tabular}{|c|c|c|}
\hline Temperature $\left({ }^{\circ} \mathbf{F}\right)$ & $\begin{array}{c}\text { Number of } \\
\text { Compression Tests }\end{array}$ & $\begin{array}{c}\text { Number of Split } \\
\text { Tensile Tests }\end{array}$ \\
\hline-13 & 3 & 3 \\
\hline 5 & 3 & 3 \\
\hline 23 & 3 & 3 \\
\hline 41 & 3 & 3 \\
\hline 59 & 3 & 3 \\
\hline 77 & 3 & 3 \\
\hline 95 & 3 & 3 \\
\hline 113 & 3 & 3 \\
\hline 131 & 3 & 27 \\
\hline Total & 27 & 3 \\
\hline
\end{tabular}




\subsubsection{Specimen Preparation for Moisture Testing}

Moisture testing presented a few challenges. It was too difficult and cost prohibitive to use moisture sensors for cured concrete specimens, but an accurate way to measure the moisture level in the specimens was needed. The specimens instead were weighed on a scale accurate to the hundredths place. Caution had to be used to prevent errors. All dust had to be removed from the specimen and the scale before each test. The modulus of elasticity, compression, and tension tests were done in conjunction with a variable humidity environment.

The weighing was done using an ACCULAB SV-30 scale. The capacity of the scale is 66 pounds or 30 kilograms. The readability of the scale is 0.01 pounds or 0.005 kilograms. A fully water saturated 6 inch by 12 inch concrete specimen has a weight about 1.5 pounds greater than a fully dry specimen. This translates to an accuracy of 0.66 percent degrees saturation for the 6 inch by 12 inch specimens and an accuracy of about 2 percent degrees saturation for the 4 inch by 8 inch specimens. This is more than enough accuracy needed since the moisture testing was at $0,20,40,60,80,100$ percent levels.

The procedure for completing the compression testing at variable degrees of saturation went as follows. The specimens were cured for thirty days submerged in a tank filled with water kept at $68^{\circ} \mathrm{F}$. The specimens were then removed from the tank, excess water removed from the surface, and then weighed while they were saturated. All of the specimens were then subsequently put into a large oven where they were dried at a temperature of $212^{\circ} \mathrm{F}$ for four days. All of the specimens were then weighed, and then put back in the oven for 1 day at a temperature of $230^{\circ} \mathrm{F}$. It is important to get the specimens over $212^{\circ} \mathrm{F}$ in order to vaporize any liquid water in the pores of the specimens and to stop the curing process of all specimens at the same time. The mass stayed constant after the additional day at an elevated temperature so it was concluded that there degrees of saturation was close to zero. Twenty four specimens were prepared. The first four specimens were tested right away while they were at 0 percent degrees of saturation. The other 20 specimens were put back in the water tank. They were then subsequently removed and dried to the degrees of saturation of interest. The test at saturation just 
involved drying the surface and immediately testing the specimen while its temperature remained at $68^{\circ} \mathrm{F}$. This is important because the evaporative effect of water will cool the specimen. The percentage of saturation was found through interpolation by finding the mass of the specimen oven dried, and then finding the mass of the specimen after it was completely saturated. The degree of saturation is 0 percent in an oven dried specimen and 100 percent in a saturated specimen. To find the degrees of saturation in between the two values one must interpolate between the two values or use equation 3.1. The degrees of saturation will vary linearly between the two values. For example if the specimen weighs 29.52 pounds when it is oven dried and 30.62 pounds when saturated, then at a 50 percent degree of saturation or degrees saturation it would weigh 30.07 pounds. Details of the specimen mass in the various tests are in Tables 3.8 to 3.10 .

Degrees Saturation $(\%)=\frac{M W}{S M-D M} * 100 \%$ equation 3.1

$M W=$ water weight (lbs.)

$S M=$ saturated weight (lbs.)

$D M=$ dry weight

The tests were conducted at $0,20,40,60,80$, and 100 percent degrees of saturation. All of the tests other than the 100 percent degrees of saturation test involved drying the specimens in an oven. Time was required to allow the specimens to cool down to $68{ }^{\circ} \mathrm{F}$ before testing so the moisture could spread evenly throughout the specimen. Tables 3.5 to 3.7 give detailed descriptions of the testing program and the number of tests carried out for each test relative to degrees of saturation changes. All moisture level testing was completed with the temperature of the concrete specimens at $68^{\circ} \mathrm{F}$. 
Table 3.5 Quantity of Concrete Specimens used for Degree of Saturation Testing

\begin{tabular}{|c|c|}
\hline Description & Quantity \\
\hline Total Number of Concrete Cylinders Used & 53 \\
\hline (6in. X 12in.) Cylinders & 29 \\
\hline (4in. X 8in.) Cylinders & 24 \\
\hline Instrumented (6in. X 12in.) Cylinders & 5 \\
\hline Non-Instrumented (6in. X 12in.) Cylinders & 24 \\
\hline Total Number of Tests & 60 \\
\hline Total Number of Destructive Tests & 48 \\
\hline Total Number of Non-Destructive Tests & 12 \\
\hline
\end{tabular}

Table 3.6 Uninstrumented Cured Concrete Specimens used for Compressive and Split Tensile Strength Tests at Variable Degrees of Saturation Temperature $=\mathbf{6 8}^{\circ} \mathrm{F}$

\begin{tabular}{|c|c|c|c|c|c|c|c|}
\hline Degree of Saturation (\%) & 0 & 20 & 40 & 60 & 80 & 100 & Total \\
\hline $\begin{array}{c}\text { Number of Compressive } \\
\text { Tests }\end{array}$ & 4 & 4 & 4 & 4 & 4 & 4 & 24 \\
\hline $\begin{array}{c}\text { Number of Split Tensile } \\
\text { Tests }\end{array}$ & 4 & 4 & 4 & 4 & 4 & 4 & 24 \\
\hline
\end{tabular}

Table 3.7 Instrumented Concrete Specimens for Modulus Testing at Varying Degrees of Saturation After Curing Temperature $=68^{\circ} \mathrm{F}$

\begin{tabular}{|c|c|c|c|c|c|c|c|}
\hline $\begin{array}{c}\text { Degree of } \\
\text { Saturation (\%) }\end{array}$ & 0 & 20 & 40 & 60 & 80 & 100 & Total \\
\hline $\begin{array}{c}\text { Number of } \\
\text { Modulus of } \\
\text { Elasticity Tests }\end{array}$ & 2 & 2 & 2 & 2 & 2 & 2 & 12 \\
\hline
\end{tabular}


Table 3.8 Concrete Specimen Mass for Variable Degrees of Saturation (Compressive Test)

\begin{tabular}{|c|c|c|c|c|c|}
\hline Specimen \# & $\begin{array}{c}\text { Saturated } \\
\text { Weight } \\
\text { (lbs.) }\end{array}$ & $\begin{array}{c}\text { Dry Weight } \\
\text { (lbs.) }\end{array}$ & $\begin{array}{c}\text { Water } \\
\text { Capacity } \\
\text { (lbs.) }\end{array}$ & $\begin{array}{c}\text { Degree of } \\
\text { Saturation } \\
(\%)\end{array}$ & $\begin{array}{c}\text { Moisture } \\
\text { Present } \\
\text { during } \\
\text { testing (lbs.) }\end{array}$ \\
\hline 1 & 29.89 & 28.48 & 1.41 & 0 & 0.00 \\
\hline 2 & 30.33 & 28.95 & 1.38 & 0 & 0.00 \\
\hline 3 & 30.04 & 28.69 & 1.35 & 0 & 0.00 \\
\hline 4 & 30.13 & 28.81 & 1.32 & 0 & 0.00 \\
\hline 5 & 29.98 & 28.63 & 1.35 & 20 & 0.27 \\
\hline 6 & 29.66 & 28.35 & 1.31 & 20 & 0.26 \\
\hline 7 & 29.69 & 28.32 & 1.37 & 20 & 0.27 \\
\hline 8 & 30.06 & 28.97 & 1.09 & 20 & 0.22 \\
\hline 9 & 29.82 & 28.52 & 1.30 & 40 & 0.52 \\
\hline 10 & 29.79 & 28.68 & 1.11 & 40 & 0.44 \\
\hline 11 & 29.88 & 28.53 & 1.35 & 40 & 0.54 \\
\hline 12 & 29.90 & 28.51 & 1.39 & 40 & 0.56 \\
\hline 13 & 30.01 & 28.74 & 1.27 & 60 & 0.76 \\
\hline 14 & 29.96 & 28.82 & 1.14 & 60 & 0.68 \\
\hline 15 & 26.31 & 25.16 & 1.15 & 60 & 0.69 \\
\hline 16 & 29.92 & 28.61 & 1.31 & 60 & 0.79 \\
\hline 17 & 29.82 & 28.50 & 1.32 & 80 & 1.06 \\
\hline 18 & 29.60 & 28.28 & 1.32 & 80 & 1.06 \\
\hline 19 & 29.54 & 28.24 & 1.30 & 80 & 1.04 \\
\hline 20 & 28.55 & 27.28 & 1.27 & 80 & 1.02 \\
\hline 21 & 30.08 & 28.84 & 1.24 & 100 & 1.24 \\
\hline 22 & 29.57 & 28.34 & 1.23 & 100 & 1.23 \\
\hline 23 & 30.06 & 28.70 & 1.36 & 100 & 1.36 \\
\hline 24 & 29.56 & 28.30 & 1.26 & 100 & 1.26 \\
\hline & & & & & \\
\hline
\end{tabular}


Table 3.9 Concrete Specimen Mass for Variable Degrees of Saturation (Split Tensile Test)

\begin{tabular}{|c|c|c|c|c|c|}
\hline Specimen \# & $\begin{array}{c}\text { Saturated } \\
\text { Weight } \\
\text { (lbs.) }\end{array}$ & $\begin{array}{c}\text { Dry Weight } \\
\text { (lbs.) }\end{array}$ & $\begin{array}{c}\text { Water } \\
\text { Capacity } \\
\text { (lbs.) }\end{array}$ & $\begin{array}{c}\text { Degree of } \\
\text { Saturation } \\
(\%)\end{array}$ & $\begin{array}{c}\text { Moisture } \\
\text { Present } \\
\text { during } \\
\text { testing (lbs.) }\end{array}$ \\
\hline 1 & 13.12 & 12.56 & 0.56 & 0 & 0 \\
\hline 2 & 13.34 & 12.74 & 0.60 & 0 & 0 \\
\hline 3 & 13.12 & 12.58 & 0.55 & 0 & 0 \\
\hline 4 & 13.35 & 12.80 & 0.55 & 0 & 0 \\
\hline 5 & 12.67 & 12.11 & 0.56 & 20 & 0.11 \\
\hline 6 & 13.11 & 12.53 & 0.58 & 20 & 0.12 \\
\hline 7 & 13.14 & 12.55 & 0.59 & 20 & 0.12 \\
\hline 8 & 13.24 & 12.65 & 0.59 & 20 & 0.12 \\
\hline 9 & 13.28 & 12.70 & 0.58 & 40 & 0.23 \\
\hline 10 & 11.68 & 11.17 & 0.51 & 40 & 0.20 \\
\hline 11 & 13.30 & 12.79 & 0.51 & 40 & 0.20 \\
\hline 12 & 13.32 & 12.76 & 0.56 & 40 & 0.23 \\
\hline 13 & 13.27 & 12.65 & 0.62 & 60 & 0.37 \\
\hline 14 & 13.26 & 12.66 & 0.60 & 60 & 0.36 \\
\hline 15 & 13.22 & 12.73 & 0.49 & 60 & 0.30 \\
\hline 16 & 13.24 & 12.66 & 0.58 & 60 & 0.35 \\
\hline 17 & 13.34 & 12.86 & 0.48 & 80 & 0.39 \\
\hline 18 & 13.18 & 12.57 & 0.61 & 80 & 0.49 \\
\hline 19 & 13.16 & 12.58 & 0.58 & 80 & 0.47 \\
\hline 20 & 13.31 & 12.71 & 0.60 & 80 & 0.48 \\
\hline 21 & 13.37 & 12.79 & 0.59 & 100 & 0.59 \\
\hline 22 & 13.33 & 12.73 & 0.60 & 100 & 0.60 \\
\hline 23 & 13.46 & 12.85 & 0.61 & 100 & 0.61 \\
\hline 24 & 13.27 & 12.64 & 0.63 & 100 & 0.63 \\
\hline & & & & & \\
\hline
\end{tabular}


Table 3.10 Concrete Specimen Mass for Variable Degrees of Saturation (Modulus Test)

\begin{tabular}{|c|c|c|c|c|c|}
\hline Specimen \# & $\begin{array}{c}\text { Saturated } \\
\text { Weight } \\
\text { (lbs.) }\end{array}$ & $\begin{array}{c}\text { Dry Weight } \\
\text { (lbs.) }\end{array}$ & $\begin{array}{c}\text { Water } \\
\text { Capacity } \\
\text { (lbs.) }\end{array}$ & $\begin{array}{c}\text { Degree of } \\
\text { Saturation } \\
(\%)\end{array}$ & $\begin{array}{c}\text { Moisture } \\
\text { Present } \\
\text { during } \\
\text { testing (lbs.) }\end{array}$ \\
\hline 1 & 29.92 & 28.61 & 1.31 & 0 & 0.00 \\
\hline 3 & 29.75 & 28.59 & 1.16 & 0 & 0.00 \\
\hline 1 & 29.92 & 28.61 & 1.31 & 20 & 0.26 \\
\hline 3 & 29.75 & 28.59 & 1.16 & 20 & 0.23 \\
\hline 1 & 29.92 & 28.61 & 1.31 & 40 & 0.52 \\
\hline 3 & 29.75 & 28.59 & 1.16 & 40 & 0.46 \\
\hline 1 & 29.92 & 28.61 & 1.31 & 60 & 0.79 \\
\hline 3 & 29.75 & 28.59 & 1.16 & 60 & 0.70 \\
\hline 1 & 29.92 & 28.61 & 1.31 & 80 & 1.05 \\
\hline 3 & 29.75 & 28.59 & 1.16 & 80 & 0.93 \\
\hline 1 & 29.92 & 28.61 & 1.31 & 100 & 1.31 \\
\hline 3 & 29.75 & 28.59 & 1.16 & 100 & 1.16 \\
\hline
\end{tabular}




\section{Chapter 4 \\ Experimental Testing}

\subsection{Introduction}

In order to conduct modulus of elasticity testing at varying temperatures and preheat or cool specimens for strength testing a number of other devices were needed first. The list included:

1. Hydraulic Actuators

2. Microprocessor-Based Process Controller

3. Specimen Storage Container (Freezer)

4. Heat Gun

5. Computer Fan and Flexible Air Ducts

6. 120 Volt AC to 12 Volt DC Adaptor

7. Thermocouple

8. Data Acquisition System

9. Data Logger

10. Strain Gages

11. Temperature Controlled Testing Chamber

\subsection{Specimen Temperature Controlling and Testing Chamber}

\subsubsection{Hydraulic Actuators}

In order to find the various properties of concrete, which were Poisson's Ratio, modulus of elasticity, compressive strength, and tensile strength a plan was developed to use two types of hydraulic actuators for the testing. In order to find Poisson's Ratio and modulus of elasticity a computer controlled MTS actuator was used. The MTS actuator was capable of applying 110,000 pounds of force in compression. The MTS actuator was connected to a large steel frame, which in turn was mounted to the floor via large bolts, 
which anchor into a strong reinforced concrete floor. To apply compression to a test specimen the actuator pushed up on the frame, and down on the specimen an equal amount.

In the experiments, the MTS actuator was not used for compression or tensile strength testing because of its limited capacity. The large 6 inch diameter by 12 inch high specimens required about 150,000 pounds of force before failure occurred. The large specimens were broken in compression on another manually controlled actuator. The actuator was made by Forney Testing Machines and was manually controlled. It can easily provide 150,000 pounds of force, but only in compression. A split tensile test was used to find the tensile strength of concrete with small 4 inch diameter by 8 inch high specimens. Since the MTS actuator was only used in modulus of elasticity testing it does not need to be configured for use up to its 110,000 pound capacity. It was configured for use up to 50,000 pounds force to make sure the stresses were within the elastic limits of the specimens.

\subsubsection{Microcontroller}

The freezer compressor, computer fan, and heat gun were all controlled via an Automation Direct PC 35 microprocessor-based process controller. The controller received its input from a type $\mathrm{K}$ thermocouple. The unit had two internal relays. The relays could close up to 3 amps of current safely at 115 VAC. Since both the compressor and heat gun needed more than 3 amps each continuous current to operate, the internal relay drove larger external relays. The external relays were rated for 10 amps continuous current that was sufficient to power the compressor or heat resistor, both of which needed 5 amps continuous current each. All operations of cooling and heating could be controlled through the controller, no external switching is necessary. A four degree Fahrenheit hysteresis was used in order to minimize the amount of compressor cycling, thus reduce wear. There were various protections from electrocution and wire overheating throughout the system. There was a main fuse for the entire system, which was 7 amps. It was used to safeguard the entire system. The compressor and computer fan were wired through one fuse, then separately the heat gun was wired through another 
fuse. Both of those fuses were 6 amps. The freezer compressor and heat gun should not run at the same time. If they did, they would draw more than 7 amps and blow the main fuse, thus protecting the wiring of the system. This is the reason why a 7 amp fuse was used instead of a 10-12 amp fuse. The metal case of the specimen storage container, heat gun, and process controller box are grounded so that if a wire were to touch the case of any internally the electric charge would flow through the ground wire instead of a person touching the case. A schematic can be seen in Figure 4.1.

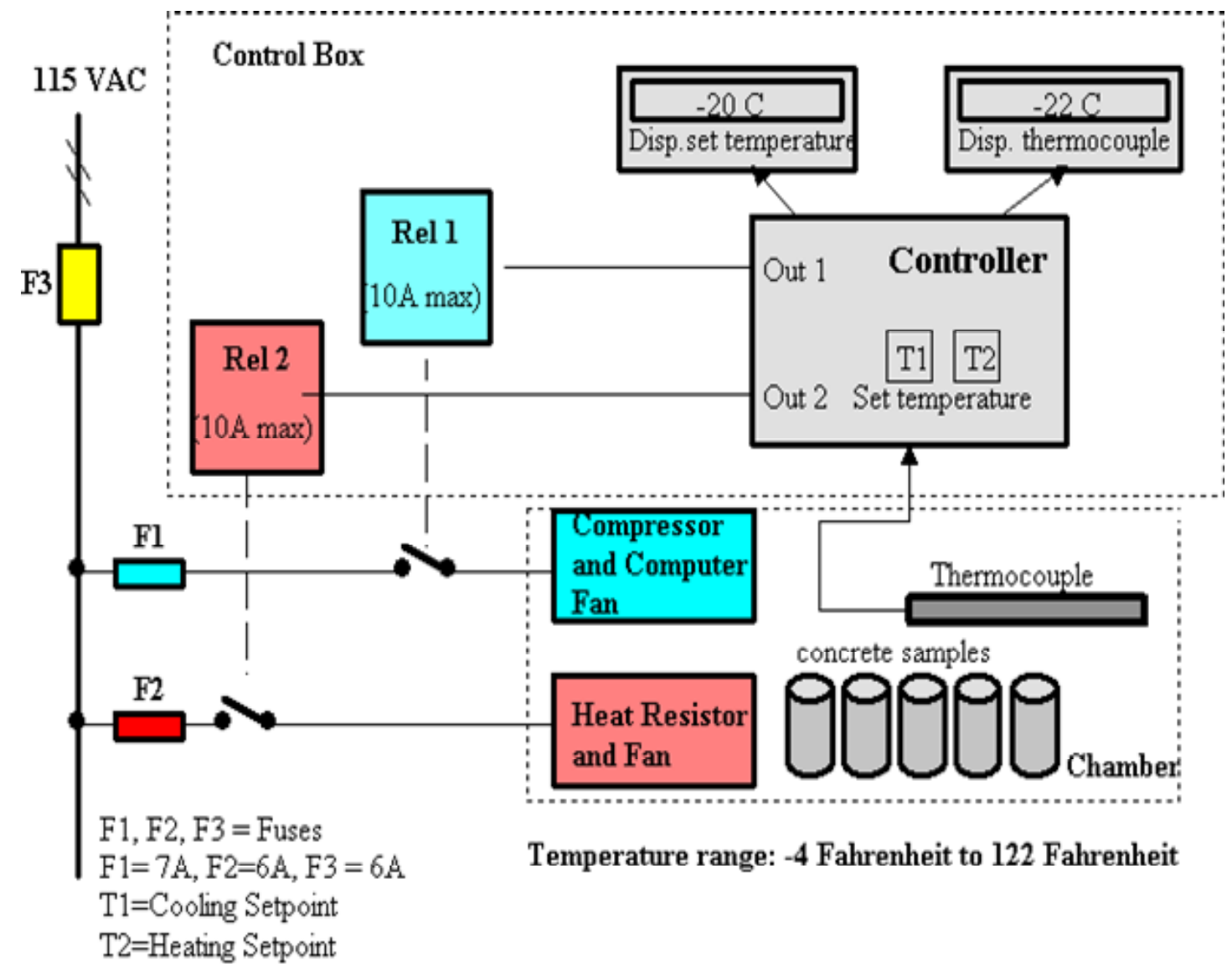

Figure 4.1 Control System Schematic 


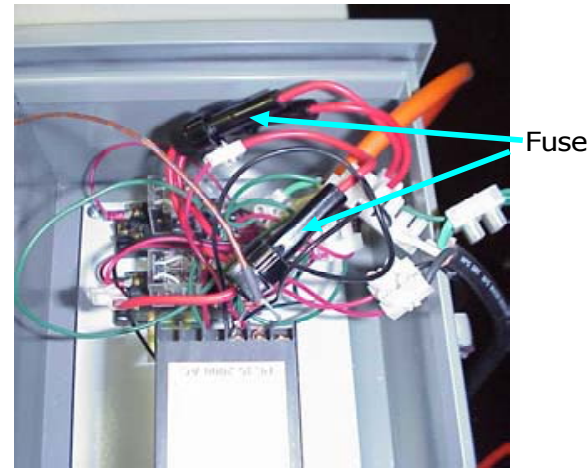

Figure 4.2a Controller Wiring

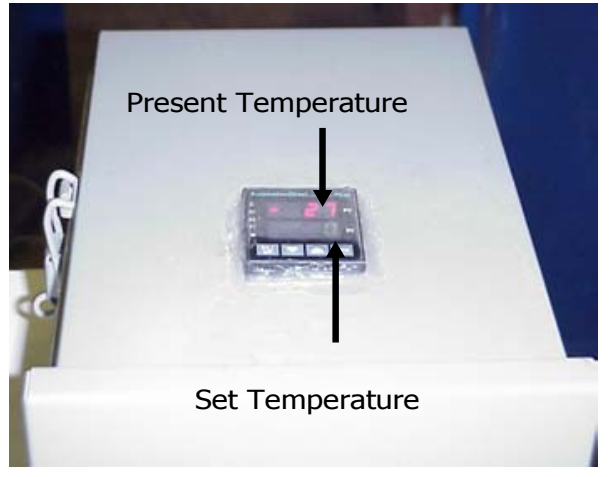

Figure 4.2b Microcontroller and Box Top View

Figure 4.2 Microprocessor Based Controller

\subsubsection{Specimen Storage Container}

A commercial freezer capable of producing temperatures of less than $-20^{\circ} \mathrm{F}$ was obtained and modified. It was renamed specimen storage container after the modification in Figure 4.4. The dimensions are in Table 4.3. It was needed to provide chilled air to the testing chamber, pre-chill, pre-heat with use of a heat gun, and store concrete specimens. The freezer cooling assembly transfers heat from the inside air to the outside air leaving the air inside the freezer cooler than the outside air. This was accomplished with a compressor, an expansion valve, a condenser, and an evaporator. R-134a refrigerant initially at the outside ambient temperature is compressed. The compressed refrigerant still in the form of a gas was now much warmer than the ambient temperature. The hot refrigerant flowed through the condenser where it was cooled back to ambient temperature at which time it condenses into a liquid. The refrigerant then flowed into the expansion valve where it expanded into a gas and cooled at the same time in the evaporator. The gas was heated back to ambient temperature and then flowed back through the compressor. To the touch, the evaporator felt warm; the evaporator coils are 
located on the outside wall of the freezer. The condenser coils are cold to the touch and are located on the inside wall of the freezer.

The compressor and a computer fan run at the same time. The temperature required of the test sample was used as the temperature set point in the controller. The freezer was modified in several ways to accommodate the testing operation. The onboard thermostat was bypassed and the compressor was controlled by the process controller. Two holes were cut through the side of the freezer so chilled air could be supplied to the testing chamber. Short pipes with outside diameter of 3.75 inches were inserted through the side wall of the specimen storage container. The pipe were flush with the inside wall of the container and protruded three inches from the outside wall. Flexible ducts were attached to the protruding section of pipe to supply temperature controlled air to the testing chamber. A heat gun was inserted into the short section of pipe that goes through the side wall of the container. The heat gun resided inside the specimen storage container.

The specimen storage container was not a frost-free model. This is important since frost-free freezers have a cycle in which the compressor is shut off and heat coils turn on in the side panel for a few minutes in order to melt accumulated frost from the sides of the container. Since this model was not frost-free, that problem was avoided. The thermostat that was removed had a large temperature hysteresis that caused too much temperature deviation of the sample. This is important because the compressor will overload if it is turned back on after running within five minutes. If the compressor overloaded an internal breaker would shut it off to prevent motor burnout.

The compressor overloads because refrigerant inside the cylinder of the compressor is still at a high pressure. If the compressor comes on at that point it will encounter more resistance than the driving motor can overcome. The compressor will come on for a few seconds then shut off for a few seconds then come back on for a few seconds and so forth. The refrigerant needs time to cool and contract back into the accumulator before the compressor can be turned back on. A four-degree hysteresis still allowed adequate time for this to occur when the setpoint is at $-4{ }^{\circ} \mathrm{F}$. If a cooler temperature is required especially in a hot and humid climate, a five-degree hysteresis was used. Above $32{ }^{\circ} \mathrm{F}$ a two degree hysteresis was used. At lower temperatures inside 
the specimen storage container the temperature differential is much higher between the outside of the specimen storage container and inside. Heat flows much faster at high temperature differentials and will cause the compressor to cycle too much.
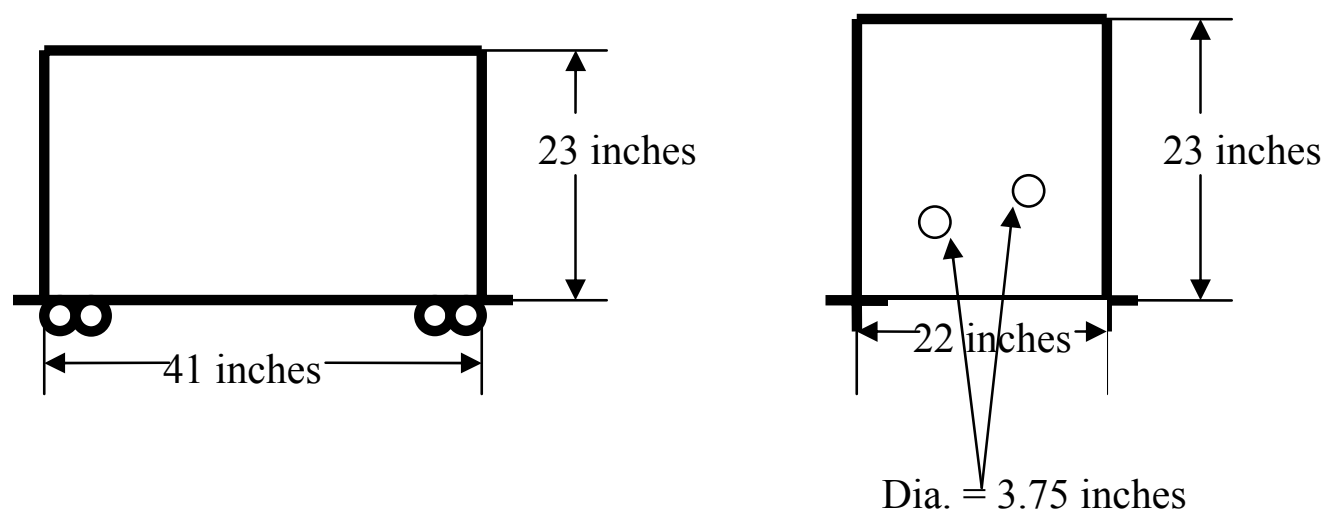

Figure 4.3 Specimen Storage Container Dimensions 


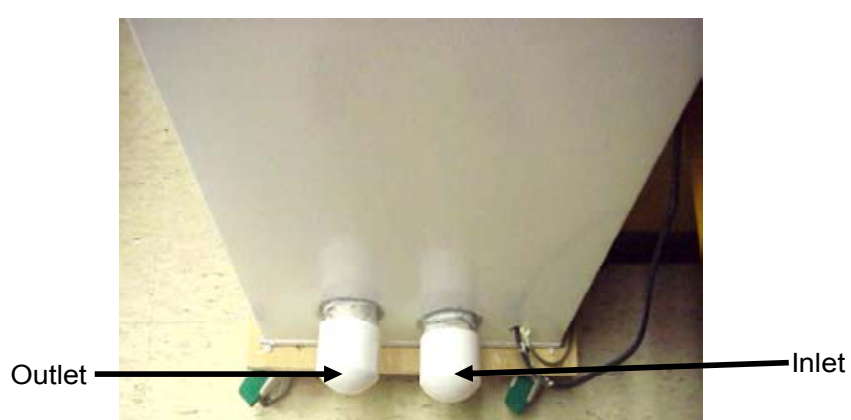

Figure 4.4a Specimen Storage Container Side View

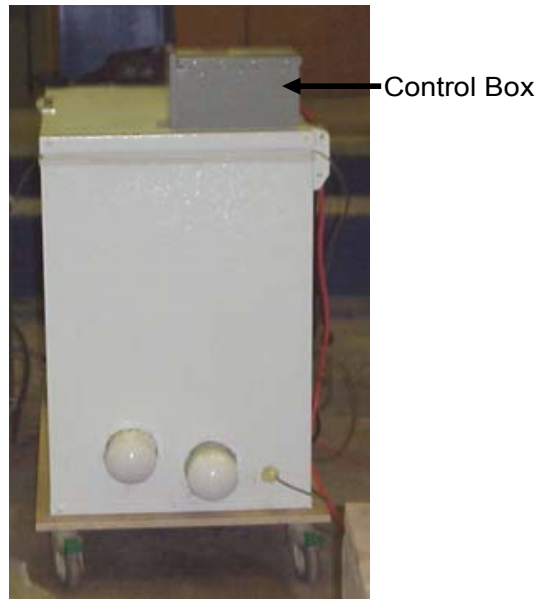

Figure 4.4b Specimen Storage Container Side View

\section{Figure 4.4 Specimen Storage Container}

\subsubsection{Heat Gun}

A heat gun was used to supply warm air to the testing chamber when needed. The heat gun would maintain the testing chamber greater than $130^{\circ} \mathrm{F}$. The heat gun was inserted inside the temperature controlled compartment. The system was designed so the heat gun and freezer compressor do not run at the same time. The heat gun was also used to pre-heat samples before a test. A four-degree hysteresis was used when operating the heat gun at $122{ }^{\circ} \mathrm{F}$ and below. A five or six degree hysteresis was used at higher temperatures, especially in a cold climate. If the resistor is turned on and off too frequently it will overheat, since more current goes through the resistor when it is initially turned on. 


\subsubsection{Computer Fan and Air Ducts}

A small efficient computer fan and flexible ducts supplied chilled air from the freezer to the testing chamber as needed. An efficient fan was needed since fan heat raised the temperature of the test sample by as much as 18 degrees with a high wattage fan. The computer fan used less than 2 watts while still moving 15 cubic feet per minute of airflow and adds less than 1 degree of heat. Initially the heat gun fan was also going to be used to circulate chilled air, it provided an adequate supply of air, and unfortunately it produced too much internal heat. The waste heat was acceptable when the heat gun was used for its intended purpose of heating but not when it is used to transport chilled air. The computer fan motor worked fine when moving the sub-freezing air. The insulated flexible air duct with a four inch inside diameter fit over the pipe protruding from the specimen storage container, which had a diameter of 3.75 inches. This provided a tight fit and was secured with hose clamps. The 2.5 inch fan in Figure 4.5 fit inside the output duct of the specimen storage container, insulation is used to seal gaps around the fan.

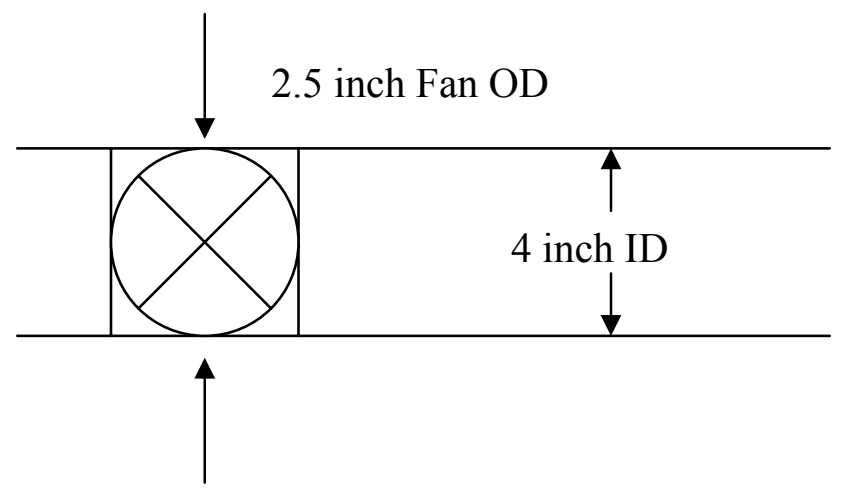

Figure 4.5 Fan and Duct Dimensions 


\subsubsection{Computer Fan Power Supply}

An alternating current to direct current voltage transformer (power supply) was used in order to power the computer fan, which required a low voltage direct current source. The microcontroller provided alternating household current.

\subsubsection{Thermocouple}

A type $\mathrm{K}$ thermocouple was used to measure temperature. It had an accuracy of \pm 1 digit or in this case \pm 1 degree Fahrenheit. The temperature range was from $-130^{\circ} \mathrm{F}$ up to $2498{ }^{\circ} \mathrm{F}$. The thermocouple induces a change in voltage as the temperature changes. Unfortunately, this does not occur linearly. The controller through its software and microprocessor provided linearization for the thermocouple. If more accuracy was needed an RTD could have been used which had an accuracy of \pm 0.1 degree Fahrenheit.

\subsubsection{Data Acquisition System}

The data acquisition system works with three main devices the Geokon data logger (model 8020), Geokon multiplexer (model 8032), and a personal computer. Data from the Geokon strain gages and thermistors inside the concrete specimen was retrieved and stored on the data logger. The strain gauges and thermistors are physically wired to the multiplexer and then the multiplexer is connected to the data logger. The multiplexer has 16 or 32 channels of input depending if temperature was monitored. Since there were five concrete specimens used only five channels were used out of 16 since each specimen had four conductors for both strains and temperatures. The information including strain and temperature are stored on the data logger until the user downloads the data from the data logger to a personal computer. The load was recorded via a Labview program. 


\subsubsection{Data Logger}

The data logger has multiple functions including collecting and storing data from up to 16 specimens. The specifications can be reviewed in the Table 4.1.

Table 4.1 Geokon Data Logger Specifications

\begin{tabular}{|l|l|}
\hline Range (Analog) & $\pm 2.5 \mathrm{mV}$ to $\pm 2.5 \mathrm{~V}$ \\
\hline Resolution (Analog) & $0.33 \mathrm{mV}$ to $333 \mathrm{mV}$ \\
\hline Range (Frequency) & $\mathrm{DC}$ to $200 \mathrm{kHz}$ \\
\hline Resolution (Frequency) & $\pm 60 \mathrm{nS} /$ no. cycles measured \\
\hline Accuracy & $0.2 \%, 20 \mathrm{ppm}$ (ref) \\
\hline Excitation Output & $\pm 2.5 \mathrm{~V}$ at $20 \mathrm{~mA}$, \\
& Frequency Sweep $(2.5 \mathrm{~V}$ peak) \\
\hline Temperature Range & $-23^{\circ} \mathrm{C}$ to $+50^{\circ} \mathrm{C}$ \\
\hline Battery & $12 \mathrm{~V}, 2.6 \mathrm{Amp} \mathrm{Ahr}$ Gel Cell \\
\hline Dimensions $(\mathrm{L} \times \mathrm{W} \times \mathrm{H})$ & 14 in. $\mathrm{x} 12$ in. $\mathrm{x} 6 \mathrm{in}$. \\
\hline
\end{tabular}

\subsubsection{Vibrating Wire Strain Gages}

The Geokon VCE-4202 strain gages measured strain with the use of a vibrating wire. The wire changed length as the strain of concrete changes. The wire vibrated at its natural frequency. The vibration was induced by small electromagnetic pulses. The natural frequency changed directly as the wire changed length. The frequency is measured and with the use of a proper gage factor gives an output in microstrain. Two strain gages were used. The strain gages are powered indirectly by the Geokon data logger through the Geokon multiplexer. The dimensions can be seen in Figure 4.6 and specifications in Table 4.2. The gages reside in the center of the 6 inch by 12 inch specimens. The thermal coefficient of expansion of the strain gage was taken into account when measuring strain at varying temperatures. 
Table 4.2 Geokon Strain Gage Specifications

\begin{tabular}{|l|l|}
\hline Model Number & VCE-4202 \\
\hline Method of attachment & embedment \\
\hline Active gage length: mm. (inches) & $2(50)$ \\
\hline Maximum strain range: microstrain & 3000 \\
\hline Sensitivity: microstrain & 1.0 \\
\hline Temperature range: ${ }^{\circ} \mathrm{C}$ & -20 to +80 \\
\hline Thermal coefficient of expansion: $\mathrm{ppm} /{ }^{\circ} \mathrm{C}$ & 12.0 \\
\hline Coil resistance: ohms & 180 \\
\hline Cable types & $4-$ cond. Shielded 22 awg \\
\hline Typical frequency datum: $\mathrm{Hz}$ & 2600 \\
\hline Readout Position & $\mathrm{E}$ \\
\hline Gage Factor & 0.391 \\
\hline Experimental & 0.359 \\
\hline
\end{tabular}

0.25 inch OD

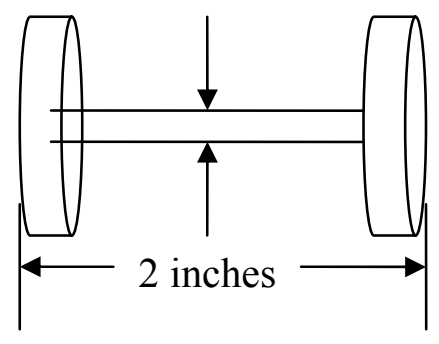

Figure 4.6 Geokon VCE-4202 Vibrating Wire Strain Gage Dimensions 


\subsubsection{Temperature Controlled Chamber}

In order to test the modulus of elasticity of cured concrete at various temperature and moisture conditions in a lab environment a system was required that would control the temperature of the concrete being tested. Concrete cylinders were allowed to cure under ideal conditions of $68^{\circ} \mathrm{F}$ and a saturated moisture level for 28 days, or till it was scheduled to be tested whichever was later. The modulus of elasticity testing lasted for 20 minutes so the concrete had to be insulated, heated, and or cooled to maintain the proper temperature. A chamber with chilled air plumbed into it was used to keep the concrete cylinder at the appropriate temperature while the modulus of elasticity testing was conducted. Dimensions can be seen in Figure 4.7. Such a chamber was not available in the marketplace so it had to be developed using widely available materials as can be see in Figure 4.8. The chamber was constructed of thick plywood and lined internally with insulation. It was connected to the specimen storage container via two four-inch flexible insulated ducts. There was a rubber gasket in the chambers removable lid to allow for the actuator spacer that applies force to the concrete.

The chamber was primarily used for modulus of elasticity testing at varying temperatures, but was also used to store specimens used for compression and split tensile testing. The compression and split tensile tests were done on the manually controlled Forney actuator for two reasons. The Forney actuator provided sufficient force to fail the specimens in compression, and the compression test only lasted approximately one minute, therefore there was no need to worry about maintaining the temperature of the specimen since it was tested quickly and would be at proper temperature before the test.

The chamber had the capability to cool specimens down to $-4{ }^{\circ} \mathrm{F}$. This assumed that the chamber and specimen storage container would be operated in a room where the temperature was no more than $+68^{\circ} \mathrm{F}$. The calculations (equations 4.1 to 4.4 ) for the testing chamber, ducts, and specimen storage container were derived on page 44 . 


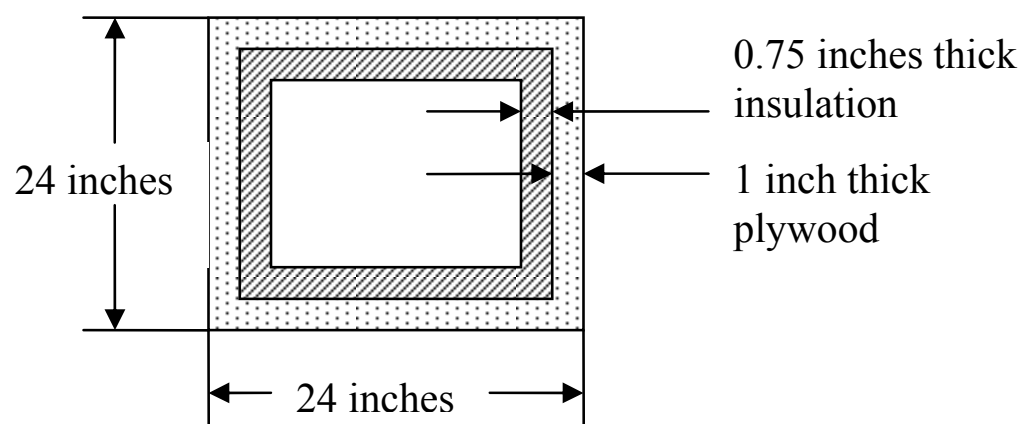

Section View of Testing Chamber

Figure 4.7 Temperature Controlled Chamber Dimensions

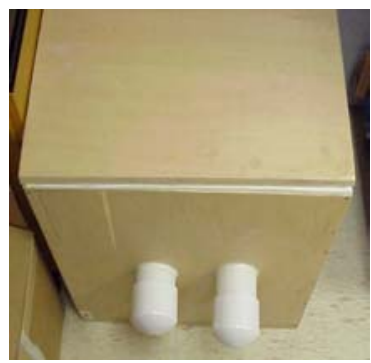

Figure 4.8a Temperature Controlled Chamber Diagonal View

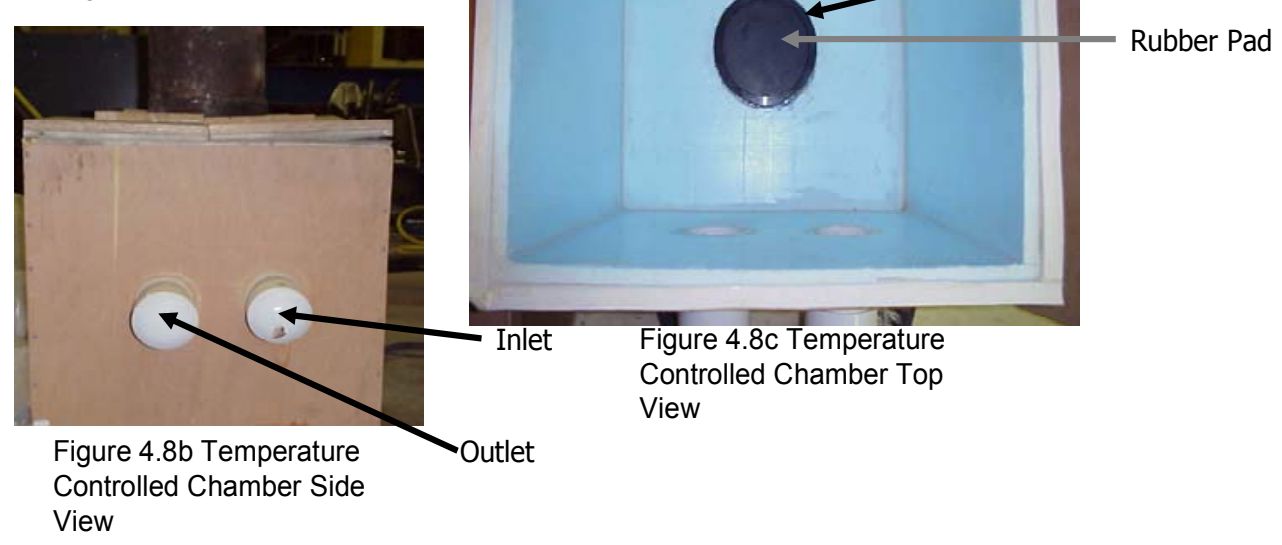

Figure 4.8 Temperature Controlled Chamber 


\section{Heat Load Calculations for the Temperature Controlled Testing Chamber and Specimen Storage Container}

$$
\begin{aligned}
& \mathrm{q} 1=\mathrm{U} 1 * \mathrm{~A} 1 *(\Delta \mathrm{t}) \\
& \mathrm{q} 2=\mathrm{U} 2 * \mathrm{~A} 2 *(\Delta \mathrm{t}) \\
& \mathrm{q} 3=\mathrm{U} 3 * \mathrm{~A} 3 *(\Delta \mathrm{t}) \\
& \mathrm{q}=\mathrm{q} 1+\mathrm{q} 2+\mathrm{q} 3
\end{aligned}
$$

equation 4.1

equation 4.2

equation 4.3

equation 4.4

$\mathrm{q}=$ heat removing capacity of specimen storage container refrigeration system

$\mathrm{q} 1=$ heat loss due to conduction and convection of the specimen storage container

$\mathrm{q} 2=$ heat loss due to conduction and convection of the insulated ducts

$\mathrm{q} 3=$ heat loss due to conduction and convection of the temperature controlled testing chamber

$\mathrm{U} 1=$ air to air heat transfer coefficient of the specimen storage container

$\mathrm{U} 2=$ air to air heat transfer coefficient of the insulated ducts

$\mathrm{U} 3=$ air to air heat transfer coefficient of the temperature controlled testing chamber

$\mathrm{A} 1=$ area of the specimen storage container

$\mathrm{A} 2=$ area of the insulated ducts

A3 $=$ area of temperature controlled testing chamber

$\Delta \mathrm{t}=$ change in temperature $=72^{\circ} \mathrm{F}$

\subsection{Concrete Specimen Testing}

\subsubsection{Modulus of Elasticity Test and Calculations}

In order to conduct modulus of elasticity tests instrumented 6 inch diameter by 12 inch high specimens were utilized. Five instrumented concrete specimens were produced. The Modulus of Elasticity Test is a non-destructive test meaning that the specimens can be reused many times since the level of stresses were always kept within the elastic range. The molds for the instrumented concrete specimens contained two Geokon strain gages for which the specifications can be seen in Table A.12. The two gages must be 90 degrees apart from one another and attached at their centers to make a strain gage rosette, which can be seen in Figure 3.2. The first gage measures vertical strain and must be parallel with the vertical axis of the concrete specimen. The second gage measures horizontal strain and must remain parallel with the horizontal axis of the specimen. Thermistors were used to measure the temperature within the specimens. The gages are connected to a data logger. The specimens receive a compressive force applied at an increasing rate of 20 pounds per second up to 7500 pounds force then a decrease of 20 pounds per second back down to 0 pounds force. This was accomplished using the 
multi-ramp input on the 407 controller. The actuator is always increasing or decreasing load, less than a second of time is spent at 7500 pounds force. This is only about 4 percent of the force required to break the specimen. The force always stays well within the elastic region causing no harm to the specimen.

In order to calculate Poisson's Ratio the vertical strain and horizontal strain were obtained with the use of the strain gauges within the concrete specimens and the data logger. Poisson's Ratio is the horizontal strain divided by the vertical strain. In order to calculate modulus of elasticity the vertical strain, load, and specimen area were found. The load and specimen area can be used to calculate stress by dividing the load by the area. The modulus of elasticity is calculated by dividing stress by strain at the linear part of the relation. Since temperature has a large impact on expansion when heated and contraction when cooled on concrete, the strain data must be corrected if there is any temperature variation during the tests. The change in strain per unit temperature was simple to calculate. One must simply divide either vertical or horizontal strain by the change in temperature. A formula was used since the steel vibrating wire strain gauges will expand at a different rate than the concrete. Temperature of the specimen, load, vertical strain, and horizontal strain were continuously monitored and recorded. The temperature of the specimen was monitored by the data acquisition system. The temperature of the testing chamber was maintained by the microprocessor based controller in Figure 4.3. The data was monitored and recorded on the data logger. This eliminated human error when recording measurements. The tests of the instrumented cylinders took about twenty minutes. The actuator sensitivity is about \pm 100 pounds. The MTS 407 controller controlled the MTS actuator. The MTS 407 controller could be programmed by the user to provide a number of inputs to the actuator. The inputs include ramp input, multi-ramp input, cyclic input, or the actuator can be controlled manually. The MTS 407 controller was interfaced to a personal computer via a serial connection, which could be controlled by the computer as shown in Figure 4.9.

In order to operate the microcontroller for cooling use with the modulus of elasticity test a number of steps were followed including:

Step 1: The PC35 microcontroller must be plugged in to an outlet producing household current of at least 15 amps. 
Step 2: The setup button should be pressed and released until run is displayed on the top line of the controller.

Step 3: To turn the controller on the up arrow should be pressed and released; "run yes" will be displayed. To turn off the controller the down arrow should be pressed and released, "run no" will be displayed. The controller should be kept off until the start of a test, but can left on also. If the user tries to run both the compressor and heat gun the circuit will not overload because a fuse will blow. To prevent this from occurring the user should not heat and cool at the same time. If the user wanted to heat and cool at the same time a high amperage circuit would need to be utilized.

Step 4: To adjust the setpoint of the testing chamber the back button must be pressed and held while the setup button is pushed and released once. "Atun no" will be displayed. Note: If the back button is pressed and held too long or the pause between pushing and releasing the setup button is too long problems will occur.

Step 5: The setup button must be pressed and released until "SP.A2" is displayed on the top line the arrow keys can be used to change the setpoint.

Step 6: The alarm output relay then must be turned on. Press and hold the back button while pressing and releasing the setup button five times. "lo1" will be displayed. Set "lo1" to 0 with the down arrow key if it is not already.

Step 7: Push the setup button once and release it. "lo2" will be displayed. "lo2" must be set to 2 with the arrow keys.

Step 8: In order to check the hysteresis and function alarms the back button must be pressed and held while the setup button is pressed and released three times. "Fu A1" will appear. Make sure "Fu A1" is set to Lo. If "Fu A1" is set to Hi press the down arrow to set it to Lo. Press the setup button again. "Fu A2" will appear. Make sure "Fu A2" is set to Hi. If "Fu A2" is set to Lo press the up arrow to set it to Hi. Press and release the setup button until "Hya 1" is displayed and make sure it is 2 if not use the up and down arrows to adjust it to 2. Press and release the setup button one more time and "Hya 2" will display. Make sure it is set to 2 and use the up or down arrows to adjust it to 2 if it is not already.

Step 9: Connect the flexible ducts to the specimen storage container and the temperature controlled temperature chamber including the wires to operate the fan. 
Step 10: Turn on the 407 controller and MTS actuator. Do not forget to turn on the PC35 microcontroller by going to run and selecting yes. Select run no after the test is complete and make adjustments to the setpoint as necessary.

Step 11: Turn on the data logger and begin taking data.

Step 12: Start the Modulus of Elasticity Test

In order to operate the microcontroller for heating use with the modulus of elasticity test a number of steps were followed including:

Step 1: The PC35 microcontroller must be plugged in to an outlet producing household current of at least 15 amps.

Step 2: The setup button should be pressed and released until run is displayed on the top line of the controller.

Step 3: To turn the controller on the up arrow should be pressed and released; "run yes" will be displayed. To turn off the controller the down arrow should be pressed and released, "run no" will be displayed. The controller should be kept off until the start of a test, but can left on also. If the user tries to run both the compressor and heat gun the circuit will not overload because a fuse will blow. To prevent this from occurring the user should not heat and cool at the same time. If the user wanted to heat and cool at the same time a high amperage circuit would need to be utilized.

Step 4: To adjust the setpoint of the testing chamber the back button must be pressed and held while the setup button is pushed and released once. "Atun no" will be displayed. Note: If the back button is pressed and held too long or the pause between pushing and releasing the setup button is too long problems will occur.

Step 5: The setup button must be pressed and released until "SP.A1" is displayed on the top line the arrow keys can be used to change the setpoint.

Step 6: The alarm output relay then must be turned on. Press and hold the back button while pressing and releasing the setup button five times. "lo1" will be displayed. Set "lo1" to 1 with the down arrow key if it is not already.

Step 7: Push the setup button once and release it. "lo2" will be displayed. "lo2" must be set to 0 .

Step 8: In order to check the hysteresis and function alarms the back button must be pressed and held while the setup button is pressed and released three times. "Fu A1" will 
appear. Make sure "Fu A1" is set to Lo. If "Fu A1" is set to Hi press the down arrow to set it to Lo. Press the setup button again. "Fu A2" will appear. Make sure "Fu A2" is set to Hi. If "Fu A2" is set to Lo press the up arrow to set it to Hi. Press and release the setup button until "Hya 1" is displayed and make sure it is 2 if not use the up and down arrows to adjust it to 2. Press and release the setup button one more time and "Hya 2" will display. Make sure it is set to 2 and use the up or down arrows to adjust it to 2 if it is not already.

Step 9: Connect the flexible ducts to the specimen storage container and the temperature controlled temperature chamber.

Step 10: Turn on the 407 controller and MTS actuator. Do not forget to turn on the PC35 microcontroller by going to run and selecting yes. Select run no after the test is complete and make adjustments to the setpoint as necessary.

Step 11: Turn on the data logger and begin taking data.

Step 12: Start the Modulus of Elasticity Test

The entire setup can be seen in Figure 4.9 it is important to use precautions when operating machinery required for the testing. The following safety guidelines were adhered to. Safety glasses must be worn at all times. Gloves should be worn when handling equipment. It is very important to stand clear of the MTS actuator when a test is in progress. Absolutely no testing should be done when the setup is unattended. Fire extinguishers should always be handy. The setup should be unplugged when not in use. 


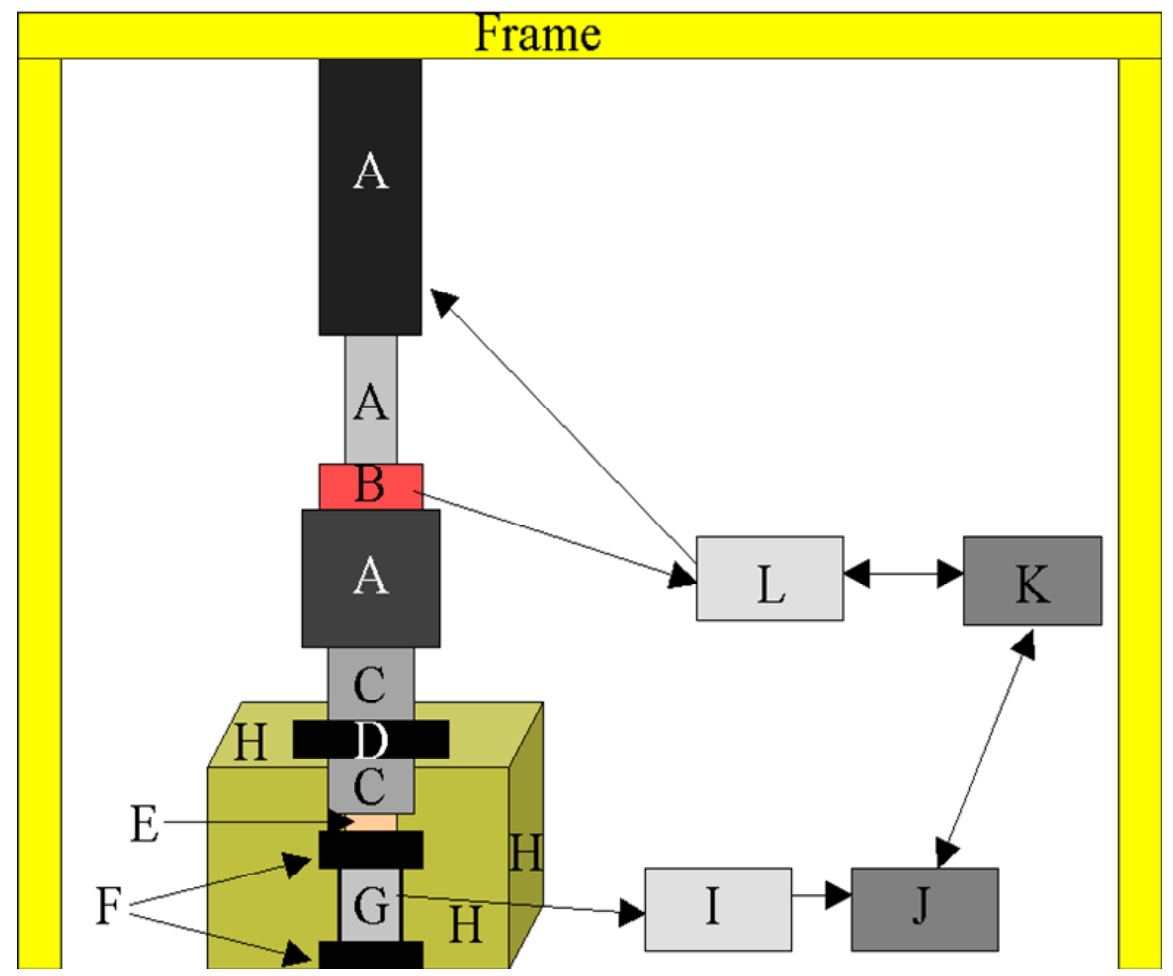

Figure 4.9 Modulus Testing System Layout
$\mathrm{A}=$ MTS Actuator
$\mathrm{G}=$ Concrete Specimen
$\mathrm{B}=$ Load Cell
$\mathrm{H}=$ Testing Chamber
$\mathrm{C}=$ Spacer
I = Multiplexer
$\mathrm{D}=$ Seal
$\mathrm{J}=$ Data Logger
$\mathrm{E}=$ Spherical Washers
$\mathrm{K}=\mathrm{IBM}$ Computer
$\mathrm{F}=$ Pads and Caps
$\mathrm{L}=407$ Controller 


$$
\begin{aligned}
& \text { Modulus of Elasticity } E=\frac{\operatorname{Stress}(\sigma)}{\operatorname{Vertical\operatorname {Strain}}(\varepsilon)}=\frac{\frac{\operatorname{Load}(P)}{\operatorname{Cross} \sec \cdot \operatorname{Area}(A)}}{\operatorname{Vertical\operatorname {Stain}}(\varepsilon)} \quad \text { equation } 4.5 \\
& \text { Poisson's ratio } v=\frac{\text { HorizontalStrain }}{\text { VerticalStrain }} \\
& \text { equation } 4.6
\end{aligned}
$$

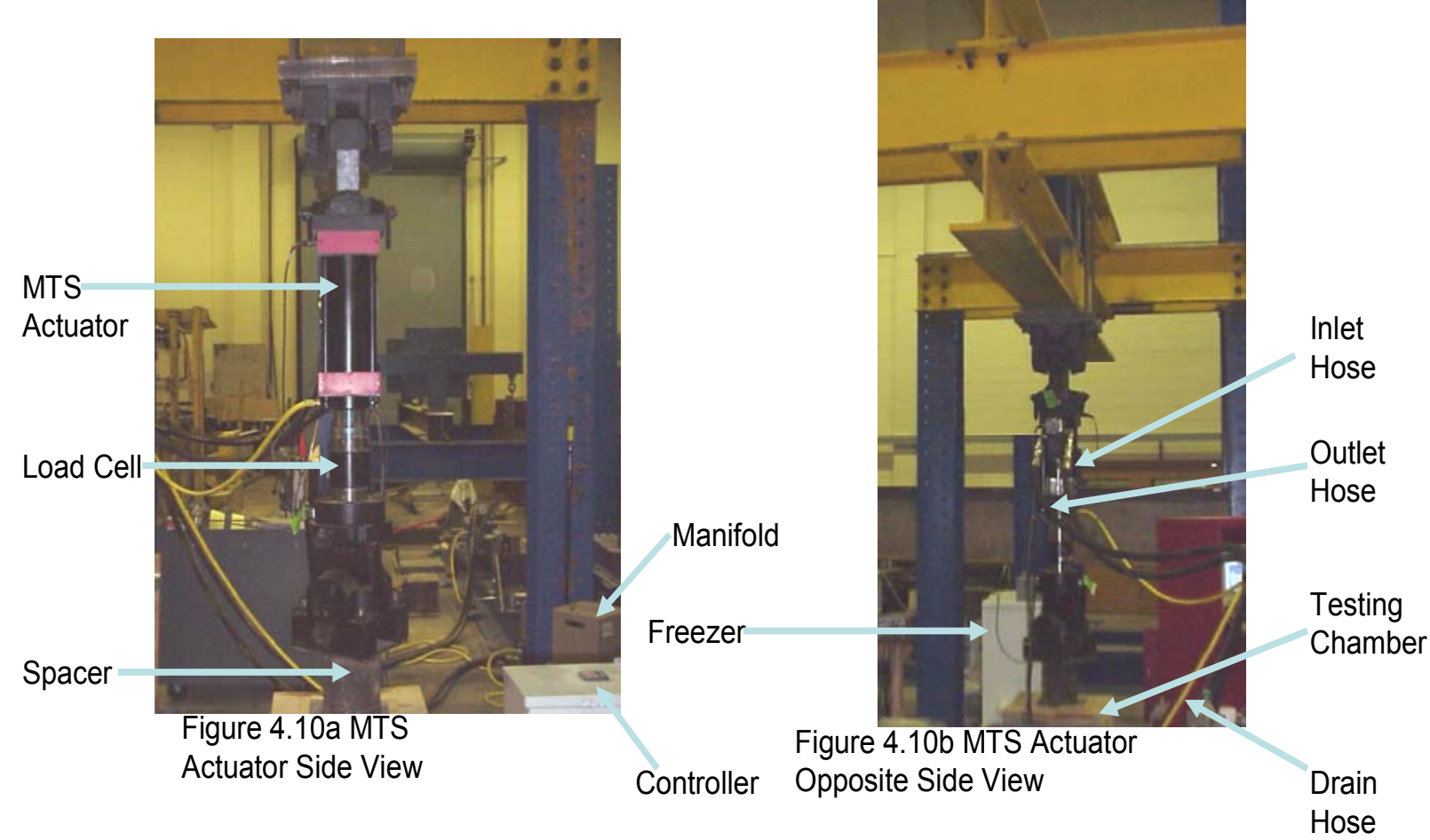

Figure 4.10 Modulus Test 


\subsubsection{Compression Test and Calculations}

The compression test is similar to the modulus of elasticity test as far as the testing procedure goes except it is a destructive test. The force at which the specimen breaks was divided by the area of the specimen to find its strength. Figure 4.11 shows a picture of the Forney Compression Tester Control Panel which was used to control the actuator on the right. The Forney Compression Tester is manually controlled, thus it was very important to maintain the same loading rate with all of the compression tests.

$$
\sigma=\frac{P}{A}
$$

$P=$ Load at Failure

$A=$ Cross Sectional Area of the Concrete Cylinder $=\pi^{*} \mathrm{r}^{2}$

$\sigma=$ Stress at Failure $=$ Compressive Strength

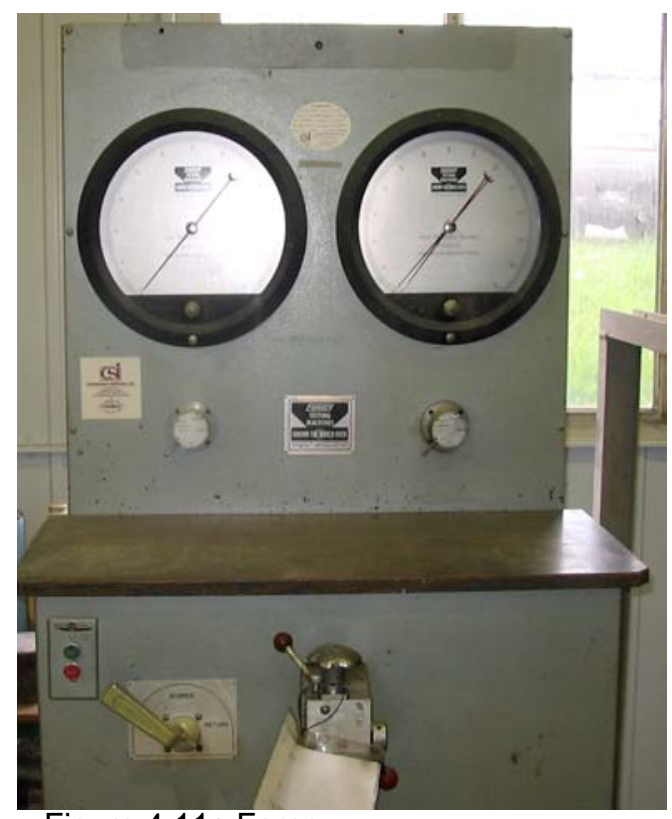

Figure 4.11a Forney Compression Tester Control Panel

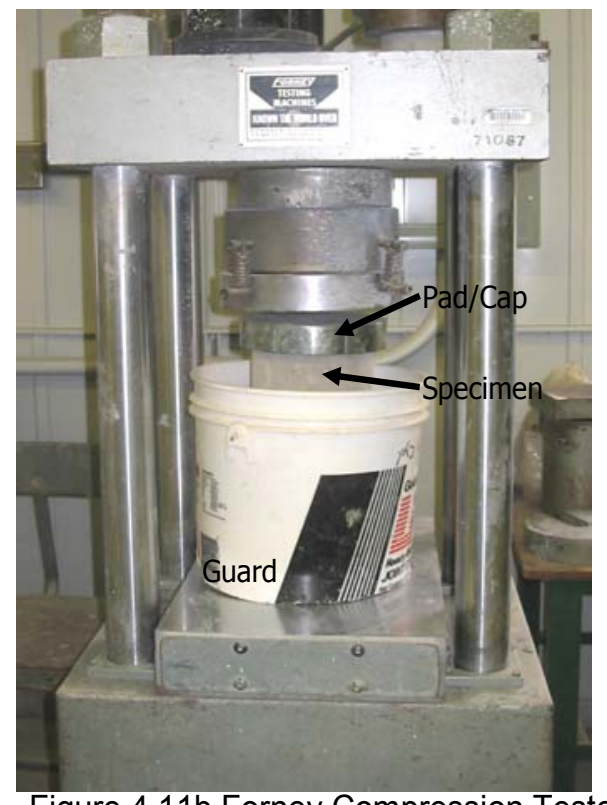

Figure 4.11b Forney Compression Tester

Figure 4.11 Compression Test 


\subsubsection{Tensile Strength Test (Modulus of Rupture) and Calculations}

The tensile test was done with the small 4 inch diameter by 8 inch high specimen. The tensile testing was done with a modified a compression test, with the specimen resting on its side instead of its end. According to Poisson's Ratio if a specimen undergoes compression in the $\mathrm{y}$-axis then it will experience tension in the $\mathrm{x}$-direction. Force was applied laterally to the specimen, which simulates tension in the y-direction as can be seen in Figure 4.12. Loading Rate must remain constant for all tests.

$\sigma=\frac{2 P}{\Pi D L}$

equation 4.8

$\sigma=$ Compressive Strength $\quad P=$ Load at Failure

$D=$ Diameter of the Concrete Cylinder

$L=$ Length of the Concrete Cylinder

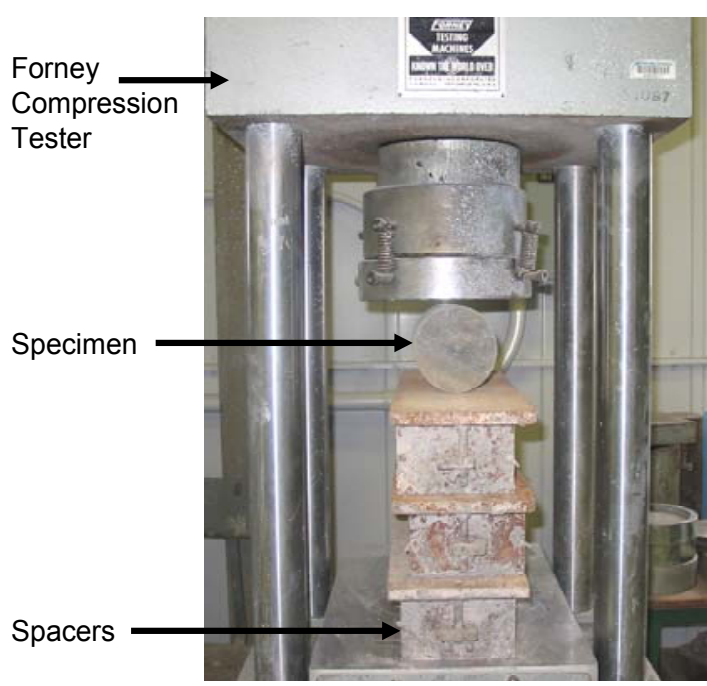

Figure 4.12a Forney Compression Tester Front View

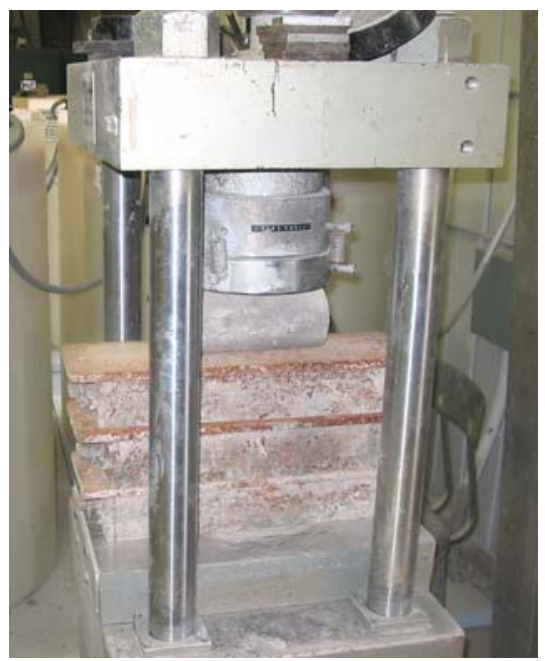

Figure 4.12b Forney Compression Tester Side View

Figure 4.12 Split Tensile Test 


\section{Chapter Five \\ Results}

\subsection{Introduction}

In order to develop a material model for concrete at varying temperatures and degrees of saturation a set of three tests were set up as mentioned in chapter 3 . Compressive tests were conducted on cured concrete at varying temperatures and degrees of saturation. Split Tensile tests were also conducted on cured concrete at varying temperatures and degrees of saturation. Compressive and split tensile tests were conducted during the curing process at $20^{\circ} \mathrm{C}$ and $100 \%$ saturation to ensure proper curing of the specimens. Modulus of Elasticity tests were conducted at varying temperatures and degrees of saturation on cured concrete. Modulus of Elasticity tests were also conducted at varying temperatures during the curing process. Finally a coefficient of thermal expansion test was conducted. The result are organized in a similar fashion to the literature review, the results are in line with the results of the literature review.

\subsection{Error Analysis}

In order to determine the compressive strength and tensile strength of concrete with respect to curing time concrete specimens were tested periodically during the curing process. In order to limit error developing the concrete model a number of steps were followed. Before proceeding with a compressive test, the specimen temperature was checked. The temperature was kept at $68^{\circ} \mathrm{F}$ and the moisture level was kept at 100 percent degrees saturation. Next, all specimens were inspected for cracks, voids, and trueness. All specimens that did not meet ASTM standard were discarded before testing. Three specimens were tested at each time interval. The error between the measured values and the line of best fit was greatest during the first week of curing and became less as the concrete specimens cured. All measured values were kept regardless of error since 
the specimens met ASTM standards before testing. The split tensile test had more scattering of data than the compressive test. The reasons for the results variability most likely were the non-homogeneous mixture of concrete and voids not visible on the surface. The split tensile test due to its configuration did not allow for the use of the pad and cap setup in the compression test. The pad and cap on the end of the specimen during compression testing make up for untrueness in the actuator and specimen itself. This led to more scattering of data in the split tensile test.

The same procedures for limiting and determining error were used for compression, modulus of elasticity, and split tensile testing at varying temperatures and varying degrees of saturation though one outlay in the compressive test at varying temperatures was not included in the formula of the linear best fit line. The main difference was the line of best fit was completed using a linear trendline instead of an exponential trend line with the compressive and split tensile tests during the curing process.

The Forney actuator was the only known source of error completing the compressive and tensile strength tests. The error for the Forney actuator was $\pm 1 \%$. Unknown errors for the compressive and tensile testing included but were not limited to the concrete mixture inconsistency and operator error. The main sources of known errors in the modulus test included the actuator setup ( $\pm 0.5 \%$ error), thermisters ( $\pm 1 \%$ error), and the strain gages ( $\pm 0.5 \%$ error). Most of the unknown error among the five instrumented specimens in modulus testing was due to mixture inconsistency and strain gage placement. The known errors for the coefficient of thermal expansion included the thermisters ( $\pm 1 \%$ error) and the strain gages ( $\pm 0.5 \%$ error). Most of the unknown error among the three instrumented specimens in coefficient of thermal expansion testing was due to mixture inconsistency and strain gage placement.

The data scatter in most of the tests is greater than the known errors. This is most likely due concrete mixture inconsistency. Concrete is not a homogeneous mixture. There is variability in the coarse aggregate, fine aggregate, moisture content, and cement at the time of pour. The data points were used to find the standard deviation in each formula. $\mathrm{S}_{\mathrm{N}}=\sqrt{\frac{1}{N} \sum_{i=1}^{N}(x i-\bar{x})^{2}}$ 


\subsection{Concrete Strength While Curing}

Concrete strength increases as the concrete cures according to the compression and split tensile tests. The rate of curing is much faster early on and then slows by day 14. On day 21 the concrete curing rate slows abruptly according to Figures 5.1 to 5.2 and Tables 5.1 to 5.2. Three specimens were tested at each time interval for both compression and tensile tests. An average of the three specimens is given in Table 5.1 and 5.2.

Compressive Strength $=\left(A e^{k t}+f^{\prime} c\right)(p s i)$

equation 5.2

Tensile Strength $=\left(C e^{k t}+f^{\prime} t\right)(p s i)$

equation 5.3

$A=$ Compressive Strength Constant

$C=$ Split Tensile Strength Constant

$f^{\prime} c=$ Ultimate Compressive Strength of Completely Cured Specimens

$f^{\prime} t=$ Ultimate Split Tensile Strength of Completely Cured Specimens

$t=$ time

Table 5.1 Effect of Curing on Compressive Strength

Time (Days)

Day 1

Day 3

Day 7

Day 14

Day 21

Day 28
Average Strength (psi)

2500

2960

4040

4170

4260

4360 
Temperature $=68^{\circ} \mathrm{F}$ at saturation

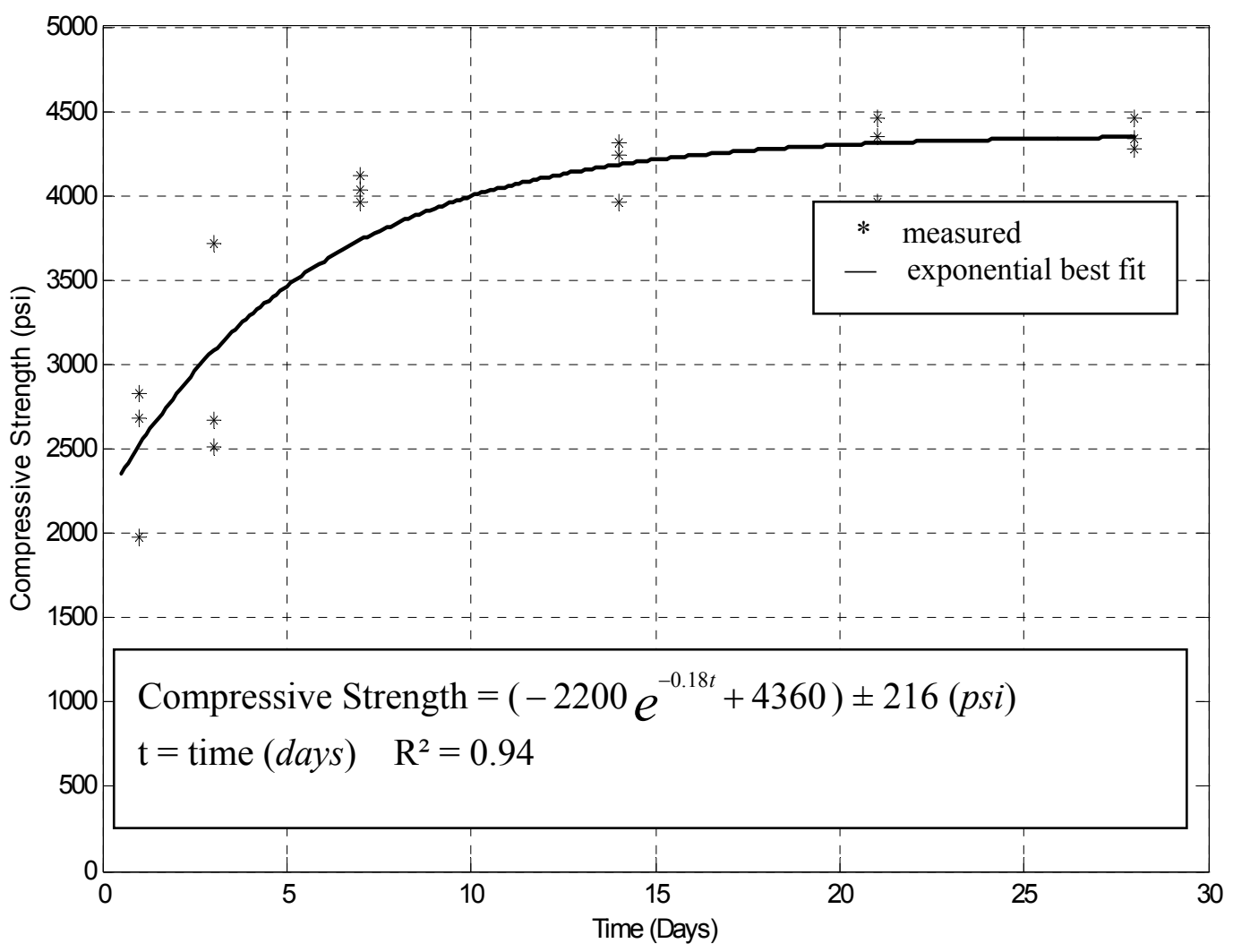

Figure 5.1 Effect of Curing on Compressive Strength

Table 5.2 Effect of Curing on Tensile Strength

Time (Days)

Average Strength (psi)

Day 1

320

Day 3

320

Day 7

380

Day 14

380

Day 21

440

Day 28

450 
Temperature $=68^{\circ} \mathrm{F}$ at saturation

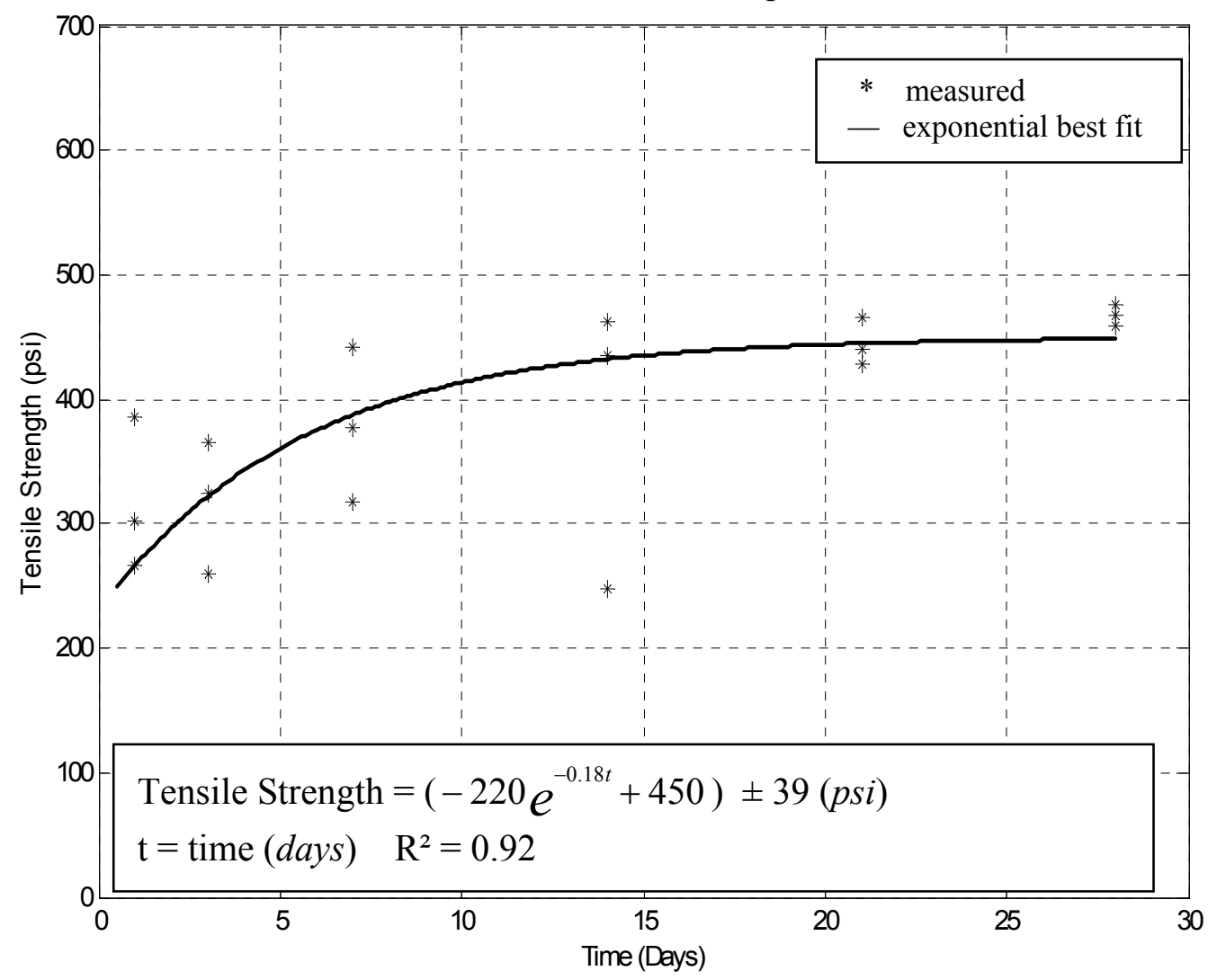

Figure 5.2 Effect of Curing on Tensile Strength 


\subsection{Effect of Temperature on Concrete Strength}

Compression and split tensile tests were done at the same temperature range as the Modulus of Elasticity and Poisson's Ratio Tests on day 28. The overall results of the compression and split tensile test are somewhat similar to the modulus of elasticity. The concrete specimens are stronger at lower temperatures and weaker at higher temperatures. There is a slightly wider range in strength values with the split tension test than with the compressive test. The compressive strength and tensile strength decreased noticeably in all specimens with rising temperature. The trend continued through $131^{\circ} \mathrm{F}$ similar to the modulus of elasticity tests according to Figures 5.3 to 5.4 and Tables 5.3 to 5.4. According to Long T. Phan various tests that were reviewed concrete loses upwards of $50 \%$ of its compressive strength for every 180 degree Fahrenheit rise in temperature [16]. In this case concrete lost $40 \%$ of its strength in an 144 degree Fahrenheit temperature rise.

Table 5.3 Effect of Temperature on Compressive Strength

\begin{tabular}{cc} 
Temperature $\left({ }^{\circ} \mathrm{F}\right)$ & Strength $(\mathbf{p s i})$ \\
\hline-13 & 5560 \\
5 & 5450 \\
23 & 5040 \\
41 & 5020 \\
59 & 4940 \\
77 & 4590 \\
95 & 4290 \\
113 & 3950 \\
131 & 3440
\end{tabular}


Degree of Saturation $=100 \%$

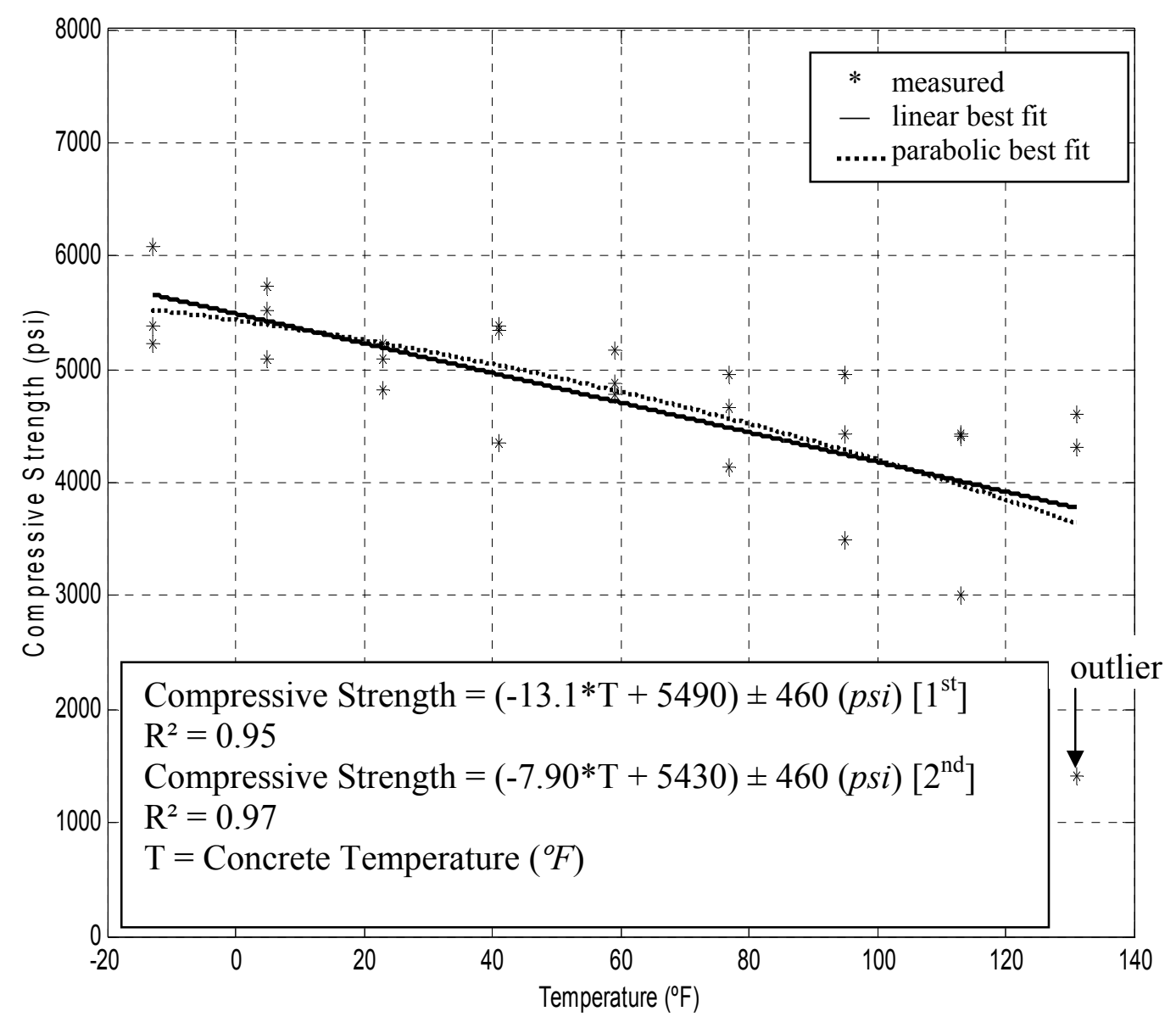

Figure 5.3 Effect of Temperature on Compressive Strength

Concrete age: 28 days 
Table 5.4 Effect of Temperature on Tensile Strength

\begin{tabular}{cc} 
Temperature $\left({ }^{\circ} \mathrm{F}\right)$ & Strength $(\mathbf{p s i})$ \\
\hline-13 & 540 \\
5 & 530 \\
23 & 480 \\
41 & 460 \\
59 & 460 \\
77 & 450 \\
95 & 420 \\
113 & 350 \\
131 & 320
\end{tabular}

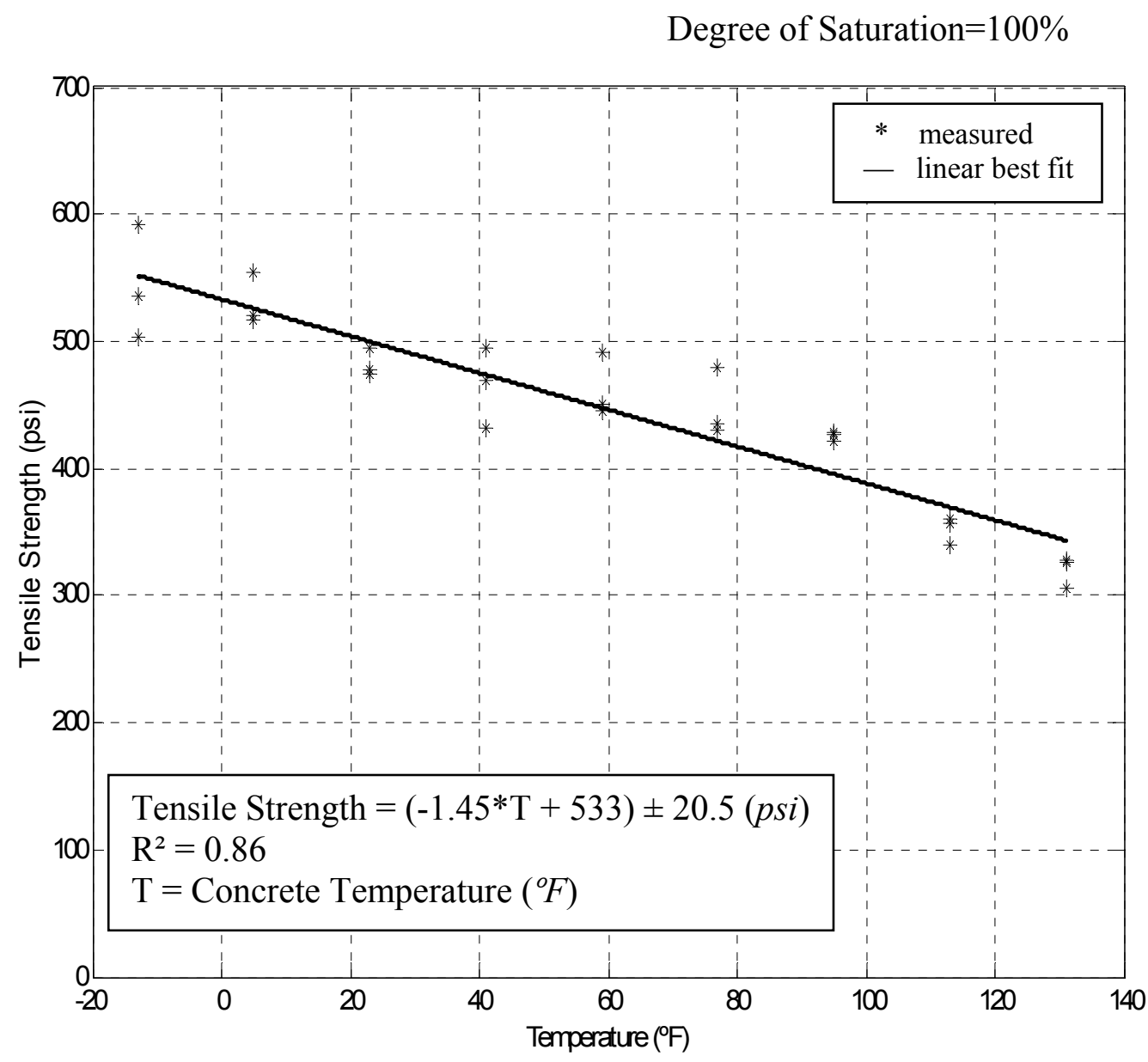

Figure 5.4 Effect of Temperature on Tensile Strength Concrete age: 28 days 


\subsection{Effect of Degree of Saturation on Concrete Strength}

Compression and Tension tests were done at the same moisture range as the Modulus of Elasticity and Poisson's Ratio Tests on day 180. The overall results of the compression and split tensile test are somewhat similar to the modulus of elasticity. The concrete specimens are stronger at lower degrees of saturation and weaker at higher degrees of saturation. There is a wider range in strength values with the split tension test than with the compressive test. As the specimen degrees of saturation increased the compressive strength and tensile strength fell. The strength in both compression and tension decreases as the degrees of saturation increases. The compressive strength and tensile strength decreased noticeably in all specimens according to Figures 5.5 to 5.6 and Tables 5.5 to 5.6 .

Table 5.5 Effect of Degree of Saturation on Compressive Strength

Degree of Saturation (\%)

$\begin{array}{cc}0 & 5430 \\ 20 & 5200 \\ 40 & 4860 \\ 60 & 4760 \\ 80 & 4360 \\ 100 & 4150\end{array}$


Temperature $=68^{\circ} \mathrm{F}$

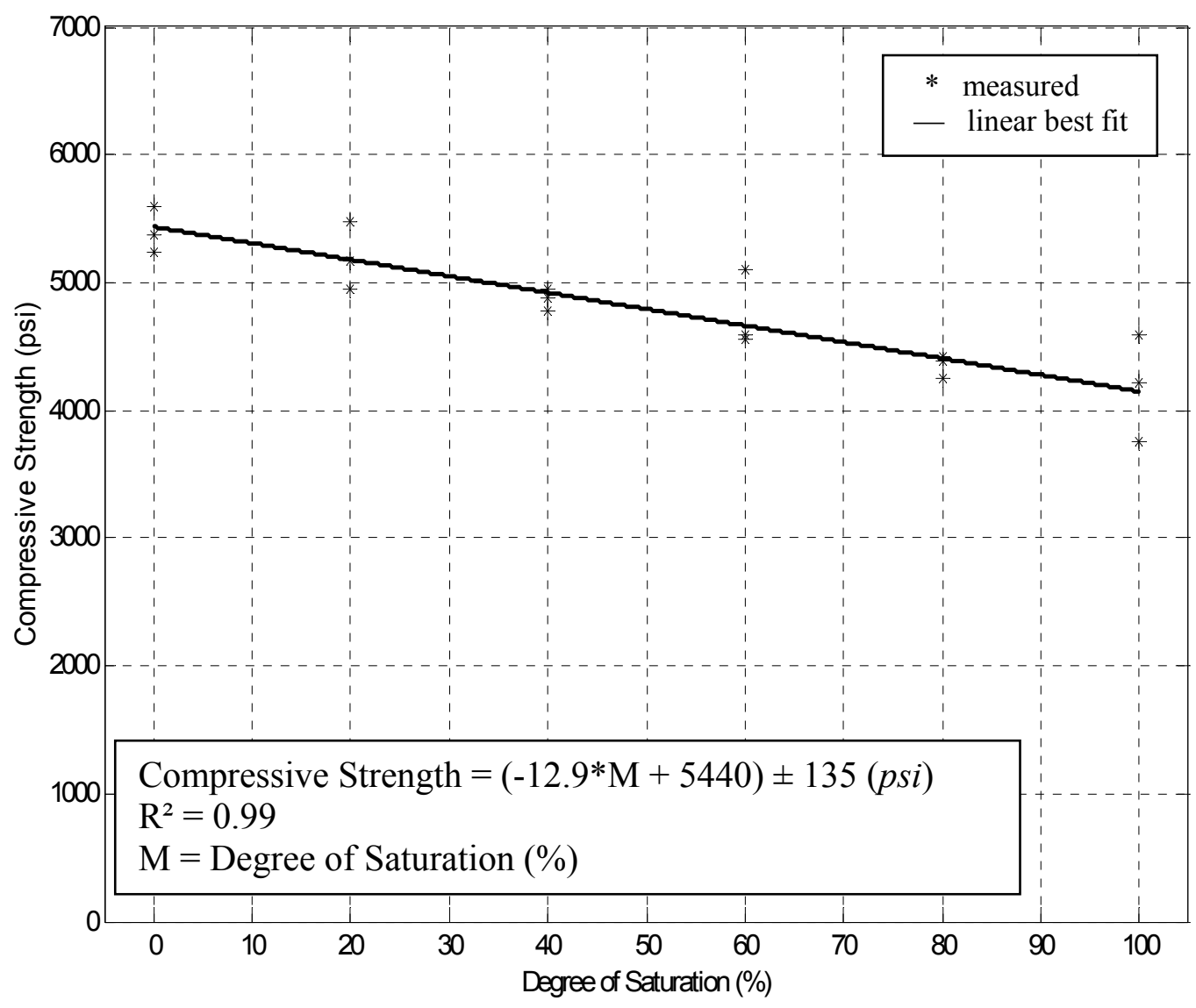

Figure 5.5 Effect of Degree of Saturation on Compressive Strength Concrete age: 28 days 
Table 5.6 Effect of Degree of Saturation on Tensile Strength

Degree of Saturation (\%)

Strength (psi)

0

20

40

60

80

100
540

510

480

460

400

350

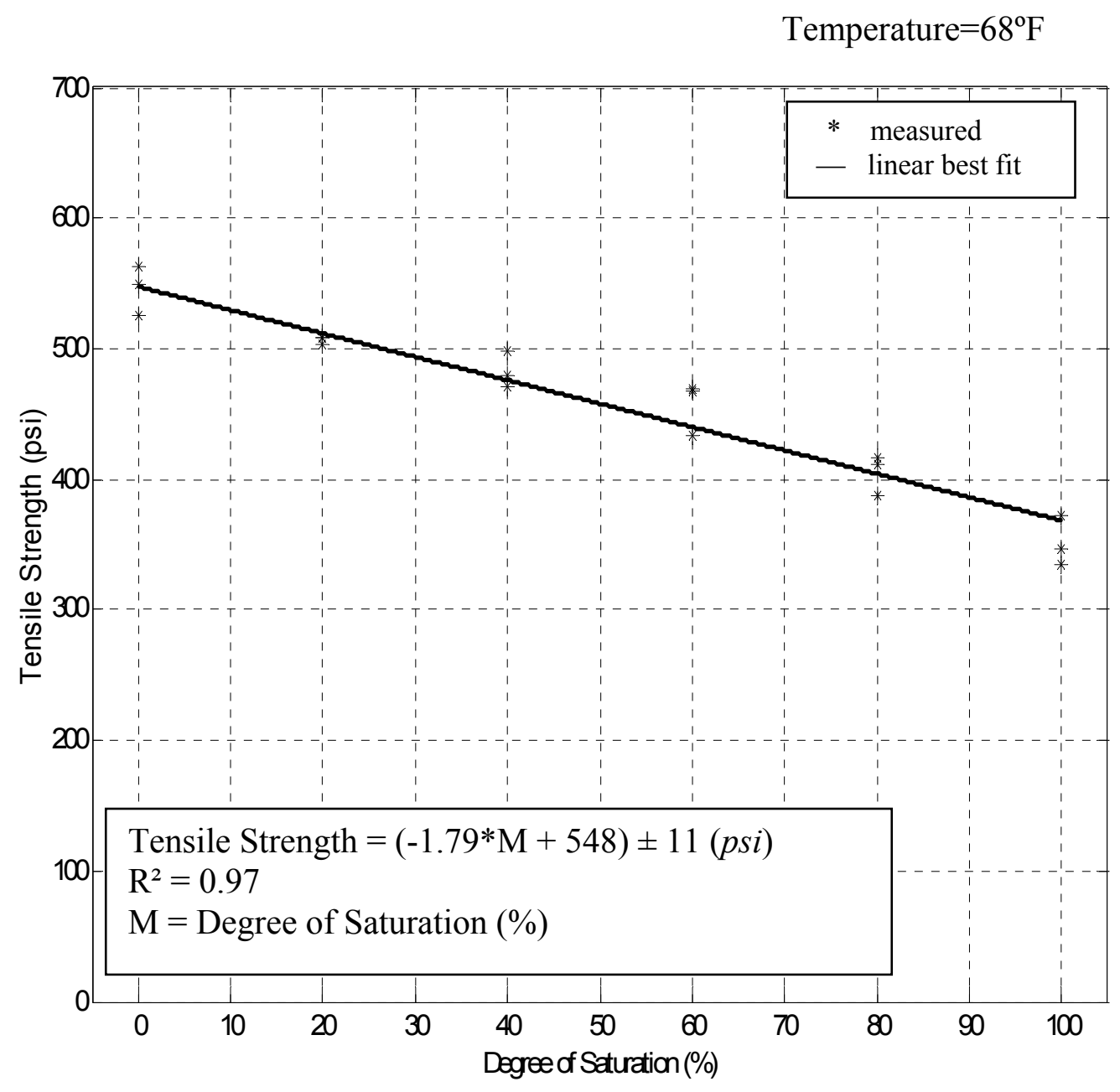

Figure 5.6 Effect of Degree of Saturation on Tensile Strength Concrete age: 180 days 


\subsection{Effect of Temperature on Modulus of Elasticity}

The modulus of elasticity of the concrete increased with time as the concrete cured. The rate of modulus of elasticity change with respect to temperature fell as the concrete cured according to Figures 5.7 to 5.12 and Tables 5.7 to 5.12. The modulus of elasticity increased after the concrete was cooled to low temperatures. The modulus of elasticity decreased after the concrete was exposed to high temperatures. For example, on day 14 specimen 2 according to Figure 5.9 and Table 5.9 had a modulus of elasticity value of $5.35 \times 10^{6} \mathrm{psi}$ at $-20^{\circ} \mathrm{C}$ and a modulus of elasticity value of $3.59 \times 10^{6}$ psi at 122 ${ }^{\circ} \mathrm{F}$. This indicates that the concrete is only 67 percent as strong at 50 degrees than at -4 ${ }^{\circ} \mathrm{F}$. Five instrumented concrete specimens were made in total. Three of them were tested as the concrete cured. Two of them were set aside and tested after the concrete was cured. The behavior of the two specimens appeared to be no different than the three specimens that were tested while they were curing. In both cases the specimens were maintained close to 100 percent degrees of saturation.

The modulus of elasticity continued to be greater at low temperatures and lower at high temperatures, hence an inverse relationship continuing after curing. The modulus of elasticity of concrete increases 22 percent from $+122^{\circ} \mathrm{F}$ down to $-4{ }^{\circ} \mathrm{F}$ according to Figure 5.11 and Table 5.11. Moisture had an affect on the modulus of elasticity of concrete also, though not as great as temperature. A completely saturated specimen will have a lower modulus of elasticity than an oven dry specimen. There are a number of theories to explain this. One is the fact that water has a lubricating affect. The water fills air voids so when the aggregate start to bind against one another there is less friction. Wet stone is very slippery. Concrete strength is primarily derived from the aggregates not the cement. Paper is a good example of what happens when material becomes wet. Wet paper tears much easier than dry paper. 
Table 5.7 Effect of Temperature on Modulus of Elasticity Day 3

\begin{tabular}{|c|c|c|c|c|}
\hline $\begin{array}{c}\text { Temperature } \\
\left({ }^{\boldsymbol{o}} \boldsymbol{F}\right)\end{array}$ & $\begin{array}{c}\text { Specimen 1 } \\
\text { Young's } \\
\text { Modulus } \\
(\boldsymbol{P} \text { si) }\end{array}$ & $\begin{array}{c}\text { Specimen 2 } \\
\text { Young's } \\
\text { Modulus } \\
(\boldsymbol{P s i})\end{array}$ & $\begin{array}{c}\text { Specimen 3 } \\
\text { Young's } \\
\text { Modulus } \\
(\boldsymbol{P s i})\end{array}$ & $\begin{array}{c}\text { Average } \\
\text { Young's } \\
\text { Modulus } \\
(\boldsymbol{P s i})\end{array}$ \\
\hline-13 & $4.84 \times 10^{6}$ & $4.85 \times 10^{6}$ & $5.10 \times 10^{6}$ & $4.93 \times 10^{6}$ \\
\hline 5 & $4.85 \times 10^{6}$ & $5.12 \times 10^{6}$ & $4.80 \times 10^{6}$ & $4.93 \times 10^{6}$ \\
\hline 23 & $4.37 \times 10^{6}$ & $4.52 \times 10^{6}$ & $4.24 \times 10^{6}$ & $4.38 \times 10^{6}$ \\
\hline 68 & $3.67 \times 10^{6}$ & $4.04 \times 10^{6}$ & $3.28 \times 10^{6}$ & $3.67 \times 10^{6}$ \\
\hline
\end{tabular}

Degree of Saturation $=100 \%$

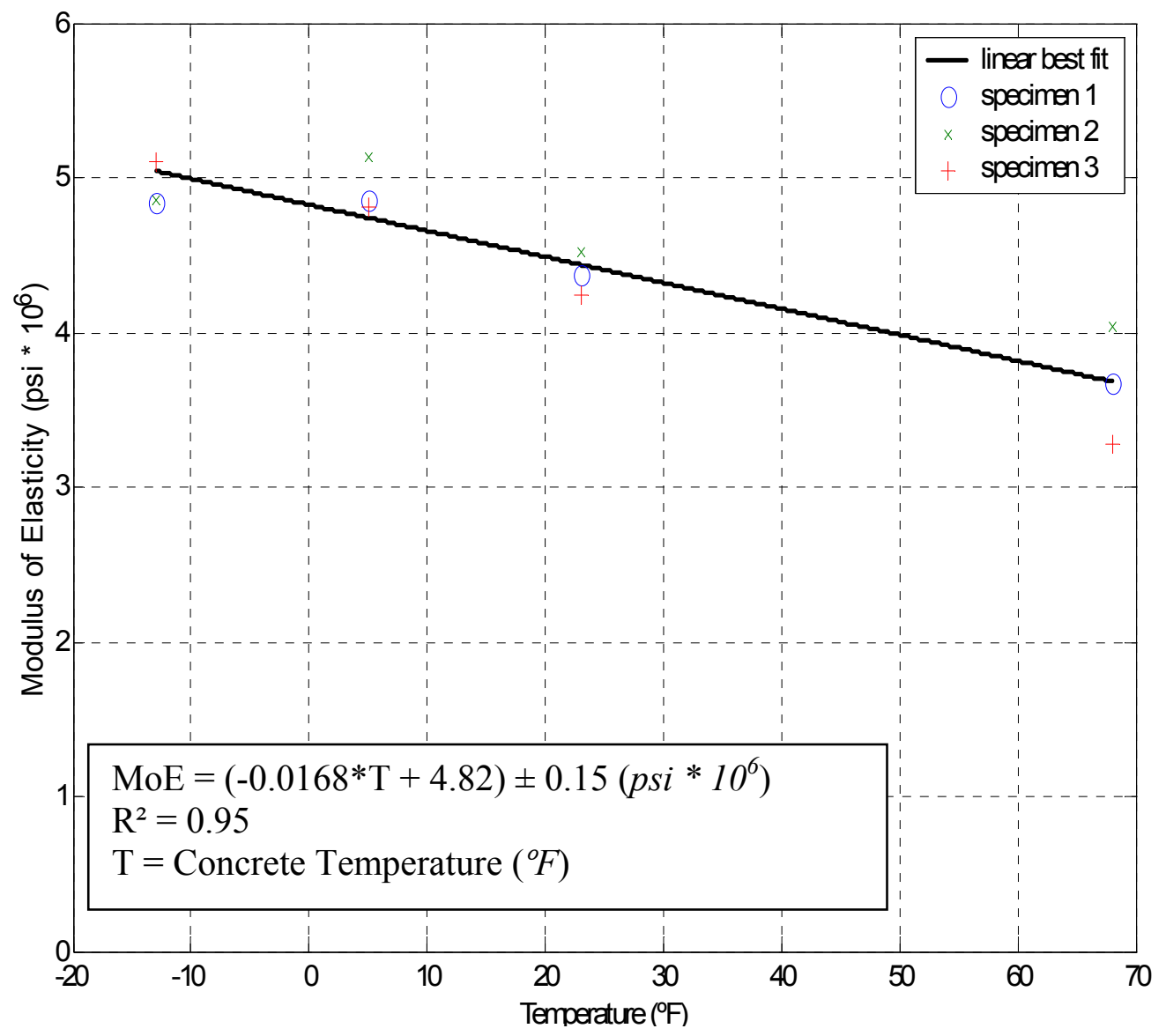

Figure 5.7 Effect of Temperature on Modulus of Elasticity Concrete age: 3 days 
Table 5.8 Effect of Temperature on Modulus of Elasticity Day 7

\begin{tabular}{|c|c|c|c|c|}
\hline $\begin{array}{c}\text { Temperature } \\
\left({ }^{\boldsymbol{o}} \boldsymbol{F}\right)\end{array}$ & $\begin{array}{c}\text { Specimen 1 } \\
\text { Young's } \\
\text { Modulus (Psi) }\end{array}$ & $\begin{array}{c}\text { Specimen 2 } \\
\text { Young's } \\
\text { Modulus (Psi) }\end{array}$ & $\begin{array}{c}\text { Specimen 3 } \\
\text { Young's } \\
\text { Modulus (Psi) }\end{array}$ & $\begin{array}{c}\text { Average } \\
\text { Young's } \\
\text { Modulus (Psi) }\end{array}$ \\
\hline-4 & $4.65 \times 10^{6}$ & $4.67 \times 10^{6}$ & $4.74 \times 10^{6}$ & $4.69 \times 10^{6}$ \\
\hline 14 & $4.34 \times 10^{6}$ & $4.61 \times 10^{6}$ & $4.65 \times 10^{6}$ & $4.54 \times 10^{6}$ \\
\hline 23 & $4.29 \times 10^{6}$ & $4.40 \times 10^{6}$ & $4.25 \times 10^{6}$ & $4.32 \times 10^{6}$ \\
\hline 68 & $3.11 \times 10^{6}$ & $4.04 \times 10^{6}$ & $2.80 \times 10^{6}$ & $3.32 \times 10^{6}$ \\
\hline 95 & $2.52 \times 10^{6}$ & --- & $2.85 \times 10^{6}$ & $2.69 \times 10^{6}$ \\
\hline
\end{tabular}

Degree of Saturation $=100 \%$

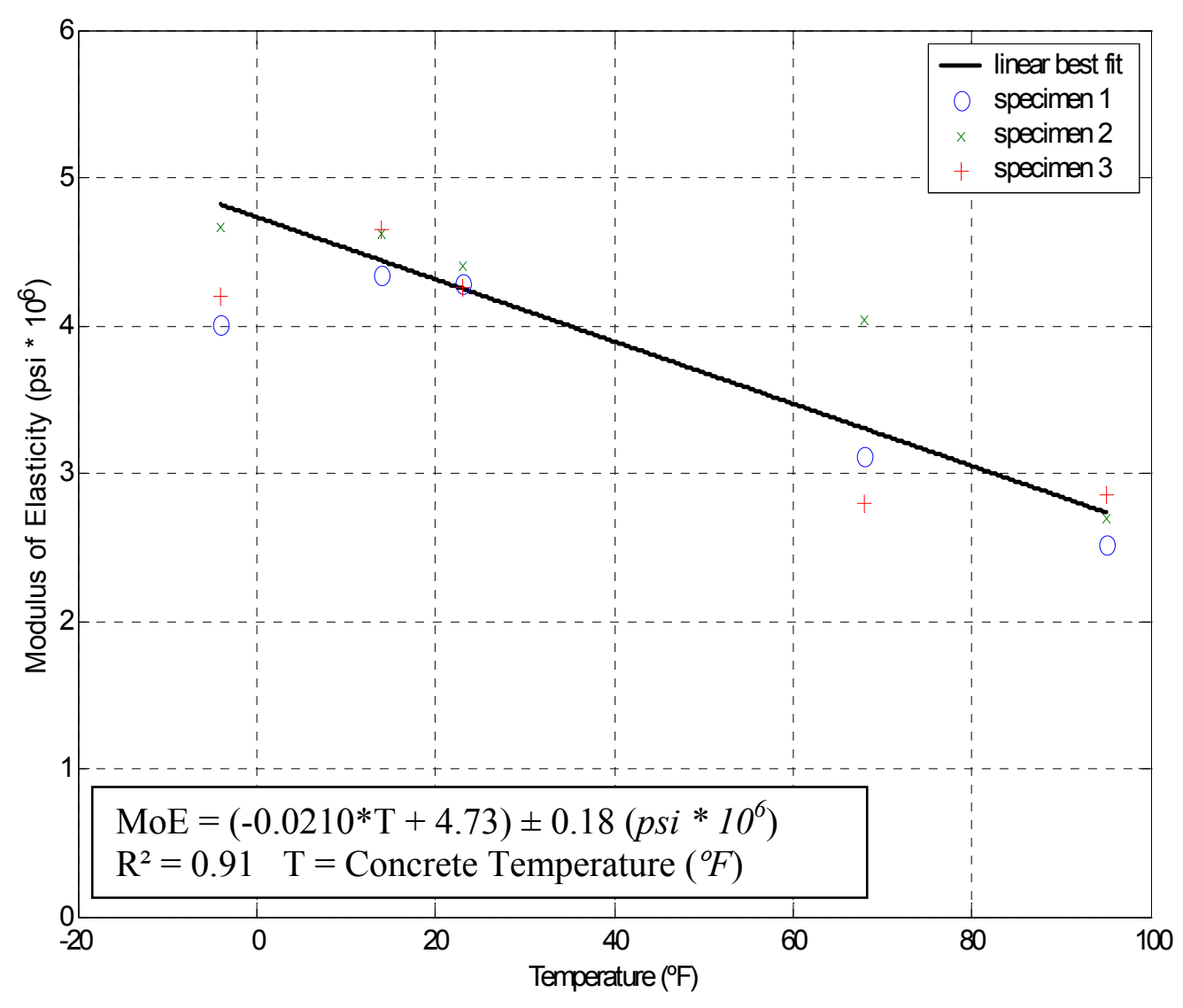


Table 5.9 Effect of Temperature on Modulus of Elasticity Day 14

\begin{tabular}{|c|c|c|c|c|}
\hline $\begin{array}{c}\text { Temperature } \\
\left({ }^{\circ} \boldsymbol{F}\right)\end{array}$ & $\begin{array}{c}\text { Specimen 1 } \\
\text { Young's } \\
\text { Modulus (Psi) }\end{array}$ & $\begin{array}{c}\text { Specimen 2 } \\
\text { Young's } \\
\text { Modulus }(\boldsymbol{P} \text { si) }\end{array}$ & $\begin{array}{c}\text { Specimen 3 } \\
\text { Young's } \\
\text { Modulus (Psi) }\end{array}$ & $\begin{array}{c}\text { Average } \\
\text { Young's } \\
\text { Modulus } \\
(\boldsymbol{P} \text { si })\end{array}$ \\
\hline-4 & $4.61 \times 10^{6}$ & $5.35 \times 10^{6}$ & $5.03 \times 10^{6}$ & $4.99 \times 10^{6}$ \\
\hline 14 & $4.38 \times 10^{6}$ & $5.24 \times 10^{6}$ & $4.94 \times 10^{6}$ & $4.85 \times 10^{6}$ \\
\hline 23 & $4.18 \times 10^{6}$ & $4.85 \times 10^{6}$ & $4.73 \times 10^{6}$ & $4.59 \times 10^{6}$ \\
\hline 68 & $3.75 \times 10^{6}$ & $4.30 \times 10^{6}$ & $4.40 \times 10^{6}$ & $4.15 \times 10^{6}$ \\
\hline 104 & $3.80 \times 10^{6}$ & $3.65 \times 10^{6}$ & $4.20 \times 10^{6}$ & $3.88 \times 10^{6}$ \\
\hline 122 & $2.20 \times 10^{6}$ & $3.59 \times 10^{6}$ & $4.77 \times 10^{6}$ & $3.52 \times 10^{6}$ \\
\hline
\end{tabular}

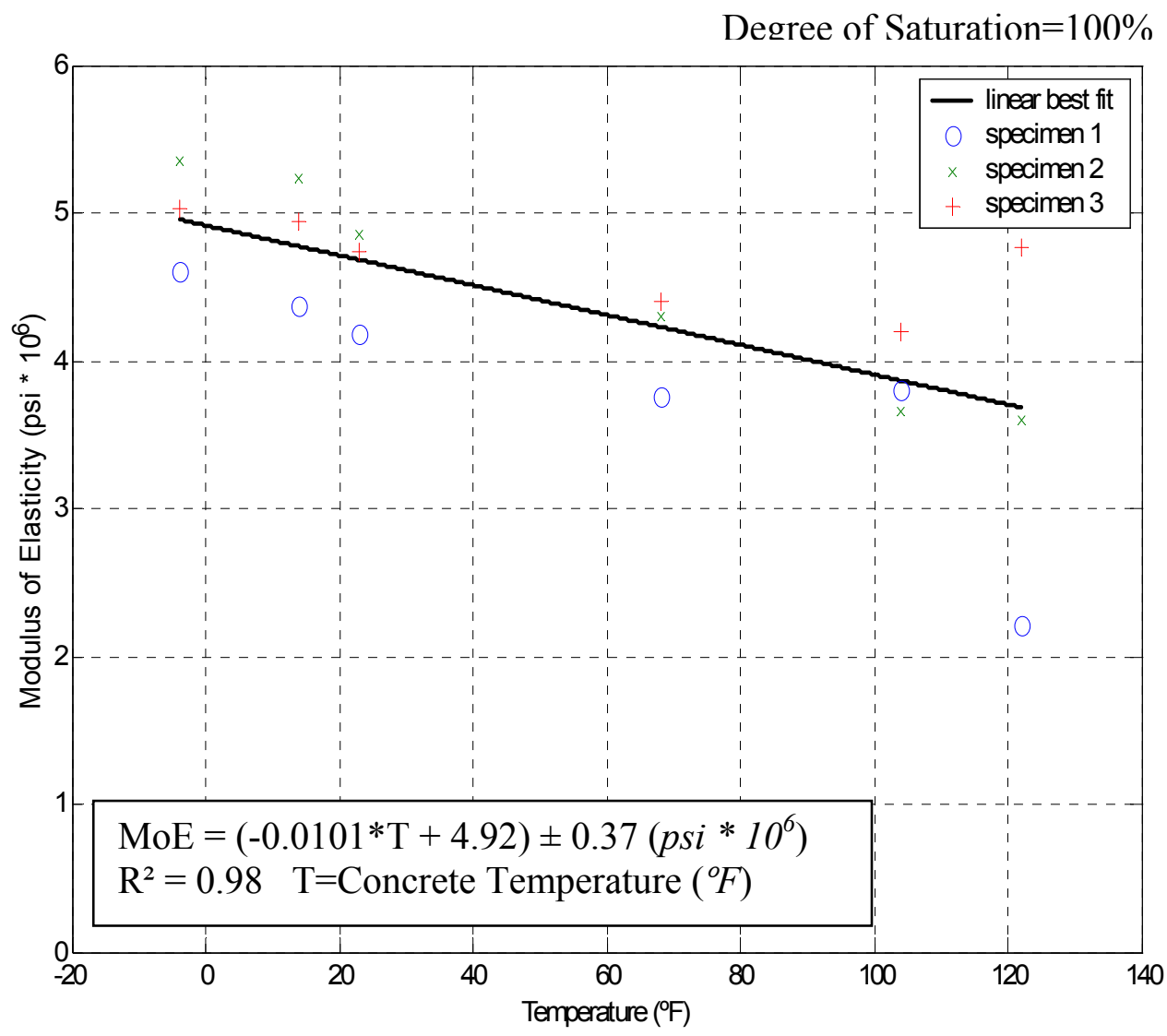

Figure 5.9 Effect of Temperature on Modulus of Elasticity Concrete age: 14 days 
Table 5.10 Effect of Temperature on Modulus of Elasticity Day 21

\begin{tabular}{|c|c|c|c|c|}
\hline $\begin{array}{c}\text { Temperature } \\
\left({ }^{\circ} \boldsymbol{F}\right)\end{array}$ & $\begin{array}{c}\text { Specimen 1 } \\
\text { Young's } \\
\text { Modulus (Psi) }\end{array}$ & $\begin{array}{c}\text { Specimen 2 } \\
\text { Young's } \\
\text { Modulus (Psi) }\end{array}$ & $\begin{array}{c}\text { Specimen 3 } \\
\text { Young's } \\
\text { Modulus (Psi) }\end{array}$ & $\begin{array}{c}\text { Average } \\
\text { Young's } \\
\text { Modulus (Psi) }\end{array}$ \\
\hline-4 & $4.72 \times 10^{6}$ & $4.97 \times 10^{6}$ & $4.85 \times 10^{6}$ & $4.85 \times 10^{6}$ \\
\hline 5 & $4.59 \times 10^{6}$ & $4.73 \times 10^{6}$ & $4.78 \times 10^{6}$ & $4.70 \times 10^{6}$ \\
\hline 14 & $4.22 \times 10^{6}$ & $4.47 \times 10^{6}$ & $4.88 \times 10^{6}$ & $4.52 \times 10^{6}$ \\
\hline 23 & $4.15 \times 10^{6}$ & $4.25 \times 10^{6}$ & $4.19 \times 10^{6}$ & $4.20 \times 10^{6}$ \\
\hline 32 & $4.08 \times 10^{6}$ & $4.06 \times 10^{6}$ & $4.15 \times 10^{6}$ & $4.10 \times 10^{6}$ \\
\hline 68 & $4.26 \times 10^{6}$ & $4.35 \times 10^{6}$ & $4.36 \times 10^{6}$ & $4.32 \times 10^{6}$ \\
\hline 86 & $2.88 \times 10^{6}$ & $5.32 \times 10^{6}$ & $3.91 \times 10^{6}$ & $4.04 \times 10^{6}$ \\
\hline 104 & $2.74 \times 10^{6}$ & $3.98 \times 10^{6}$ & $3.39 \times 10^{6}$ & $3.37 \times 10^{6}$ \\
\hline 122 & $2.78 \times 10^{6}$ & $3.24 \times 10^{6}$ & $3.47 \times 10^{6}$ & $3.16 \times 10^{6}$ \\
\hline
\end{tabular}




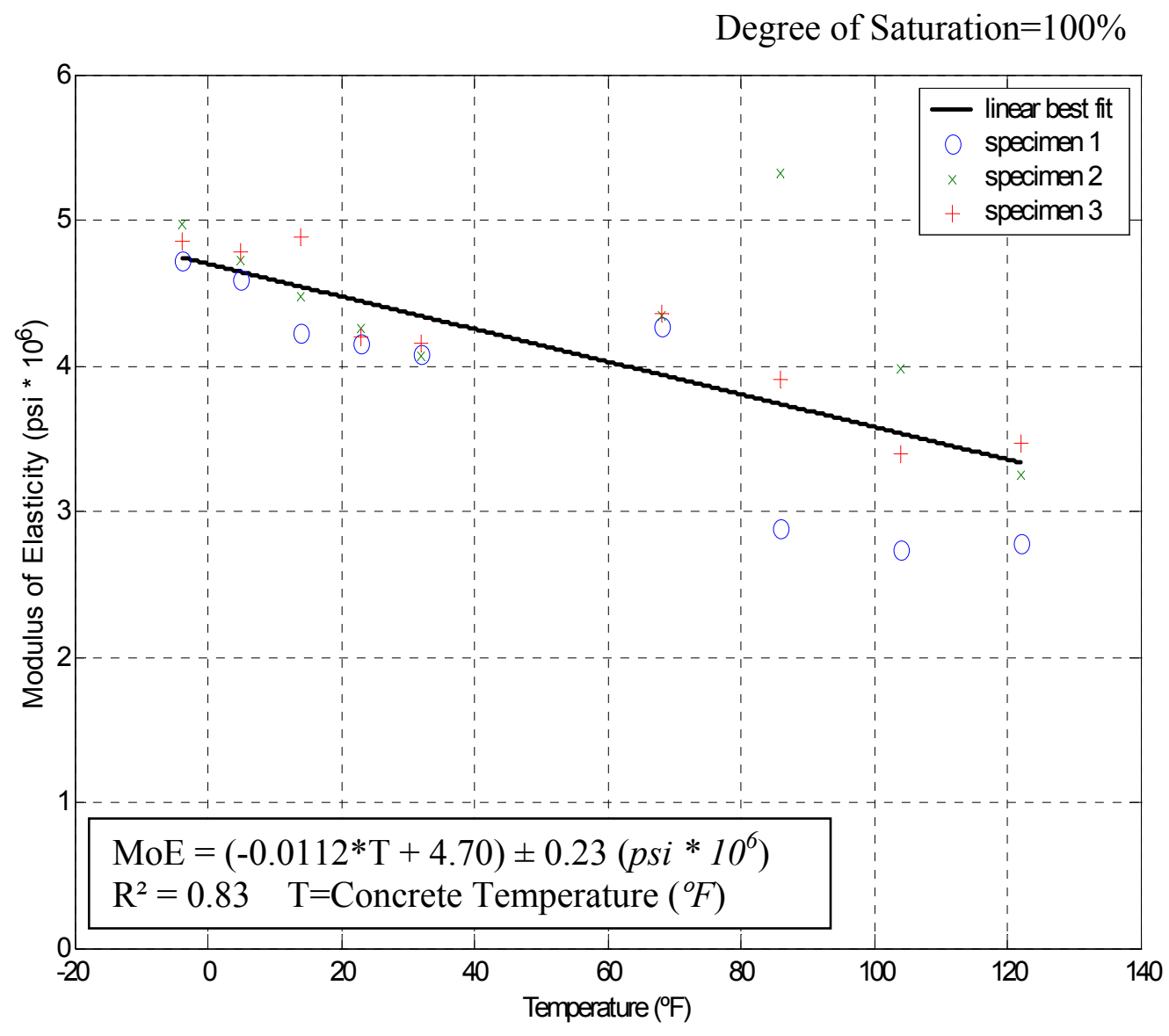

Figure 5.10 Effect of Temperature on Modulus of Elasticity Concrete age: 21 days 
Table 5.11 Effect of Temperature on Modulus of Elasticity Day 28

\begin{tabular}{|c|c|c|c|c|c|c|}
\hline $\begin{array}{c}\text { Temp. } \\
\left({ }^{o} F\right)\end{array}$ & $\begin{array}{c}\text { Specimen } \\
1 \\
\text { Young's } \\
\text { Modulus } \\
\left(p s i * 10^{6}\right)\end{array}$ & $\begin{array}{c}\text { Specimen } \\
2 \\
\text { Young's } \\
\text { Modulus } \\
\left(p s i * 10^{6}\right)\end{array}$ & $\begin{array}{c}\text { Specimen } \\
3 \\
\text { Young's } \\
\text { Modulus } \\
\left(p s i * 10^{6}\right)\end{array}$ & $\begin{array}{c}\text { Specimen } \\
4 \\
\text { Young's } \\
\text { Modulus } \\
\left(p s i * 10^{6}\right)\end{array}$ & $\begin{array}{c}\text { Specimen } \\
5 \\
\text { Young's } \\
\text { Modulus } \\
\left(p s i * 10^{6}\right)\end{array}$ & $\begin{array}{l}\text { Average } \\
\text { Young's } \\
\text { Modulus } \\
\left(p^{*}{ }^{*} 10^{6}\right)\end{array}$ \\
\hline-13 & 3.89 & --- & --- & --- & --- & --- \\
\hline-4 & 3.90 & 4.66 & 4.50 & 3.83 & 4.43 & 4.26 \\
\hline 5 & 3.68 & 4.27 & 4.31 & 4.68 & 4.34 & 4.26 \\
\hline 14 & 3.61 & 3.92 & 4.24 & 4.54 & 4.39 & 4.14 \\
\hline 23 & 3.51 & 3.78 & 4.32 & 4.14 & 4.58 & 4.07 \\
\hline 32 & 3.68 & 3.71 & 4.18 & 4.14 & 4.19 & 3.98 \\
\hline 41 & 3.69 & 3.71 & 4.28 & 4.30 & 4.45 & 4.08 \\
\hline 50 & 3.60 & 3.73 & 4.27 & 4.30 & 3.74 & 3.92 \\
\hline 59 & 3.42 & 3.66 & 3.88 & 3.88 & 4.07 & 3.78 \\
\hline 68 & 3.32 & 3.82 & 4.04 & 3.27 & 3.85 & 3.66 \\
\hline 77 & 3.23 & 3.58 & 3.92 & 3.49 & 3.78 & 3.59 \\
\hline 86 & 3.78 & 3.66 & 3.92 & 3.57 & 3.87 & 3.76 \\
\hline 95 & 3.44 & 3.82 & 3.88 & 3.41 & 3.84 & 3.70 \\
\hline 104 & 3.36 & 3.38 & 3.93 & 3.50 & 3.63 & 3.56 \\
\hline 113 & 3.36 & 3.38 & 3.78 & 3.37 & 3.59 & 3.49 \\
\hline 122 & 3.29 & 3.45 & 3.76 & 3.35 & 3.66 & 3.50 \\
\hline
\end{tabular}




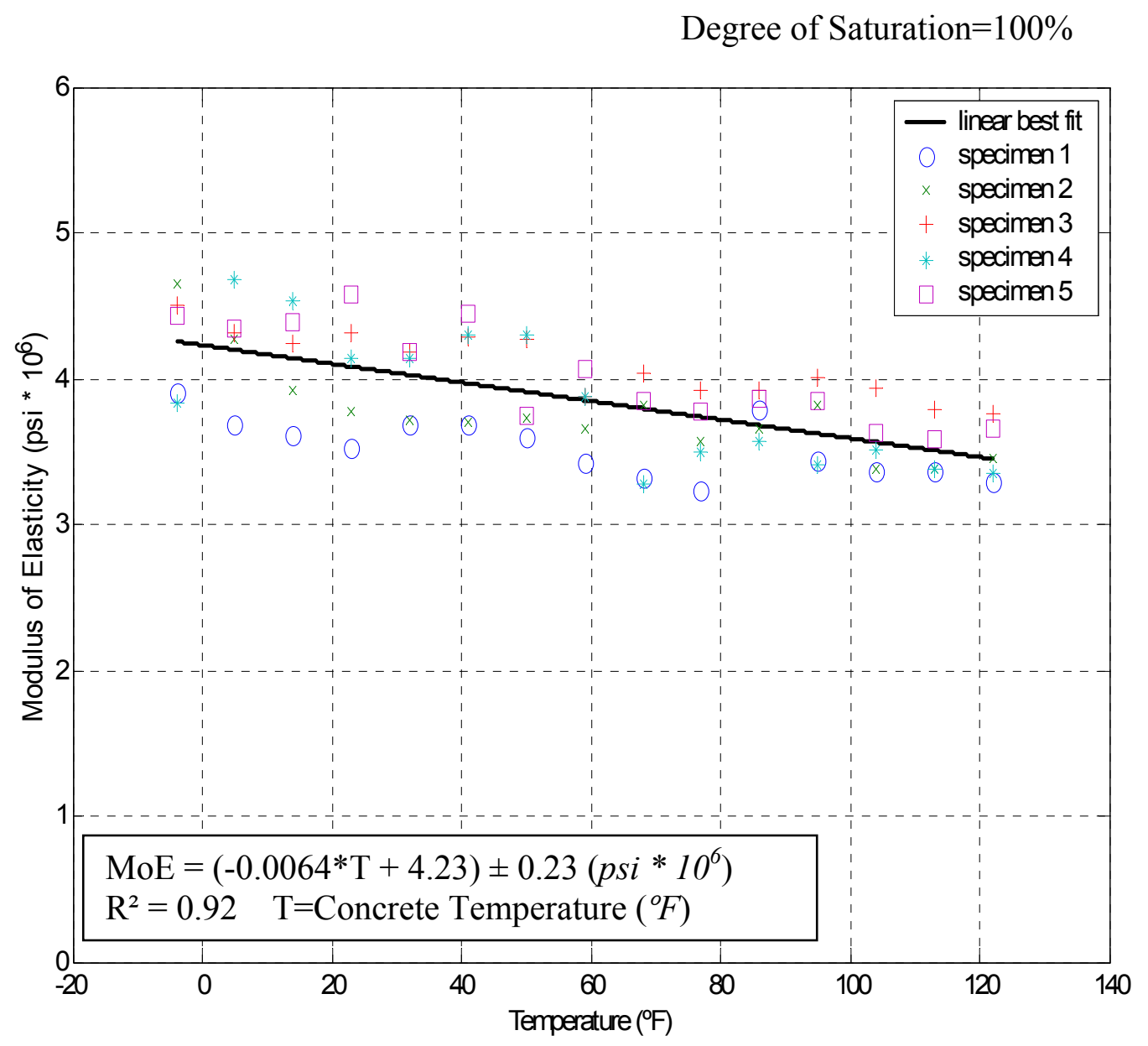

Figure 5.11 Effect of Temperature on Modulus of Elasticity Concrete age: 28 days

\subsection{Effect of Degree of Saturation on Modulus of Elasticity}

The modulus of elasticity of the specimens decreases with increased degrees of saturation. The water molecules reside in very small pores; thus, it takes several hours for the water molecules to work themselves out of the pores. The specimen's modulus of elasticity and corresponding strength increased until the specimen was completely dry. The specimen likewise will continue to lose strength and modulus of elasticity until the specimen is completely saturated. 
The modulus of elasticity decreased almost 20 percent from 0 percent degrees of saturation to 100 percent degrees of saturation according to Figure 5.12 and Table 5.12. Moisture may have more impact on the modulus of elasticity of concrete than temperature in temperate climates. Since the concrete will have a fairly high thermal mass it will take much longer to heat up and cool down compared to the air temperature. During sunny conditions a concrete slab will absorb heat, especially if it is dark in color from stains, much faster than air. Concrete slabs elevated in air will be more subject to temperature extremes than a concrete slab in contact with the ground. Moisture similar to temperature affects concrete slabs elevated in air differently. The slab elevated in air will tend to dry out more than a slab in contact with the ground. Temperature on average changes the modulus of elasticity about 22 percent between temperatures of $-4{ }^{\circ} \mathrm{F}$ and 122 ${ }^{\circ} \mathrm{F}$. Moisture on average changes the modulus of elasticity about 20 percent between saturated conditions such as during a prolonged rain and dryness as experienced in a desert. Under typical environmental conditions on the earth moisture will play a larger role in specimen modulus of elasticity than temperature. This is not to say temperature will not have a larger impact in cases where fire is present, though in that case moisture will be very low also. The modulus of elasticity as stated before will be greatest at low temperatures and low degrees of saturation and the modulus of elasticity will be lowest during periods of high degrees of saturation and high temperatures. If concrete is going to be used in hot humid climate adequate design procedures should be followed taking into consideration moisture and temperature changes.

The concrete design factor for an area should assume close to 100 percent degrees of saturation and a temperature at least 20 degrees Fahrenheit higher than the highest ever recorded in sunlight for the given region. For example, concrete exposed to desert conditions just after a rain may have only half the strength of concrete in a cool dry climate. It is also normal for high air temperatures and high air humidities to occur together. Since hot air can hold more moisture than cold air, more rain often occurs. It is also important to factor in the heat from the sun on concrete. The temperature of the concrete is of more importance than the air temperature. 
Table 5.12 Effect of Degree of Saturation on Modulus of Elasticity Day 180

\begin{tabular}{|c|c|c|c|}
\hline $\begin{array}{c}\text { Degree of } \\
\text { Saturation (\%) }\end{array}$ & $\begin{array}{c}\text { Specimen 1 } \\
\text { Young's Modulus } \\
\left(\mathbf{p s i} * \mathbf{1 0}^{\mathbf{6}}\right)\end{array}$ & $\begin{array}{c}\text { Specimen 3 } \\
\text { Young's Modulus } \\
\left(\mathbf{p s i} * \mathbf{1 0}^{\mathbf{6}}\right)\end{array}$ & $\begin{array}{c}\text { Average } \\
\text { Young's Modulus } \\
\left(\mathbf{p s i} * \mathbf{1 0}^{\mathbf{6}}\right)\end{array}$ \\
\hline 0 & 4.11 & 4.23 & 4.17 \\
\hline 20 & 4.03 & 4.15 & 4.09 \\
\hline 40 & 3.88 & 4.05 & 3.97 \\
\hline 60 & 3.82 & 3.75 & 3.79 \\
\hline 80 & 3.62 & 3.65 & 3.64 \\
\hline 100 & 3.45 & 3.52 & 3.48 \\
\hline
\end{tabular}

Temperature $=68^{\circ} \mathrm{F}$

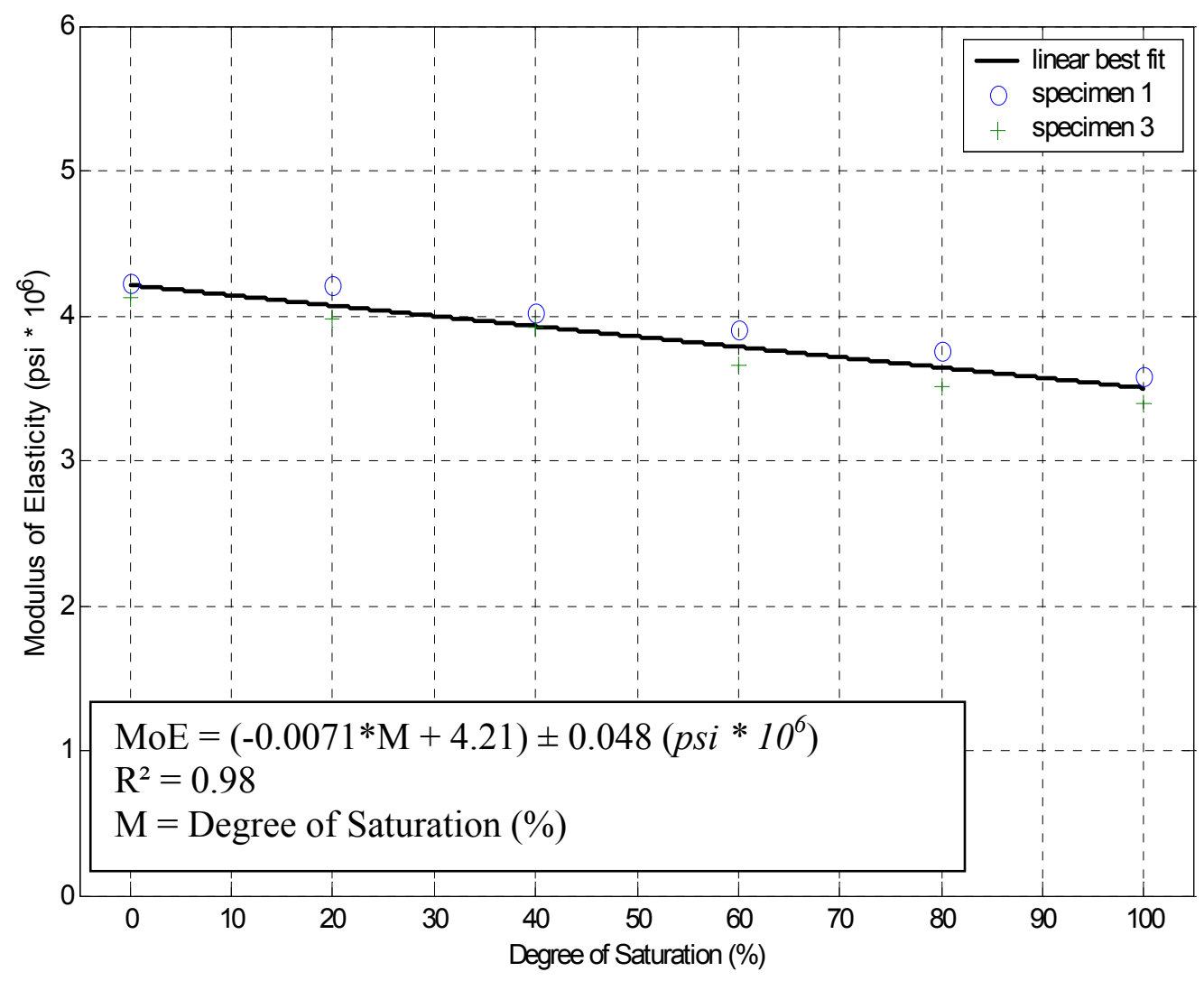

Figure 5.12 Effect of Degree of Saturation on Modulus of Elasticity Concrete age: 180 days 


\subsection{Effect of Temperature and Degree of Saturation on Poisson's Ratio}

Poisson's Ratio for most of the tests was between 0.17 and 0.19 according to Figures 5.13 to 5.14 and Tables 5.13 to 5.14 whether or not the concrete was cold, damp, and uncured or cured, hot, and dry. Temperature changes caused the horizontal strain and vertical strain to change. In general higher temperature cause both horizontal and vertical strain to increase. Colder temperature causes both strains to decrease. The net effect on Poisson's ratio should be small since both horizontal and vertical strain change by a similar amount.

The effect of both temperature and moisture on Poisson's ratio seemed to be negligible after the concrete had cured. It is difficult to discern any pattern in how Poisson's ratio reacts to temperature and moisture. Since Poisson's Ratio is nothing more than the ratio of 2 orthogonal strain values, it is easy to see why there is no effect on the ratio since temperature and moisture impact the 2 orthogonal strain values the exact same amount. The reason for Poisson's Ratio varying somewhat is due to the fact that it is difficult to change the temperature and moisture in the entire specimen at the same rate. When doing the temperature tests, the moisture inside the specimen may change some as well and at an uneven rate changing the Poisson's Ratio. 
Table 5.13 Effect of Temperature on Poisson's Ratio

\begin{tabular}{|c|c|c|c|c|c|c|}
\hline $\begin{array}{c}\text { Temp. } \\
\left({ }^{o} F\right)\end{array}$ & $\begin{array}{c}\text { Specimen } \\
1 \\
\text { Poisson's } \\
\text { Ratio } \\
\end{array}$ & $\begin{array}{c}\text { Specimen } \\
2 \\
\text { Poisson's } \\
\text { Ratio } \\
\end{array}$ & $\begin{array}{c}\text { Specimen } \\
3 \\
\text { Poisson's } \\
\text { Ratio }\end{array}$ & $\begin{array}{c}\text { Specimen } \\
4 \\
\text { Poisson's } \\
\text { Ratio } \\
\end{array}$ & $\begin{array}{c}\text { Specimen } \\
5 \\
\text { Poisson's } \\
\text { Ratio }\end{array}$ & $\begin{array}{c}\text { Average } \\
\text { Poisson's } \\
\text { Ratio }\end{array}$ \\
\hline-13 & 0.146 & --- & --- & --- & --- & 0.146 \\
\hline-4 & 0.192 & 0.231 & 0.174 & 0.202 & 0.153 & 0.190 \\
\hline 5 & 0.205 & 0.255 & 0.217 & 0.268 & 0.196 & 0.228 \\
\hline 14 & 0.180 & 0.242 & 0.213 & 0.251 & 0.186 & 0.214 \\
\hline 23 & 0.118 & 0.204 & 0.181 & 0.196 & 0.189 & 0.177 \\
\hline 32 & 0.094 & 0.160 & 0.109 & 0.196 & 0.201 & 0.152 \\
\hline 41 & 0.161 & 0.204 & 0.190 & 0.210 & 0.221 & 0.197 \\
\hline 50 & 0.137 & 0.186 & 0.169 & 0.210 & 0.156 & 0.171 \\
\hline 59 & 0.146 & 0.157 & 0.156 & 0.149 & 0.194 & 0.160 \\
\hline 68 & 0.114 & 0.212 & 0.152 & 0.186 & 0.166 & 0.166 \\
\hline 77 & 0.095 & 0.164 & 0.186 & 0.227 & 0.214 & 0.179 \\
\hline 86 & 0.129 & 0.173 & 0.186 & 0.245 & 0.205 & 0.188 \\
\hline 95 & 0.129 & 0.215 & 0.211 & 0.218 & 0.197 & 0.194 \\
\hline 104 & 0.110 & 0.098 & 0.182 & 0.231 & 0.204 & 0.165 \\
\hline 113 & 0.110 & 0.098 & 0.182 & 0.222 & 0.203 & 0.163 \\
\hline 122 & 0.129 & 0.177 & 0.162 & 0.207 & 0.209 & 0.177 \\
\hline
\end{tabular}


Degree of Saturation $=100 \%$

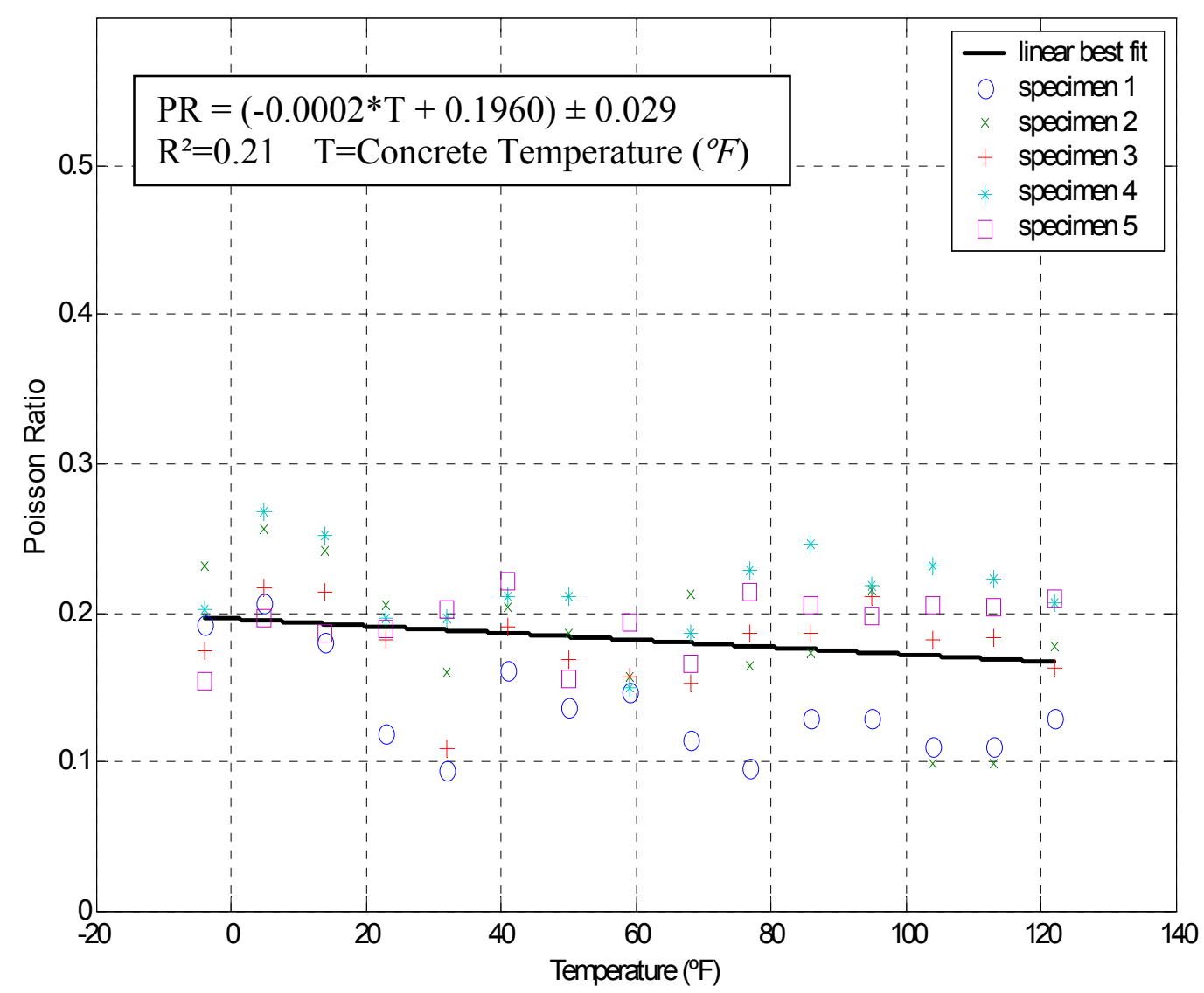

Figure 5.13 Effect of Temperature on Poisson's Ratio Concrete age: 28 days 
Table 5.14 Effect of Degrees of saturation on Poisson's Ratio

\begin{tabular}{|c|c|c|c|}
\hline $\begin{array}{c}\text { Degree of } \\
\text { Saturation (\%) }\end{array}$ & $\begin{array}{c}\text { Specimen 1 } \\
\text { Poisson's Ratio }\end{array}$ & $\begin{array}{c}\text { Specimen 3 } \\
\text { Poisson's Ratio }\end{array}$ & $\begin{array}{c}\text { Average Poisson's } \\
\text { Ratio }\end{array}$ \\
\hline 0 & 0.184 & 0.179 & 0.182 \\
\hline 20 & 0.186 & 0.194 & 0.190 \\
\hline 40 & 0.179 & 0.174 & 0.176 \\
\hline 60 & 0.187 & 0.165 & 0.176 \\
\hline 80 & 0.187 & 0.186 & 0.187 \\
\hline 100 & 0.185 & 0.184 & 0.184 \\
\hline
\end{tabular}

Temperature $=68^{\circ} \mathrm{F}$

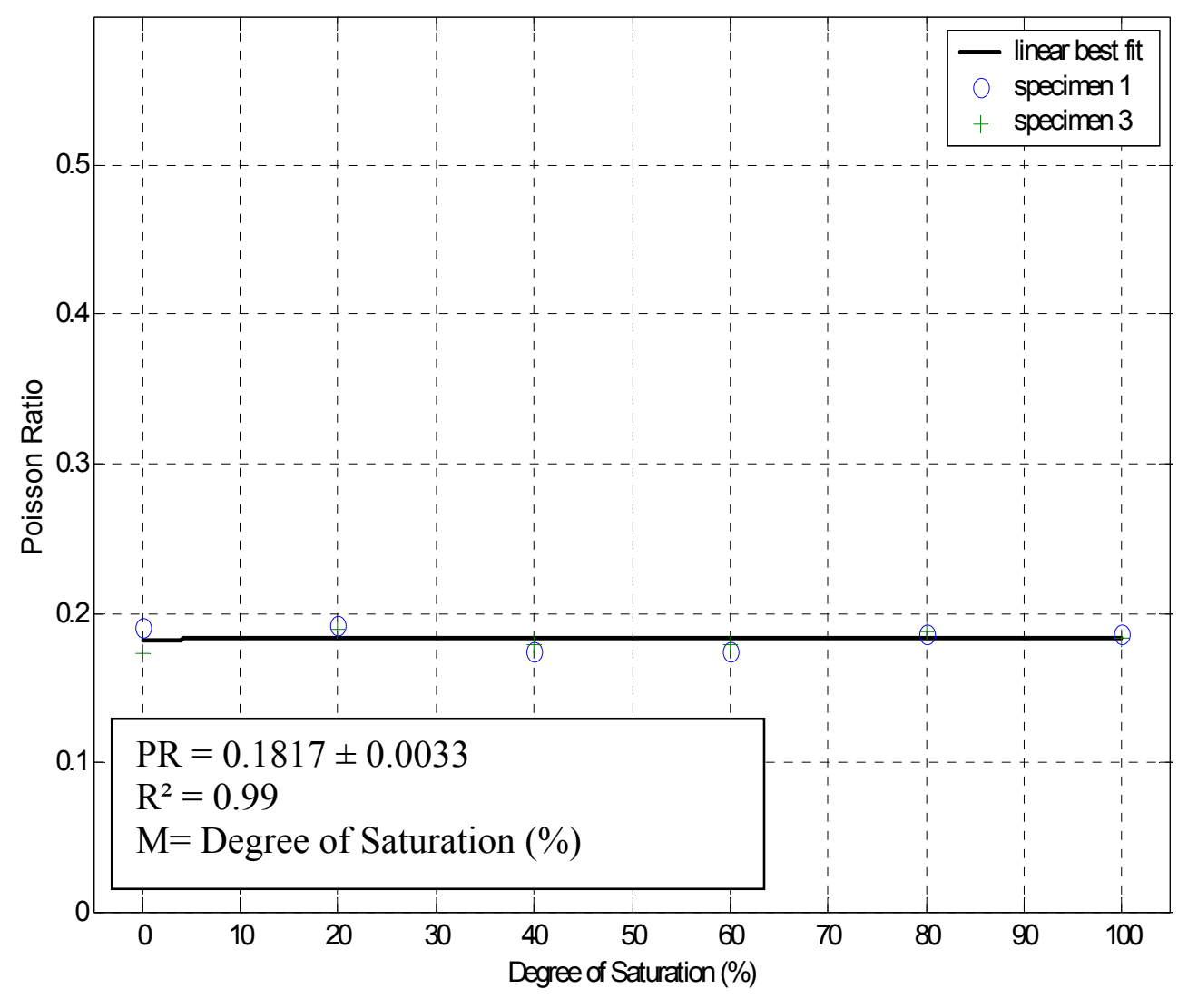

Figure 5.14 Effect of Degrees of Saturation on Poisson's Ratio Concrete age: 180 days 


\subsection{Effect of Curing Age on the Thermal Coefficient of Concrete}

The coefficient of thermal expansion of concrete decreased as the concrete cured according to Figure 5.15 and Table 5.15. The coefficient of thermal expansion was found by dividing the change in strain by change in temperature. The behavior of concrete expansion with respect to temperature was not linear. More strain occurred per unit change in temperature during the first week of curing than after the fourth week. It was concluded that the coefficient of thermal expansion will decrease as the specimens cure. At 28 days the specimens were essentially completely cured, thus the value for coefficient of thermal expansion did not continue to fall substantially.

$\mathrm{TC}=\left(\right.$ microstrain $\left./{ }^{\circ} \mathrm{F}\right)$

$\mathrm{TC}=$ coefficient of concrete thermal expansion

equation 5.4

Figure 5.16 and Table 5.16 show an additional coefficient of thermal expansion test that was performed. The first test was performed after 16 hours. The specimens were heated and cooled. The coefficient of thermal expansion dropped much faster than the test performed in Figure 5.15. The reason for the drop was most likely do to a much faster curing rate due to two reasons. The temperature on the day of concrete pour was very warm and the specimens were heated to $221^{\circ} \mathrm{F}$ within one day. The specimens in Figure 5.15 were allowed to cure at room temperature and saturation before their first test on day 3. Figures 5.17 to 5.22 show the strains with respect to time and temperatures of the concrete during the curing process. 
Table 5.15 Effect of Age on the Thermal Coefficient of Concrete

\begin{tabular}{|c|c|c|c|c|}
\hline & Specimen 1 & Specimen 2 & Specimen 3 & Average \\
\hline Day 3 & $7.61\left(\mu \varepsilon /{ }^{o} F\right)$ & $7.22\left(\mu \varepsilon^{/}{ }^{\circ} F\right)$ & $7.17\left(\mu \varepsilon /{ }^{o} F\right)$ & $7.33\left(\mu \varepsilon /{ }^{\circ} F\right)$ \\
\hline Day 7 & $\left.6.61(\mu \varepsilon)^{\circ} F\right)$ & $6.56\left(\mu \varepsilon{ }^{\circ} F\right)$ & $\left.6.56(\mu \varepsilon)^{\circ} F\right)$ & $6.56\left(\mu \varepsilon /{ }^{o} F\right)$ \\
\hline Day 14 & $\left.6.00(\mu \varepsilon)^{\circ} F\right)$ & $5.89\left(\mu \varepsilon{ }^{\circ} F\right)$ & $5.89\left(\mu \varepsilon /{ }^{\circ} F\right)$ & $5.94\left(\mu \varepsilon /{ }^{\circ} F\right)$ \\
\hline Day 21 & $5.94\left(\mu \varepsilon /{ }^{\circ} F\right)$ & $5.83\left(\mu \varepsilon^{/}{ }^{o} F\right)$ & $5.83\left(\mu \varepsilon /{ }^{\circ} F\right)$ & $5.83\left(\mu \varepsilon /{ }^{\circ} F\right)$ \\
\hline Day 28 & $5.94\left(\mu \varepsilon /{ }^{\circ} F\right)$ & $5.78\left(\mu \varepsilon^{/}{ }^{\circ} F\right)$ & $6.11\left(\mu \varepsilon /{ }^{o} F\right)$ & $5.94\left(\mu \varepsilon /{ }^{\circ} F\right)$ \\
\hline Day 60 & $5.77\left(\mu \varepsilon /{ }^{\circ} F\right)$ & $5.67\left(\mu \varepsilon^{/}{ }^{\circ} F\right)$ & $5.94\left(\mu \varepsilon /{ }^{\circ} F\right)$ & $5.78\left(\mu \varepsilon /{ }^{\circ} F\right)$ \\
\hline Day 75 & $5.77\left(\mu \varepsilon /{ }^{\circ} F\right)$ & $5.67\left(\mu \varepsilon /{ }^{o} F\right)$ & $5.94\left(\mu \varepsilon /{ }^{\circ} F\right)$ & $5.78\left(\mu \varepsilon /{ }^{\circ} F\right)$ \\
\hline
\end{tabular}


Degree of Saturation $=100 \%$

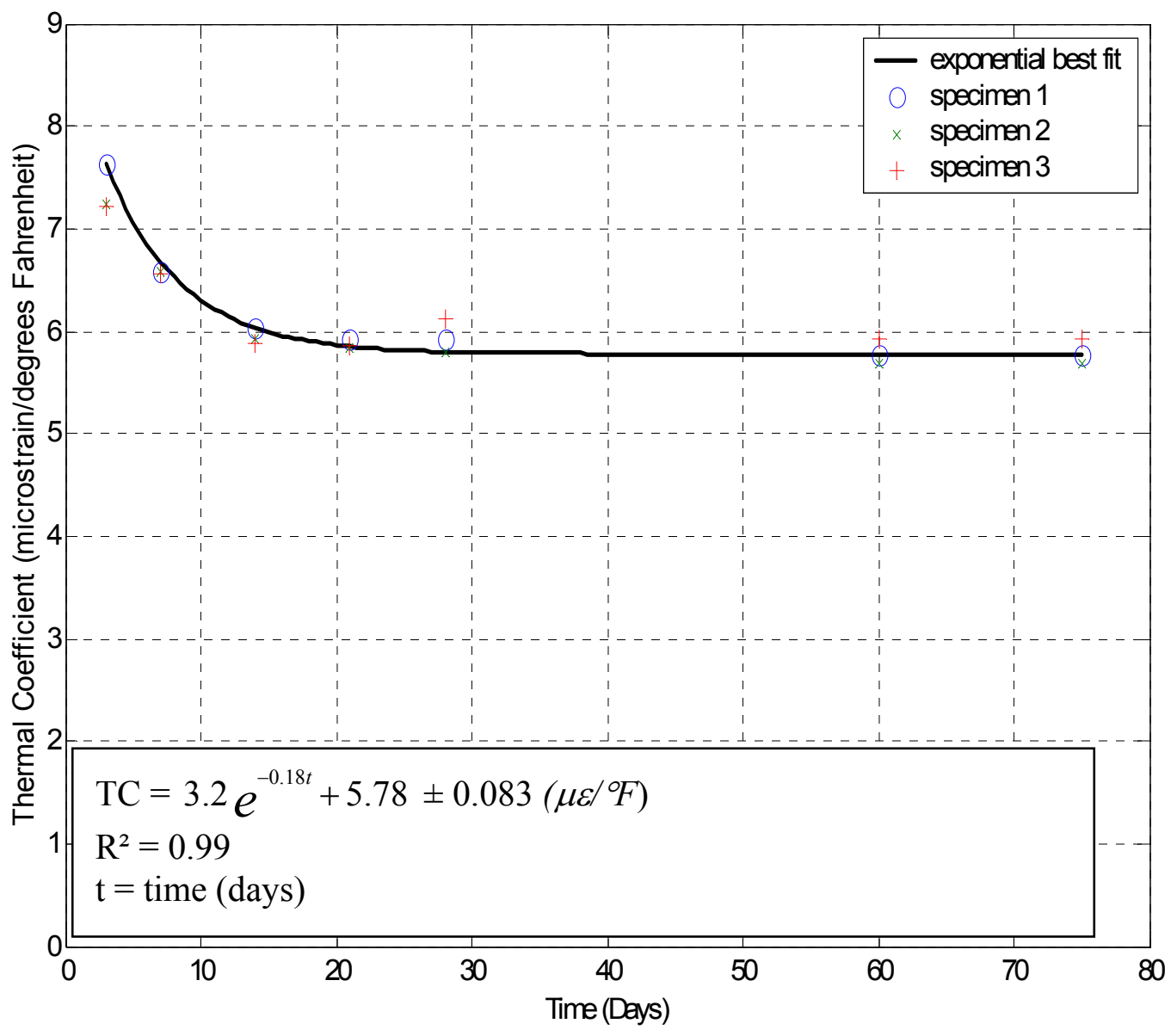

Figure 5.15 Effect of Age on the Thermal Coefficient of Concrete 
Table 5.16 Effect of Age on the Thermal Coefficient of Concrete (Confirmation)

\begin{tabular}{|c|c|c|c|c|}
\hline Time (Hours) & Specimen 1 & Specimen 2 & Specimen 3 & Average \\
\hline 16 & $7.78\left(\mu \varepsilon /{ }^{\circ} F\right)$ & $8.67\left(\mu \varepsilon /{ }^{\circ} F\right)$ & $9.56\left(\mu \varepsilon /{ }^{o} F\right)$ & $8.67\left(\mu \varepsilon /{ }^{o} F\right)$ \\
\hline 24 & $7.17\left(\mu \varepsilon /{ }^{\circ} F\right)$ & $6.67\left(\mu \varepsilon /{ }^{\circ} F\right)$ & $6.83\left(\mu \varepsilon^{\circ}{ }^{\circ} F\right)$ & $6.89\left(\mu \varepsilon /{ }^{\circ} F\right)$ \\
\hline 40 & $6.28\left(\mu \varepsilon /{ }^{\circ} F\right)$ & $6.28\left(\mu \varepsilon /{ }^{\circ} F\right)$ & $6.44\left(\mu \varepsilon /{ }^{\circ} F\right)$ & $6.33\left(\mu \varepsilon /{ }^{\circ} F\right)$ \\
\hline 48 & $6.33\left(\mu \varepsilon /{ }^{\circ} F\right)$ & $6.33\left(\mu \varepsilon /{ }^{o} F\right)$ & $6.22\left(\mu \varepsilon /{ }^{\circ} F\right)$ & $6.28\left(\mu \varepsilon /{ }^{\circ} F\right)$ \\
\hline 64 & $6.33\left(\mu \varepsilon /{ }^{o} F\right)$ & $6.44\left(\mu \varepsilon /{ }^{o} F\right)$ & $6.33\left(\mu \varepsilon /{ }^{o} F\right)$ & $6.39\left(\mu \varepsilon /{ }^{o} F\right)$ \\
\hline 72 & $5.94\left(\mu \varepsilon /{ }^{o} F\right)$ & $6.22\left(\mu \varepsilon /{ }^{o} F\right)$ & $5.67\left(\mu \varepsilon /{ }^{o} F\right)$ & $5.94\left(\mu \varepsilon /{ }^{o} F\right)$ \\
\hline 88 & $6.11\left(\mu \varepsilon /{ }^{\circ} F\right)$ & $6.28\left(\mu \varepsilon /{ }^{\circ} F\right)$ & $5.67\left(\mu \varepsilon /{ }^{O} F\right)$ & $6.00\left(\mu \varepsilon /{ }^{\circ} F\right)$ \\
\hline 96 & $6.11\left(\mu \varepsilon /{ }^{\circ} F\right)$ & $6.11\left(\mu \varepsilon /{ }^{o} F\right)$ & $6.11\left(\mu \varepsilon /{ }^{O} F\right)$ & $6.11\left(\mu \varepsilon /{ }^{\circ} F\right)$ \\
\hline 112 & $6.28\left(\mu \varepsilon /{ }^{\circ} F\right)$ & $6.33\left(\mu \varepsilon /{ }^{o} F\right)$ & $6.39\left(\mu \varepsilon /{ }^{o} F\right)$ & $6.33\left(\mu \varepsilon /{ }^{\circ} F\right)$ \\
\hline 120 & $6.39\left(\mu \varepsilon /{ }^{\circ} F\right)$ & $6.44\left(\mu \varepsilon /{ }^{\circ} F\right)$ & $6.56\left(\mu \varepsilon /{ }^{o} F\right)$ & $6.44\left(\mu \varepsilon /{ }^{o} F\right)$ \\
\hline 136 & $6.28\left(\mu \varepsilon /{ }^{\circ} F\right)$ & $6.33\left(\mu \varepsilon /{ }^{\circ} F\right)$ & $6.39\left(\mu \varepsilon /{ }^{\circ} F\right)$ & $6.33\left(\mu \varepsilon /{ }^{\circ} F\right)$ \\
\hline
\end{tabular}


Degree of Saturation $=100 \%$

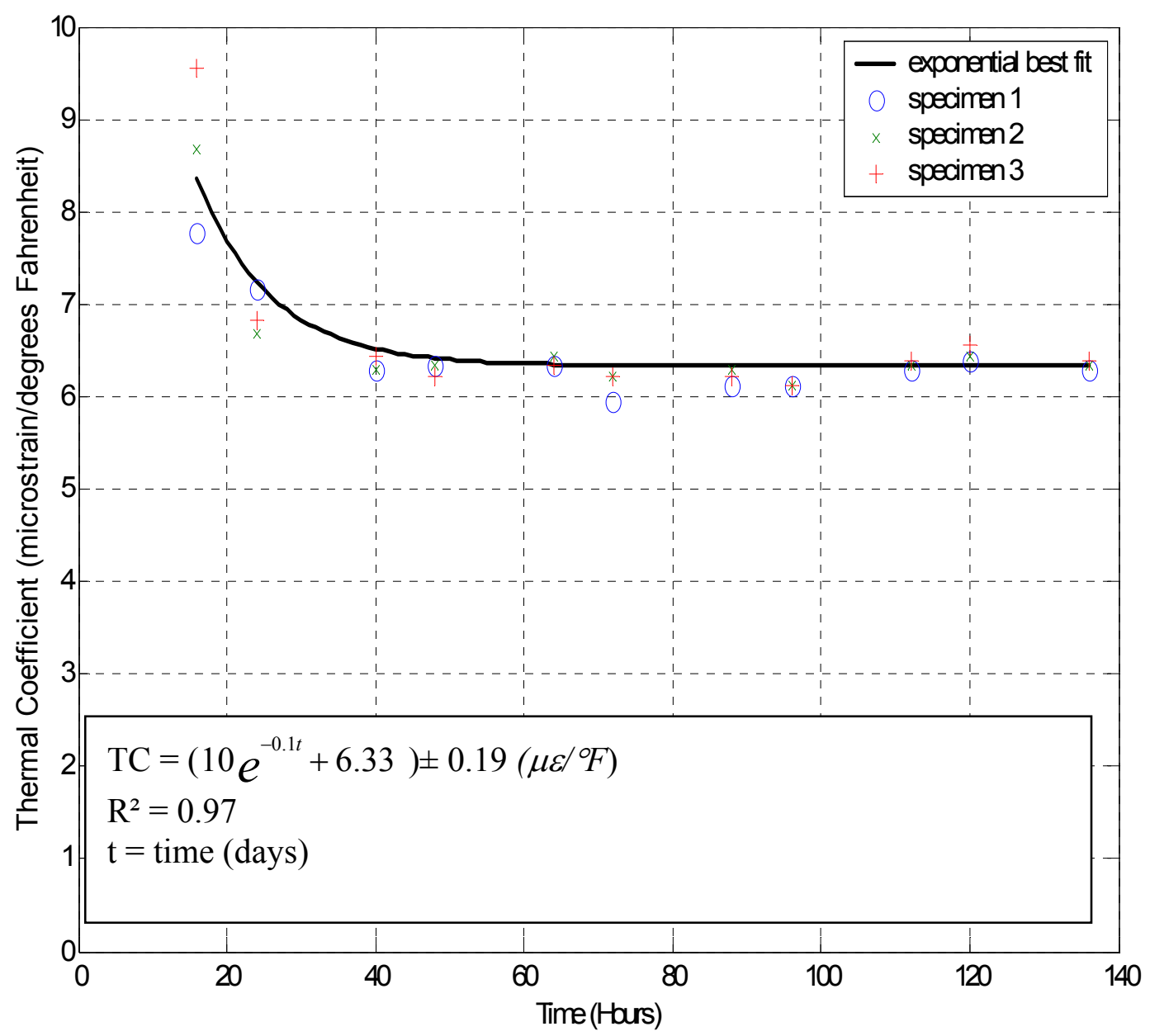

Figure 5.16 Coefficient of Thermal Expansion V. Time (Confirmation Test) 


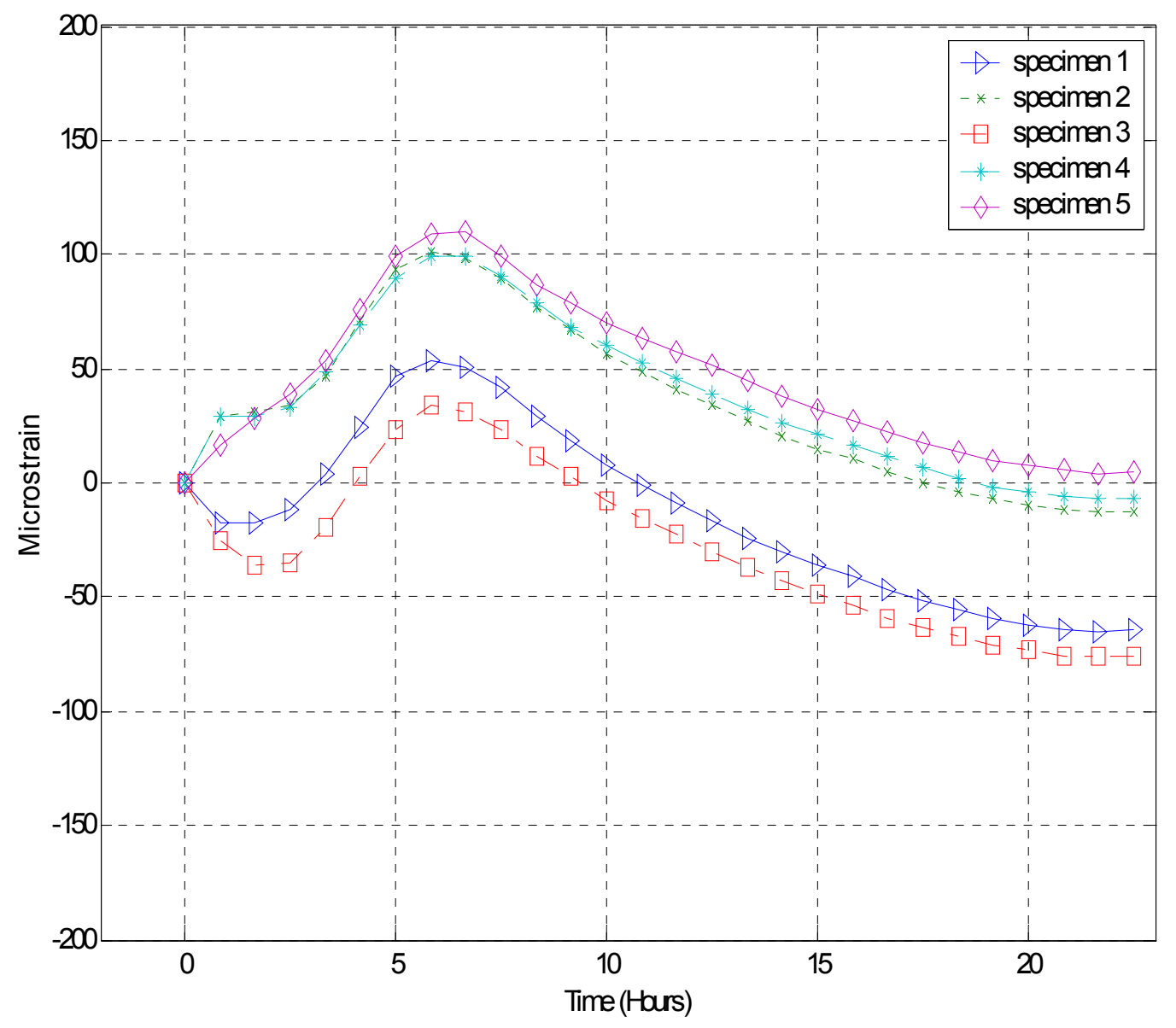

Figure 5.17 Strain V. Time 


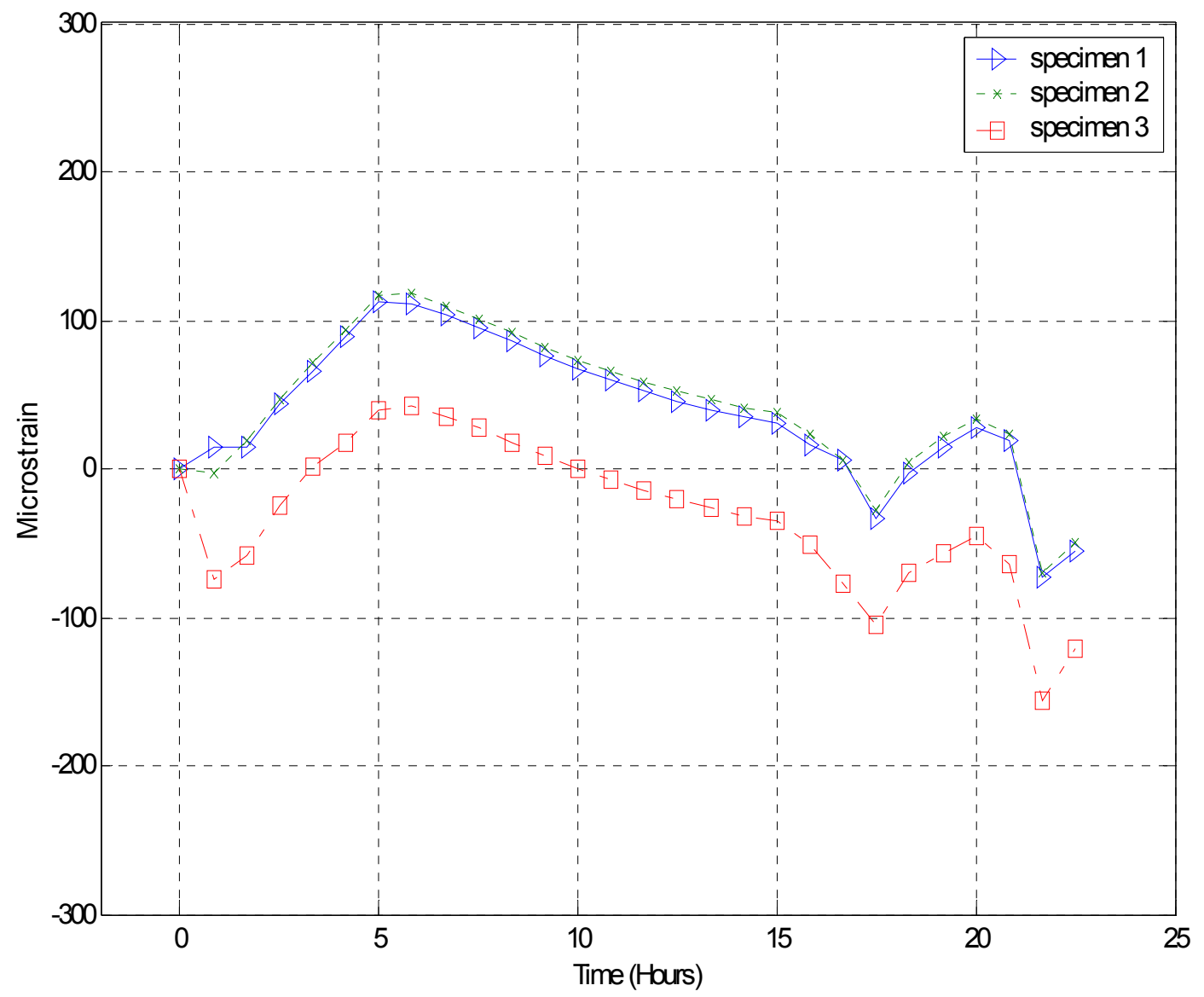

Figure 5.18 Strain V. Time (Confirmation Test) 


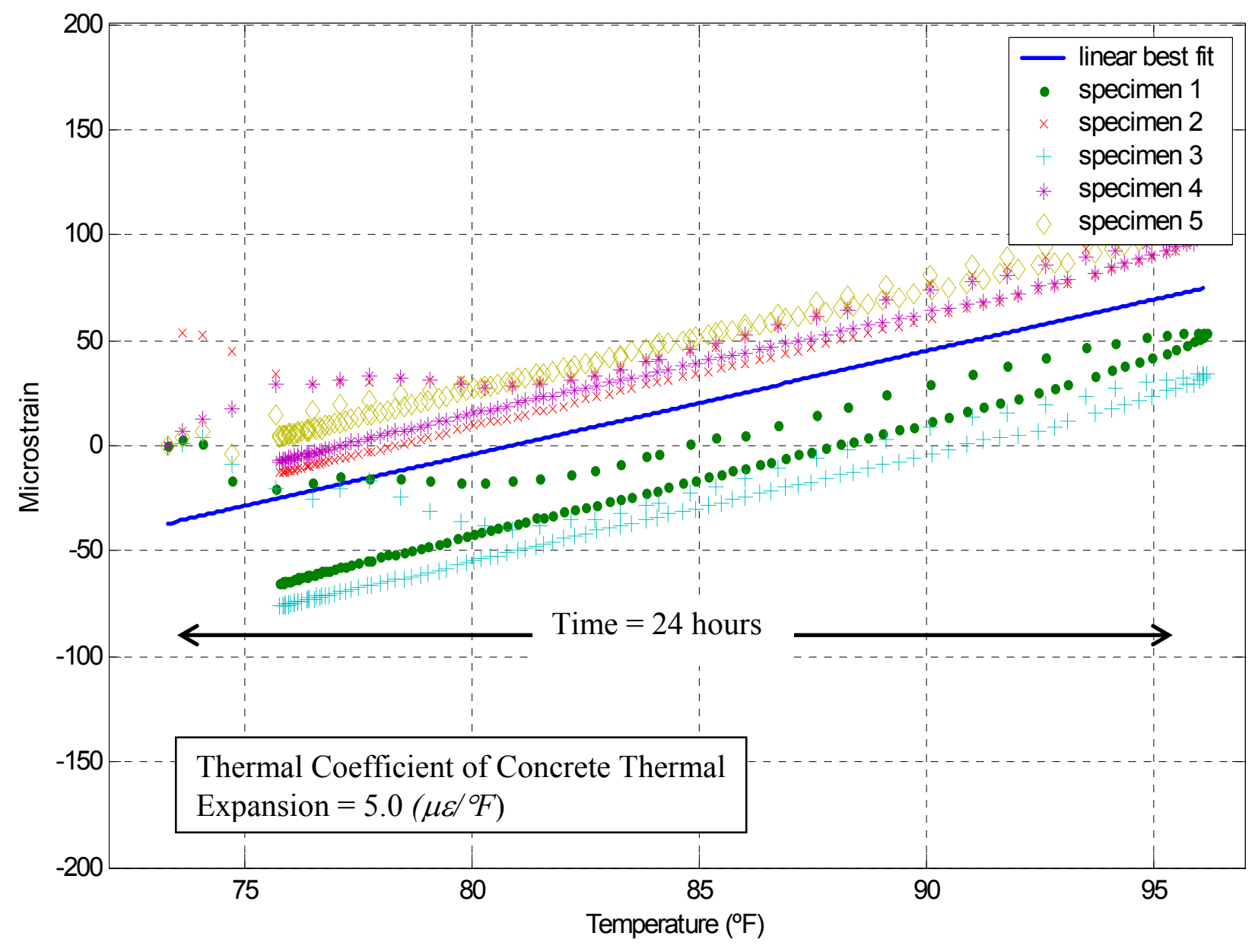

Figure 5.19 Strain V. Temperature 


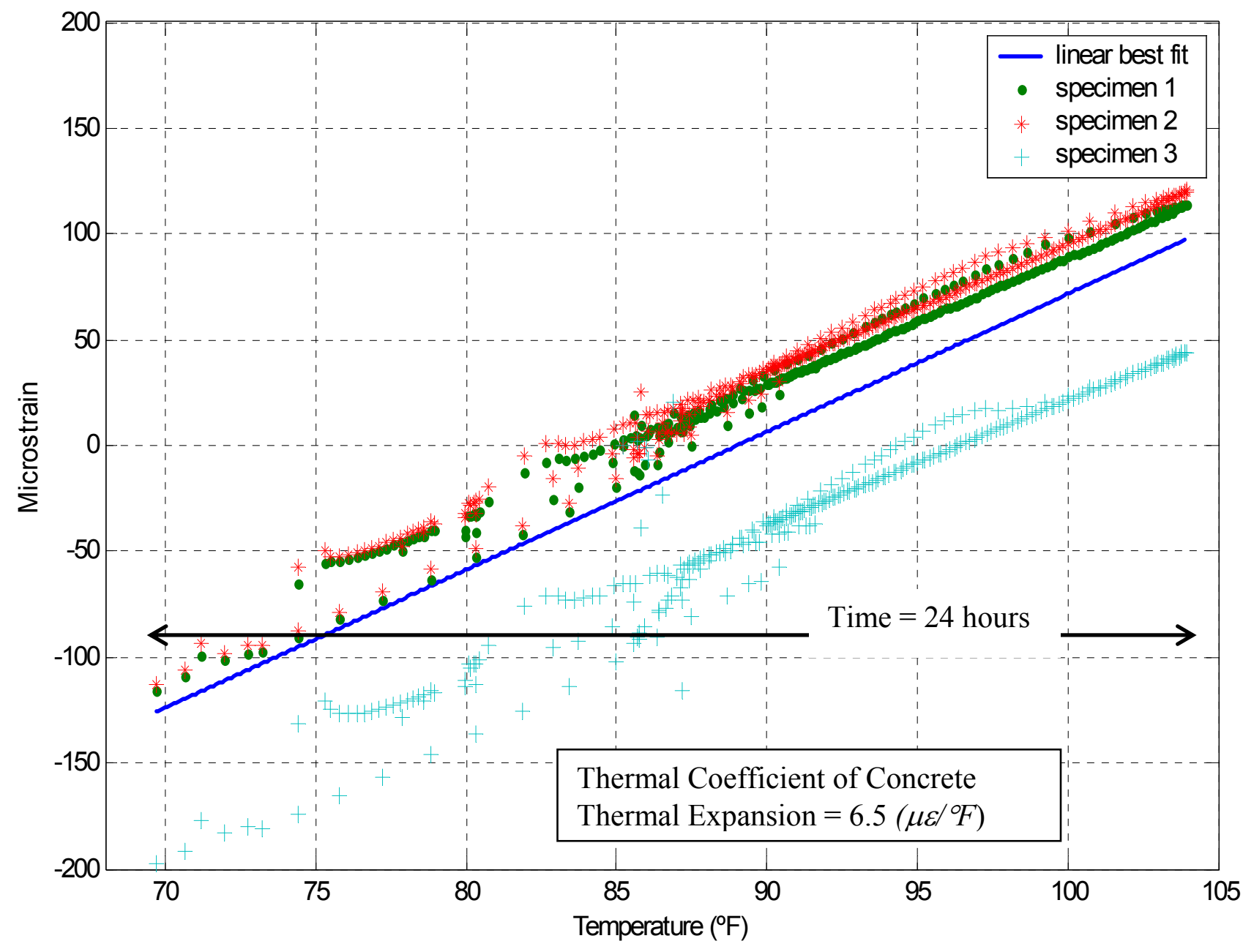

Figure 5.20 Strain V. Temperature

(Confirmation Test) 


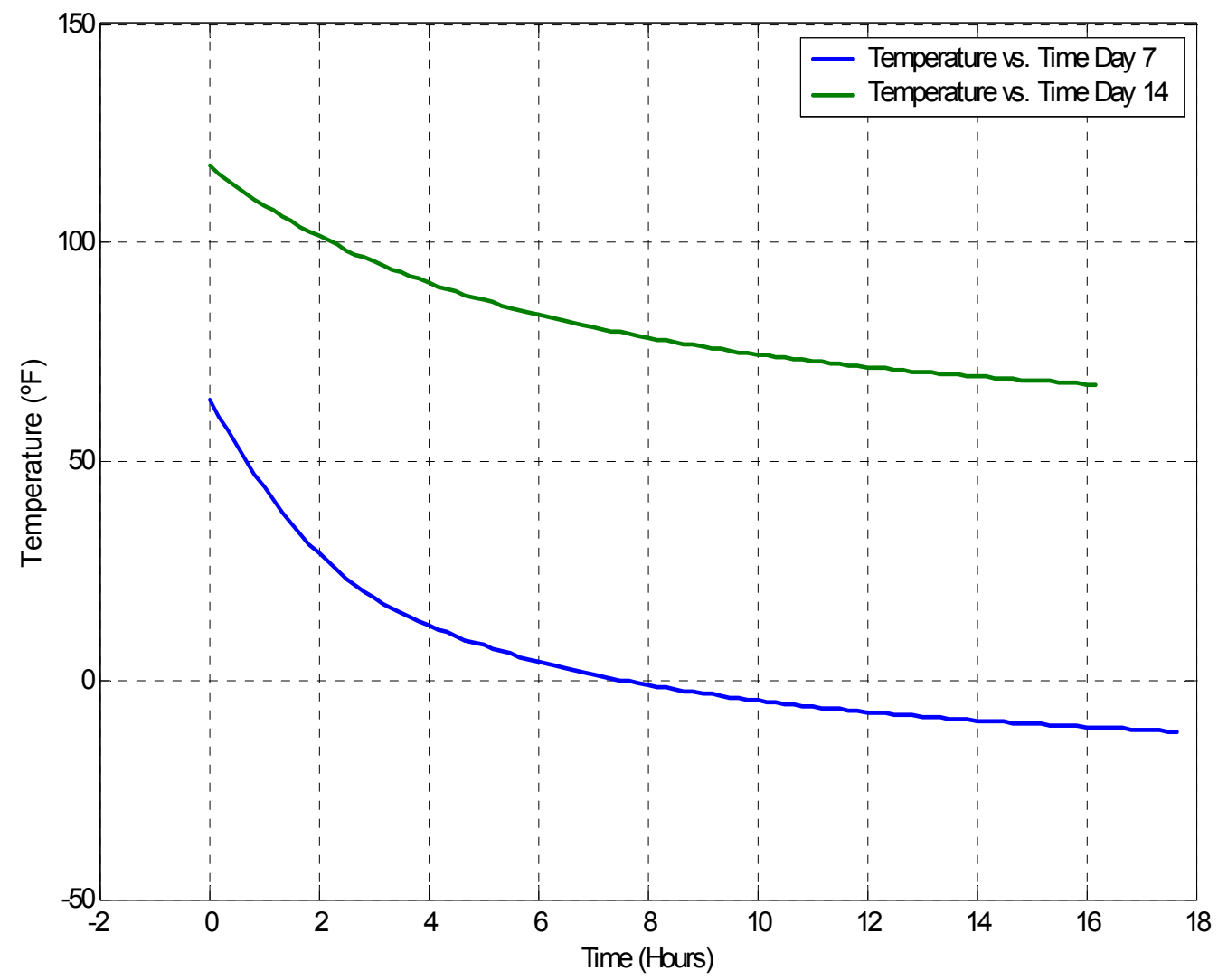

Figure 5.21Temperature V. Time 


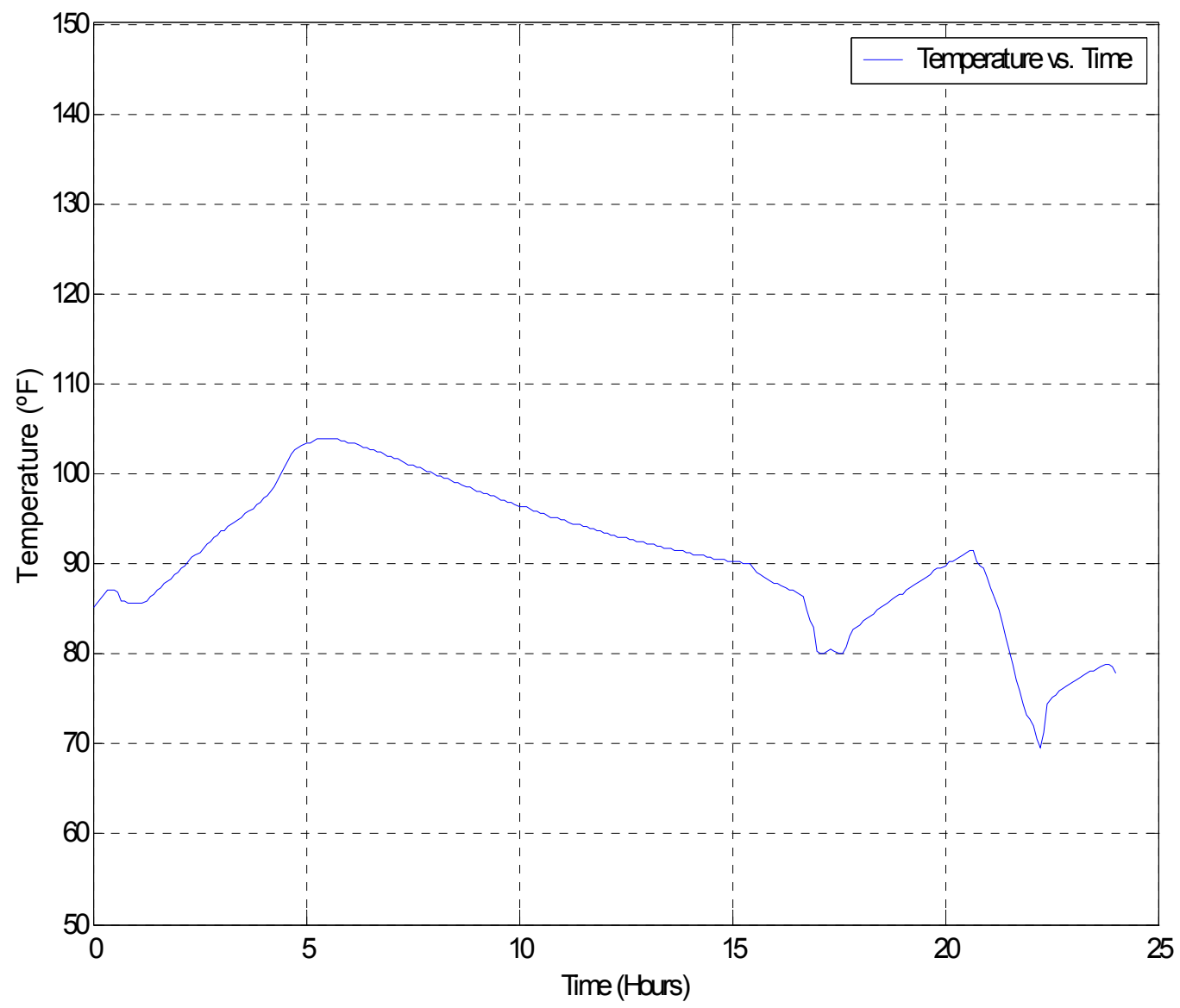

Figure 5.22 Temperature V. Time (Confirmation Test) 


\subsection{Example Problem}

A 12 inch high concrete column needs to be designed to support 100,000 pounds with a safety factor of 1.5 in subfreezing conditions with a 30 percent degrees of saturation. How thick does the column need to be using normal concrete specifications? How large does the diameter of the column need to be using the concrete moisture and temperature property formulas?

Solution using normal concrete specifications: With the safety factor the column must support 150,000 pounds evenly distributed. The compressive strength of the concrete under normal concrete conditions is 4700 psi.

Area $=$ force $/$ compressive strength

equation 5.4

Area $=150,000$ pounds $/ 4700 \mathrm{psi}=31.9$ in. sq.

Area $=3.14159 *(\text { thickness } / 2)^{2}$

Diameter $=2 * \operatorname{sqrt}($ Area/3.14159)

equation 5.5

Diameter $=2 * \operatorname{sqrt}(31.9$ in. sq. $/ 3.14159)=6.4$ in.

\section{$\underline{\text { Calculations }}$}

Compressive Strength $=-12.9 \mathrm{M}+5440$ (psi)

equation 5.6

Compressive Strength $=-12.9(30 \%)+5440(\mathrm{psi})$

Compressive Strength $=5050$ (psi) at $68 \mathrm{deg}$ F. and 30 percent degrees of saturation

Compressive Strength $=-13.1 \mathrm{~T}+5050$ (psi)

equation 5.7

Compressive Strength $=-(13.1 *-20)+5050(\mathrm{psi})$

Compressive Strength $=5310$ (psi) at $32 \mathrm{deg}$ F. and 30 percent degrees of saturation

Solution using moisture and temperature property formulas: With the safety factor the column must support 150,000 pounds evenly distributed. The compressive strength of the concrete when considering temperature and moisture conditions is 5550 psi.

Area $=$ force $/$ compressive strength

Area $=150,000$ pounds $/ 5310 \mathrm{psi}=28.2$ in. sq.

Area $=3.14159 *(\text { thickness } / 2)^{2}$

Diameter $=2 * \operatorname{sqrt}($ Area/3.14159)

Diameter $=2 *$ sqrt $(28.2$ in. sq. $/ 3.14159)=5.9$ in.

A column 0.5 inches smaller in diameter can be utilized when temperature and moisture are taken into consideration. 


\section{Chapter Six Conclusion}

Temperature and moisture played a large role in affecting the properties of concrete. Higher temperature and higher degrees of saturation will yield lower concrete strength in compression, tension, and corresponding modulus of elasticity. The effect of temperature and moisture on Poisson's ratio is negligible. Concrete curing caused the thermal coefficient of concrete expansion to decrease at early ages. Concrete curing also caused concrete compressive and tensile strength and corresponding modulus of elasticity to increase. The rate of property change was related through the use of mathematical formulas.

In order to find the compressive strength, tensile strength, or modulus of elasticity at a certain temperature mathematical formula were developed. The formulas were developed by fitting a curve to the data point. In the proceeding formulas $\mathrm{T}=$ Temperature in ${ }^{\circ} \mathrm{F}$ of Concrete, $\mathrm{M}=$ Degree of Saturation of Concrete in \%, Compressive Strength and Tensile Strength have units of ( $p s i)$, and Modulus of Elasticity has units of $\left(p s i * 10^{6}\right)$.

To find the compressive strength of concrete at various temperatures the following formula was used:

- Compressive Strength $=-13.1 * \mathrm{~T}+5490$.

equation 6.1

To find the tensile strength of concrete at various temperatures the following formula was used:

- Tensile Strength $=-1.45 * \mathrm{~T}+533$.

equation 6.2

To find the modulus of elasticity of concrete at various temperatures the following formula was used:

- Modulus of Elasticity $=-0.0064 * \mathrm{~T}+4.23$.

equation 6.3 
To find the modulus of elasticity of concrete at various degrees of saturation the following formula was used:

- $\quad$ Modulus of Elasticity $=-0.0071 * \mathrm{M}+4.21$.

equation 6.4

Poisson's Ratio will change very little with temperature and degrees of saturation. To find Poisson's Ratio at various temperatures the following formula was used:

- Poisson's Ratio $=-0.0002 * \mathrm{~T}+0.1960$.

equation 6.5

To find the Poisson's Ratio at various degrees of saturation the following formula was used:

- Poisson's Ratio $=0.1824$.

equation 6.6

To find the compressive strength at varying degrees of saturation the following formula was used:

- Compressive Strength $=-12.9 * \mathrm{M}+5440$.

equation 6.7

To find the tensile strength at varying degrees of saturation the following formula was used:

- $\quad$ Tensile Strength $=-1.79 * \mathrm{M}+548$.

equation 6.8

The relations between temperature, moisture, compressive strength, tensile strength, and modulus of elasticity for cured concrete are given in Table 6.1 as well if a tabular format is needed. 
Table 6.1 Material Model Equations

\begin{tabular}{|c|c|}
\hline Property & Formula \\
\hline $\begin{array}{l}\text { Modulus of Elasticity }\left(\mathrm{psi} * 10^{6}\right) \text { at } \\
\text { different temperatures }\left(\mathrm{T} \text { in }{ }^{\circ} \mathrm{F}\right)\end{array}$ & Modulus of Elasticity $=-0.0064 * \mathrm{~T}+4.23\left(\mathrm{psi} * 10^{6}\right)$ \\
\hline $\begin{array}{c}\text { Modulus of Elasticity }\left(\mathrm{psi} * 10^{6}\right) \text { at } \\
\text { different degrees of saturation }(\mathrm{M} \text { in } \%)\end{array}$ & Modulus of Elasticity $=-0.0071 * \mathrm{M}+4.21\left(\mathrm{psi}^{*} 10^{6}\right)$ \\
\hline $\begin{array}{c}\text { Compressive Strength (psi) at different } \\
\text { temperatures }\left(\mathrm{T} \text { in }{ }^{\circ} \mathrm{F}\right)\end{array}$ & $\begin{array}{c}\text { Compressive Strength }=-13.1 * \mathrm{~T}+5490(\mathrm{psi}) \text { or } \\
\text { Compressive Strength }=-7.90 * \mathrm{~T}+5430(\mathrm{psi})\end{array}$ \\
\hline $\begin{array}{c}\text { Compressive Strength (psi) at different } \\
\text { degrees of saturation (M in \%) }\end{array}$ & Compressive Strength $=-12.9 * \mathrm{M}+5440(\mathrm{psi})$ \\
\hline $\begin{array}{l}\text { Tensile Strength (psi) at different } \\
\text { temperatures }\left(\mathrm{T} \text { in }{ }^{\circ} \mathrm{F}\right)\end{array}$ & Tensile Strength $=-1.45 * \mathrm{~T}+533(\mathrm{psi})$ \\
\hline $\begin{array}{l}\text { Tensile Strength (psi) at different degrees } \\
\text { of saturation ( } \mathrm{M} \text { in } \%)\end{array}$ & Tensile Strength $=-1.79 * \mathrm{M}+548$ (psi) \\
\hline $\begin{array}{l}\text { Poisson's Ratio at different temperatures } \\
\left(\mathrm{T} \text { in }{ }^{\circ} \mathrm{F}\right)\end{array}$ & Poisson's Ratio $=-0.0002 * \mathrm{~T}+0.1960$ \\
\hline $\begin{array}{c}\text { Poisson's Ratio at different degrees of } \\
\text { saturation }(\mathrm{M} \text { in } \%)\end{array}$ & Poisson's Ratio $=0.1824$ \\
\hline
\end{tabular}




\section{References}

1. Arvidson, J.M., et al (Feb. 1982). Mechanical Properties of Concrete Mortar at Low Temperatures. National Bureau of Standards.

2. Brewage, Carl and A. Baroque Starker (1973). Behavior of Concrete Under Temperature Extremes. American Concrete Institute. Detroit, MI.

3. Carette, Georges G. and Mohan Malhotra (1992). The Effects of Sustained High Heat on Cured Concrete. National Bureau of Standards.

4. Cheng, F.P., et al (February 2004). Stress-strain curves for high strength concrete at elevated temperatures. National Research Council Canada. Publication NRCC46973. Accessed June 5, 2004.

http://irc.nrc-cnrc.gc.ca/fulltext/nrcc46973/nrcc46973.pdf

5. Johnson, Greg D (2001). Pavement Temperature Effects. Accessed June 10, 2004. http://www.mrr.dot.state.mn.us/research/MnROAD Project/ResearchBulletins/Temperat ure\%20Report.pdf

6. Kodur, V.K.R (July 2004). Fire Performance of High Strength Concrete Structural Members. Publication CTU31E. Accessed August 25, 2004. http://irc.nrccnrc.gc.ca/ctus/ctu31e.pdf

7. Korhonen, Charles J., et al (April 1997). Developing New Low-Temperature Admixtures for Concrete. Publication SR97_09. Accessed June 7, 2004. http://ntl.bts.gov/data/CRREL Reports/SR97 09.pdf 
8. Korhonen, Charles J (February 2002). Effect of High Doses of Chemical Admixtures on the Freeze-Thaw Durability of Portland Cement Concrete. Publication TR02-5. Accessed June 16, 2004.

http://www.crrel.usace.army.mil/techpub/CRREL Reports/reports/TR02-5.pdf

9. Korhonen, Charles J. and John W. Brook (October 1996). Freezing Temperature Protection Admixture for Portland Cement Concrete. Publication SR96_28. Accessed April 29, 2004.

http://www.crrel.usace.army.mil/techpub/CRREL_Reports/reports/SR96_28.pdf

10. Korhonen, Charles J. and Sherri A. Orchino (April 2002). Off-the-Shelf Antifreeze Admixture for Concrete. Engineer Research and Development Center. Hanover, NH. Publication A213104

11. Lawson, J. Randall, et al (March 24, 2000). Mechanical Properties of High Performance Concrete After Exposure to Elevated Temperatures. National Institute of Standards and Technology.

12. Naik, Tarun R (1985). Temperature Effects on Concrete. American Society For Testing and Materials. Philadelphia, PA.

13. Nasser, K.W. and G.A. Evans (1989). The Effects of Cold on Cured Concrete. Canadian Research Council.

14. Nawy E.G (1997). Concrete Construction Engineering Hand book, CRC press, Boca Raton, New York.

15. Ongah, R., et al (2004). Fire Performance of High Strength Reinforced Concrete Walls. The University of Melbourne, Melbourne, Victoria, Australia and Monash University, Melbourne, Victoria, Australia. 
16. Phan, Long T. and Nicholas J. Carino (June 2004). Code Provisions for High Strength Concrete Strength-Temperature Relationship at Elevated Temperatures. Accessed June 5, 2004. http://fire.nist.gov/bfrlpubs/build03/PDF/b03020.pdf

17. Phan, Long T. High Strength Concrete at High Temperature - An Overview (June 2004). Publication ART171. Accessed October 18, 2004.

http://fire.nist.gov/bfrlpubs/build02/art171.html

18. Phan, Long T. and Richard D. Peacock (May 1999). Mechanical Properties of HighStrength Concrete at Elevated Temperatures. Publication B03022. Accessed June 15, 2004. http://fire.nist.gov/bfrlpubs/build03/PDF/b03022.pdf

19. Ravindrarajah, R. Sri, et al (March 17, 2002). Effect of Elevated Temperature on the Properties of High-Strength Concrete containing Cement Supplementary Materials. Accessed June 1, 2004.

http://services.eng.uts.edu.au/ ravir/Temperature $\% 20$ on $\% 20 \mathrm{High} \% 20$ Strength $\% 20 \mathrm{Concr}$ ete.pdf

20. Rhoads, Jason L (August 2004). Basic Explanation of Creep Process. University of California.

21. Siemes, Ton, et al (March 18, 2003). Unexpectedly Low Tensile Strength in Concrete Structures. TNO Building and Construction Research.

22. Westman, Gustaf (1999). Concrete Creep and Thermal Stresses." Ph.D. thesis, Division of Structural Engineering, Luleå University of Technology at Luleå, Sweden.

23. Wu, Shengxing and Yunfeng Li (August 20, 2004). Environmental Simulation Test Technology of Modern Concrete Structures. Publication WUSHENGXING-10. Accessed November 5, 2004.

http://www.paper.edu.cn/scholar/known/wushengxing/wushengxing-10.pdf 


\section{Appendix}

\section{A.1 Modulus of Elasticity Testing Data}

The Data below was used during the modulus of elasticity test at different temperatures. This particular table of data was created at $+20^{\circ} \mathrm{C}$ on day 28 for specimen 1. The table contains raw data. The temperature values were converted from ${ }^{\circ} \mathrm{C}$ to ${ }^{\circ} \mathrm{F}$ in chapter 5 .

Table A.1 Modulus of Elasticity Test $+20^{\circ} \mathrm{C}$ day 28 specimen 1

\begin{tabular}{|c|c|c|c|c|c|c|c|c|c|}
\hline $\begin{array}{c}\text { SI } \\
\text { no }\end{array}$ & $\begin{array}{c}\text { Load } \\
(\mathbf{I b s})\end{array}$ & $\begin{array}{c}\text { Vertical } \\
\text { Strain } \\
(\mu \varepsilon)\end{array}$ & $\begin{array}{c}\text { Horizontal } \\
\text { Strain }(\mu \varepsilon)\end{array}$ & $\begin{array}{c}\text { Temp } \\
\left({ }^{\circ} \mathbf{C}\right)\end{array}$ & $\begin{array}{c}\text { Stress } \\
(\boldsymbol{p s i})\end{array}$ & $\begin{array}{c}\text { Actual } \\
\text { Vertical } \\
\text { Strain } \\
(\mu \boldsymbol{\varepsilon})\end{array}$ & $\begin{array}{c}\text { Actual } \\
\text { Horizont } \\
\text { al } \\
\text { Strain } \\
(\mu \varepsilon)\end{array}$ & $\begin{array}{c}\text { Young's } \\
\text { Modulus } \\
\mathbf{E} \\
(\boldsymbol{p s i})\end{array}$ & $\begin{array}{c}\text { Poisson's } \\
\text { ratio }\end{array}$ \\
\hline 1 & 208.90 & 1478.5 & 2082.4 & 20.756 & -7.3883 & 0.0000 & 0.0000 & - & - \\
\hline 2 & 673.20 & 1478.0 & 2082.1 & 20.697 & -23.809 & -0.6062 & 0.2478 & 2708800 & 0.1487 \\
\hline 3 & 1182.6 & 1472.9 & 2082.8 & 20.608 & -41.825 & -5.8664 & 0.5044 & 3425000 & 0.1429 \\
\hline 4 & 1726.9 & 1466.0 & 2083.7 & 20.578 & -61.077 & -12.8204 & 1.4566 & 2768200 & 0.1369 \\
\hline 5 & 2254.1 & 1459.5 & 2084.5 & 20.549 & -79.722 & -19.3726 & 2.3610 & 2845700 & 0.1380 \\
\hline 6 & 2791.7 & 1452.5 & 2085.3 & 20.519 & -98.736 & -26.4266 & 3.2150 & 2695400 & 0.1210 \\
\hline 7 & 3322.2 & 1445.8 & 2086.2 & 20.489 & -117.49 & -33.1806 & 4.1672 & 2778000 & 0.1409 \\
\hline 8 & 3854.7 & 1439.6 & 2087.0 & 20.460 & -136.33 & -39.4328 & 5.0194 & 3012200 & 0.1363 \\
\hline 9 & 4380.1 & 1433.0 & 2087.2 & 20.430 & -154.91 & -46.0868 & 5.3238 & 2792600 & 0.0457 \\
\hline 10 & 4911.7 & 1426.2 & 2087.7 & 20.430 & -173.71 & -52.8868 & 5.8760 & 2764900 & 0.0812 \\
\hline 11 & 5428.0 & 1420.1 & 2088.3 & 20.401 & -191.97 & -59.0390 & 6.5300 & 2968100 & 0.1063 \\
\hline 12 & 5976.3 & 1413.5 & 2089.1 & 20.401 & -211.36 & -65.6390 & 7.3822 & 2938200 & 0.1291 \\
\hline 13 & 6490.4 & 1407.1 & 2089.9 & 20.371 & -229.55 & -72.0930 & 8.2344 & 2817200 & 0.1320 \\
\hline 14 & 7053.2 & 1400.1 & 2090.9 & 20.371 & -249.45 & -79.0930 & 9.2866 & 2843500 & 0.1503 \\
\hline 15 & 7378.9 & 1397.8 & 2091.3 & 20.371 & -260.97 & -81.3930 & 9.7388 & 5008300 & 0.1966 \\
\hline
\end{tabular}


The Data below was used during the modulus of elasticity test at different degrees of saturation. This particular table of data was created on day 180 for specimen 2 . The table contains raw data. The temperature values were converted from ${ }^{\circ} \mathrm{C}$ to ${ }^{\circ} \mathrm{F}$ in chapter 5.

Table A.2 Modulus of Elasticity Test at $40 \%$ degrees saturation and $20^{\circ} \mathrm{C}$ day 180 specimen 2

\begin{tabular}{|c|c|c|c|c|c|c|c|c|c|}
\hline $\begin{array}{c}\text { SI } \\
\text { no }\end{array}$ & $\begin{array}{c}\text { Load } \\
(\mathbf{I b s})\end{array}$ & $\begin{array}{c}\text { Vertical } \\
\text { Strain } \\
(\mu \varepsilon)\end{array}$ & $\begin{array}{c}\text { Horizontal } \\
\text { Strain }(\mu \varepsilon)\end{array}$ & $\begin{array}{c}\text { Temp } \\
\left({ }^{\circ} \mathbf{C}\right)\end{array}$ & $\begin{array}{c}\text { Stress } \\
(\boldsymbol{p s i})\end{array}$ & $\begin{array}{c}\text { Actual } \\
\text { Vertical } \\
\text { Strain }(\mu \varepsilon)\end{array}$ & $\begin{array}{c}\text { Actual } \\
\text { Horizontal } \\
\text { Strain }(\mu \varepsilon)\end{array}$ & $\begin{array}{c}\text { Young's } \\
\text { Modulus } \\
\mathbf{E} \\
(\boldsymbol{p s i})\end{array}$ & $\begin{array}{c}\text { Poisson's } \\
\text { ratio } \\
v\end{array}$ \\
\hline 1 & 208.9 & 1686.2 & 2117.8 & 16.533 & -7.3883 & 0.0000 & 0.0000 & - & - \\
\hline 2 & 673.2 & 1686.1 & 2117.8 & 16.562 & -23.809 & -0.0478 & 0.0000 & 3435400 & 0.0000 \\
\hline 3 & 1182.6 & 1682.0 & 2118.6 & 16.562 & -41.825 & -4.1478 & 0.7478 & 4394200 & 0.1823 \\
\hline 4 & 1726.9 & 1677.0 & 2119.7 & 16.562 & -61.076 & -9.1478 & 1.9000 & 3850100 & 0.2304 \\
\hline 5 & 2254.1 & 1671.6 & 2120.8 & 16.562 & -79.722 & -14.547 & 2.9478 & 3452900 & 0.1940 \\
\hline 6 & 2791.7 & 1665.9 & 2121.1 & 16.562 & -98.736 & -20.247 & 3.2478 & 3335700 & 0.0526 \\
\hline 7 & 3322.2 & 1660.2 & 2121.8 & 16.533 & -117.49 & -26.000 & 3.9478 & 3261800 & 0.1216 \\
\hline 8 & 3854.7 & 1654.3 & 2123.6 & 16.562 & -136.33 & -31.847 & 5.6974 & 3220500 & 0.2991 \\
\hline 9 & 4380.1 & 1647.9 & 2124.7 & 16.562 & -154.91 & -38.247 & 6.8478 & 2903400 & 0.1797 \\
\hline 10 & 4911.7 & 1641.6 & 2125.8 & 16.505 & -173.71 & -44.650 & 7.9478 & 2936500 & 0.1718 \\
\hline 11 & 5428.0 & 1635.5 & 2126.6 & 16.533 & -191.97 & -50.700 & 8.6974 & 3018400 & 0.1239 \\
\hline 12 & 5976.3 & 1628.4 & 2126.4 & 16.505 & -211.36 & -57.850 & 8.5478 & 2712000 & 0.0209 \\
\hline 13 & 6490.4 & 1621.9 & 2128.2 & 16.533 & -229.55 & -64.300 & 10.247 & 2819100 & 0.2634 \\
\hline 14 & 7053.2 & 1616.1 & 2129.2 & 16.533 & -249.45 & -70.100 & 11.247 & 3431800 & 0.1724 \\
\hline 15 & 7378.9 & 1613.4 & 2128.4 & 16.533 & -260.97 & -72.800 & 10.497 & 4266400 & 0.2776 \\
\hline
\end{tabular}




\section{A.2 Compression Testing Data}

Table A.3 Compression Results During the Curing Process at Room Temperature

\begin{tabular}{|c|c|c|c|c|c|}
\hline & & $\begin{array}{c}\text { Specimen } 1 \\
\text { (Compression) }\end{array}$ & $\begin{array}{c}\text { Specimen } 2 \\
\text { (Compression) }\end{array}$ & $\begin{array}{c}\text { Specimen } 3 \\
\text { (Compression) }\end{array}$ & Average \\
\hline \multirow{2}{*}{ Day 1} & Load $(l b s)$ & 56000 & 76000 & 80000 & \\
\hline & $\begin{array}{l}\text { Strength } \\
(\text { psi) }\end{array}$ & 1981 & 2688 & 2829 & 2499 \\
\hline \multirow{2}{*}{ Day 3} & Load (lbs) & 75500 & 105000 & 71000 & \\
\hline & $\begin{array}{l}\text { Strength } \\
(p s i)\end{array}$ & 2670 & 3714 & 2511 & 2965 \\
\hline \multirow{2}{*}{ Day 7} & Load $(l b s)$ & 116500 & 114000 & 112000 & \\
\hline & $\begin{array}{l}\text { Strength } \\
(p s i)\end{array}$ & 4120 & 4031 & 3961 & 4037 \\
\hline \multirow{2}{*}{ Day 14} & Load (lbs) & 120000 & 122000 & 112000 & \\
\hline & $\begin{array}{l}\text { Strength } \\
(p s i)\end{array}$ & 4244 & 4315 & 3961 & 4173 \\
\hline \multirow{2}{*}{ Day 21} & Load (lbs) & 112000 & 123000 & 126000 & \\
\hline & $\begin{array}{l}\text { Strength } \\
\text { (psi) }\end{array}$ & 3961 & 4350 & 4456 & 4256 \\
\hline
\end{tabular}


Table A.4 Compression Results of Cured Concrete at Varying Temperatures

\begin{tabular}{|c|c|c|c|c|c|}
\hline $\begin{array}{c}\text { Temperature } \\
\left({ }^{\circ} \mathbf{F}\right)\end{array}$ & & $\begin{array}{c}\text { Specimen } 1 \\
\text { (Compression) }\end{array}$ & $\begin{array}{c}\text { Specimen } 2 \\
\text { (Compression) }\end{array}$ & $\begin{array}{c}\text { Specimen } 3 \\
\text { (Compression) }\end{array}$ & Average \\
\hline \multirow{2}{*}{-13} & Load $(l b s)$ & 172000 & 148000 & 152000 & \\
\hline & $\begin{array}{l}\text { Strength } \\
(p s i)\end{array}$ & 6083 & 5234 & 5376 & 5565 \\
\hline \multirow{2}{*}{5} & Load $(l b s)$ & 162000 & 144000 & 156000 & \\
\hline & $\begin{array}{l}\text { Strength } \\
(p s i)\end{array}$ & 5730 & 5093 & 5517 & 5447 \\
\hline \multirow{2}{*}{23} & $\begin{array}{c}\text { Load } \\
(l b s)\end{array}$ & 147500 & 144000 & 136000 & \\
\hline & $\begin{array}{l}\text { Strength } \\
(p s i)\end{array}$ & 5217 & 5093 & 4810 & 5040 \\
\hline \multirow{2}{*}{41} & Load $(l b s)$ & 151000 & 152000 & 123000 & \\
\hline & $\begin{array}{l}\text { Strength } \\
(p s i)\end{array}$ & 5341 & 5376 & 4350 & 5022 \\
\hline \multirow{2}{*}{59} & Load $(l b s)$ & 135000 & 138000 & 146000 & \\
\hline & $\begin{array}{l}\text { Strength } \\
\text { (psi) }\end{array}$ & 4775 & 4881 & 5164 & 4940 \\
\hline \multirow{2}{*}{77} & Load $(l b s)$ & 117000 & 132000 & 140000 & \\
\hline & $\begin{array}{l}\text { Strength } \\
(p s i)\end{array}$ & 4138 & 4669 & 4951 & 4586 \\
\hline \multirow{2}{*}{95} & Load $(l b s)$ & 99000 & 125000 & 140000 & \\
\hline & $\begin{array}{l}\text { Strength } \\
(p s i)\end{array}$ & 3501 & 4421 & 4951 & 4291 \\
\hline \multirow{2}{*}{113} & Load $(l b s)$ & 85000 & 124800 & 125000 & \\
\hline & $\begin{array}{l}\text { Strength } \\
(p s i)\end{array}$ & 3006 & 4414 & 4421 & 3947 \\
\hline \multirow{2}{*}{131} & Load $(l b s)$ & 130000 & 40000 & 122000 & \\
\hline & $\begin{array}{l}\text { Strength } \\
(p s i)\end{array}$ & 4598 & 1415 & 4315 & 3442 \\
\hline
\end{tabular}


Table A.5 Compression Results at Varying Degrees of Saturation

\begin{tabular}{|c|c|c|c|c|c|c|}
\hline $\begin{array}{c}\text { Degree } \\
\text { Saturation } \\
(\%)\end{array}$ & & Specimen 1 & Specimen 2 & Specimen 3 & Specimen 4 & Average \\
\hline \multirow{2}{*}{0} & Load $(l b s)$ & 158000 & 152000 & 148000 & 156000 & \\
\hline & $\begin{array}{c}\text { Strength } \\
(p s i)\end{array}$ & 5588 & 5376 & 5234 & 5517 & 5429 \\
\hline \multirow{2}{*}{20} & Load $(l b s)$ & 140000 & 146000 & 155000 & 147000 & \\
\hline & $\begin{array}{l}\text { Strength } \\
(p s i)\end{array}$ & 4951 & 5164 & 5482 & 5199 & 5199 \\
\hline \multirow{2}{*}{40} & Load $(l b s)$ & 138000 & 140000 & 135000 & 137000 & \\
\hline & $\begin{array}{c}\text { Strength } \\
(p s i)\end{array}$ & 4881 & 4951 & 4775 & 4845 & 4863 \\
\hline \multirow{2}{*}{60} & Load $(l b s)$ & 144000 & 130000 & 129000 & 135000 & \\
\hline & $\begin{array}{l}\text { Strength } \\
(p s i)\end{array}$ & 5093 & 4598 & 4562 & 4775 & 4757 \\
\hline \multirow{2}{*}{80} & Load $(l b s)$ & 120000 & 124000 & 125000 & 124500 & \\
\hline & $\begin{array}{l}\text { Strength } \\
(p s i)\end{array}$ & 4244 & 4386 & 4421 & 4403 & 4364 \\
\hline \multirow{2}{*}{100} & Load $(l b s)$ & 119000 & 106000 & 130000 & 114000 & \\
\hline & $\begin{array}{l}\text { Strength } \\
\quad(p s i)\end{array}$ & 4209 & 3749 & 4598 & 4032 & 4147 \\
\hline
\end{tabular}




\section{A.3 Split Tensile Testing Data}

Table A.6 Tension Results During the Curing Process at Room Temperature

\begin{tabular}{|c|c|c|c|c|c|}
\hline & & $\begin{array}{c}\text { Specimen } 1 \\
\text { (Tension) }\end{array}$ & $\begin{array}{c}\text { Specimen } 2 \\
\text { (Tension) }\end{array}$ & $\begin{array}{c}\text { Specimen } 3 \\
\text { (Tension) }\end{array}$ & Average \\
\hline \multirow{2}{*}{ Day 1} & Load $(l b s)$ & 19400 & 13400 & 15200 & \\
\hline & $\begin{array}{c}\text { Strength } \\
(p s i)\end{array}$ & 386 & 267 & 302 & 318 \\
\hline \multirow{2}{*}{ Day 3} & Load $(l b s)$ & 13000 & 18400 & 16300 & \\
\hline & $\begin{array}{l}\text { Strength } \\
(p s i)\end{array}$ & 259 & 366 & 324 & 316 \\
\hline \multirow{2}{*}{ Day 7} & Load $(l b s)$ & 19000 & 16000 & 22200 & \\
\hline & $\begin{array}{l}\text { Strength } \\
(p s i)\end{array}$ & 378 & 318 & 442 & 379 \\
\hline \multirow{2}{*}{ Day 14} & Load $(l b s)$ & 21900 & 23200 & 12400 & \\
\hline & $\begin{array}{l}\text { Strength } \\
(p s i)\end{array}$ & 436 & 462 & 247 & 381 \\
\hline \multirow{2}{*}{ Day 21} & Load $(l b s)$ & 23400 & 22100 & 21500 & \\
\hline & $\begin{array}{l}\text { Strength } \\
(p s i)\end{array}$ & 466 & 440 & 428 & 444 \\
\hline
\end{tabular}


Table A.7 Tension Results of Cured Concrete at Varying Temperatures

\begin{tabular}{|c|c|c|c|c|c|}
\hline $\begin{array}{c}\text { Temperature } \\
\left({ }^{\circ} \mathbf{F}\right)\end{array}$ & & $\begin{array}{c}\text { Specimen } 1 \\
\text { (Compression) }\end{array}$ & $\begin{array}{c}\text { Specimen } 2 \\
\text { (Compression) }\end{array}$ & $\begin{array}{c}\text { Specimen } 3 \\
\text { (Compression) }\end{array}$ & Average \\
\hline \multirow{2}{*}{-13} & Load $(l b s)$ & 25300 & 26900 & 29700 & \\
\hline & $\begin{array}{l}\text { Strength } \\
(p s i)\end{array}$ & 503 & 535 & 591 & 543 \\
\hline \multirow{2}{*}{5} & Load $(l b s)$ & 26000 & 26200 & 27900 & \\
\hline & $\begin{array}{l}\text { Strength } \\
\quad(p s i)\end{array}$ & 517 & 521 & 555 & 531 \\
\hline \multirow{2}{*}{23} & $\begin{array}{l}\text { Load } \\
(l b s)\end{array}$ & 23900 & 24000 & 24900 & \\
\hline & $\begin{array}{l}\text { Strength } \\
(p s i)\end{array}$ & 475 & 477 & 495 & 483 \\
\hline \multirow{2}{*}{41} & Load $(l b s)$ & 21700 & 24900 & 23600 & \\
\hline & $\begin{array}{l}\text { Strength } \\
(p s i)\end{array}$ & 432 & 495 & 470 & 466 \\
\hline \multirow{2}{*}{59} & Load $(l b s)$ & 24700 & 22600 & 22400 & \\
\hline & $\begin{array}{l}\text { Strength } \\
(p s i)\end{array}$ & 491 & 450 & 446 & 462 \\
\hline \multirow{2}{*}{77} & Load $(l b s)$ & 24100 & 21600 & 21900 & \\
\hline & $\begin{array}{l}\text { Strength } \\
(p s i)\end{array}$ & 479 & 430 & 436 & 448 \\
\hline \multirow{2}{*}{95} & Load $(l b s)$ & 21200 & 21500 & 21400 & \\
\hline & $\begin{array}{l}\text { Strength } \\
(p s i)\end{array}$ & 422 & 428 & 426 & 425 \\
\hline \multirow{2}{*}{113} & Load $(l b s)$ & 17100 & 17900 & 18100 & \\
\hline & $\begin{array}{l}\text { Strength } \\
(p s i)\end{array}$ & 340 & 356 & 360 & 352 \\
\hline \multirow{2}{*}{131} & Load $(l b s)$ & 15400 & 16500 & 16400 & \\
\hline & $\begin{array}{l}\text { Strength } \\
(p s i)\end{array}$ & 306 & 328 & 326 & 320 \\
\hline
\end{tabular}


Table A.8 Tensile Results at Varying Degrees of Saturation

\begin{tabular}{|c|c|c|c|c|c|c|}
\hline $\begin{array}{c}\text { Degree } \\
\text { Saturation } \\
(\%)\end{array}$ & & Specimen 1 & Specimen 2 & Specimen 3 & Specimen 4 & Average \\
\hline \multirow{2}{*}{0} & Load $(l b s)$ & 26400 & 28300 & 27600 & 26000 & \\
\hline & $\begin{array}{l}\text { Strength } \\
(p s i)\end{array}$ & 525 & 563 & 549 & 517 & 539 \\
\hline \multirow{2}{*}{20} & Load $(l b s)$ & 25600 & 25300 & 25600 & 26200 & \\
\hline & $\begin{array}{l}\text { Strength } \\
(p s i)\end{array}$ & 509 & 503 & 509 & 521 & 511 \\
\hline \multirow{2}{*}{40} & Load $(l b s)$ & 24100 & 23700 & 25100 & 23600 & \\
\hline & $\begin{array}{c}\text { Strength } \\
(p s i)\end{array}$ & 479 & 471 & 499 & 470 & 480 \\
\hline \multirow{2}{*}{60} & Load $(l b s)$ & 23500 & 23600 & 21800 & 23000 & \\
\hline & $\begin{array}{l}\text { Strength } \\
(p s i)\end{array}$ & 468 & 470 & 434 & 458 & 457 \\
\hline \multirow{2}{*}{80} & Load $(l b s)$ & 20900 & 20700 & 19500 & 20100 & \\
\hline & $\begin{array}{l}\text { Strength } \\
(p s i)\end{array}$ & 416 & 412 & 388 & 400 & 404 \\
\hline \multirow{2}{*}{100} & Load $(l b s)$ & 18700 & 17400 & 16800 & 17500 & \\
\hline & $\begin{array}{l}\text { Strength } \\
\quad(p s i)\end{array}$ & 372 & 346 & 334 & 348 & 357 \\
\hline
\end{tabular}




\section{A.4 Forney Actuator}

The compression and split tension tests are done using a Forney Testing Machines manually controlled actuator. The specifications are listed below:

Table A.9 Forney Actuator Specifications

\begin{tabular}{|l|l|}
\hline Model Number & Forney Model Number LT-700-2 \\
\hline Ranges & $\begin{array}{l}6,000 \mathrm{lbf} \text { to } 60,000 \mathrm{lbf} / 35,000 \mathrm{lbf} \text { to } \\
350,000 \mathrm{lbf}\end{array}$ \\
\hline Serial Number & 71087 \\
\hline Identification Number & $0 \mathrm{~B} 04317$ \\
\hline ASTM & E-04-02 \\
\hline Calibration Date & $2-19-2004$ \\
\hline Calibration Technician & WWStumpIII \\
\hline
\end{tabular}

More information about Forney Testing Machines can be found at the address

below:

Forney Incorporated

P.O. Box 310

New Castle, PA 16101

More information about the calibration company Calibration Services

Incorporated can be found at the address below:

Calibration Services Incorporated (CSI)

P.O. Box 735

Emlenton, PA 16373

Phone: (724)867-6664 or (800)793-1870

E-mail: csis@csonline.net

Web: www.calibrattonic.com 


\section{A.5 Oven}

The oven used to dry the specimens was made by The Grieve Corporation. The specifications are listed below:

Table A.10 Oven Specifications

\begin{tabular}{|l|l|}
\hline Model Number & 333 \\
\hline Maximum Temperature & $400 \mathrm{deg} \mathrm{F}$ \\
\hline Volts & 230 \\
\hline Amps & 33 \\
\hline Phase & 1 \\
\hline Hertz & 60 \\
\hline Largest Fan Motor & $.333 \mathrm{hp}$ \\
\hline Heat Input & $6.6 \mathrm{kw}$ \\
\hline Fuel & Electric \\
\hline Serial Number & $79589 \mathrm{~A} 0304$ \\
\hline
\end{tabular}

More information can be found on the oven at the following address:

The Grieve Corporation

Round Lake, IL 60073-2898

The oven has too large racks capable of holding all of the specimens at once which sped up the process. A powerful fan circulated air well enough to distribute the temperature very evenly among the specimens and remove the moisture more efficiently than an oven without a fan. 


\section{A.6 Concrete Mixture}

\section{Table A.11 Concrete Mixture}

\begin{tabular}{|l|l|}
\hline Type 1 Portland Cement (Armstrong) & $658 \mathrm{lbs}$ \\
\hline Air Content (by Volume) & $11 \mathrm{oz}$ per yd $\pm 7 \%$ \\
\hline Coarse Aggregate (Greer Lmst) & $1775 \mathrm{lbs}$ \\
\hline Fine Aggregate (Stocker Sand) & $1133 \mathrm{lbs}$ \\
\hline Water & 32 gallons \\
\hline Design Unit Weight & $142 \mathrm{lbs} / \mathrm{cubic}$ foot \\
\hline Water/Cement Ratio & 0.4 \\
\hline
\end{tabular}


MTS

\section{MTS Systems Corporation}

14000 Technology Drive

Eden Prairie, MN 55344-2290

MTS Field Service

\section{Certificate of Calibration}

Name: WVU

System ID: 100 kip portal frame

Device Type: Length

Controller/Conditioner Model: 407.14

Readout Device Model: 407.14

\begin{tabular}{lc}
$\begin{array}{l}\text { Customer } \\
\text { Equipment } \\
\end{array}$ & System ID: 100 kip portal frame \\
\hline & Device Type: Length \\
Controller/Conditioner Model: 407.14 \\
Readout Device Model: 407.14
\end{tabular}

MTS Field Service is accredited by the American Association for Laboratory Accreditation (A2LA Cert. No. 1145.01). The basis for this accreditation is the international standard for calibration laboratories, ISO/IEC 17025

"General Requirements for the Competence of Calibration and Testing Laboratories".

Defined and documented measurement assurance techniques or uncertainty analyses are used to verify the adequacy of the measurement processes. These techniques or analyses are available upon request.

Calibrations are performed with standards whose values and measurements are traceable to the National Institute of Standards and Technology.

\section{CALIBRATION INFORMATION}

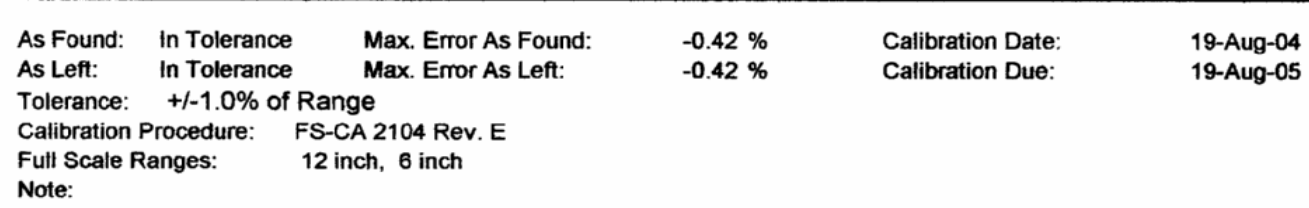

\section{STANDARDS USED FOR CALIBRATION}

\begin{tabular}{|c|c|c|c|c|c|}
\hline MTS Asset Number & Manufacturer & Model Number & Description & Cal. Date & Cal. Due \\
\hline 17358 & Fluke & 189 & Fluke 189 & 4-Feb-04 & 4-Feb-05 \\
\hline 13477 & Fluke & $80 T U 140$ & Temp Probe & 13-Nov-03 & 13-Nov-04 \\
\hline 15295 & Boeckeler (9 pin) & Microcode II & Boeckler & 19-Feb-04 & 19-Feb-05 \\
\hline
\end{tabular}

Certified r..




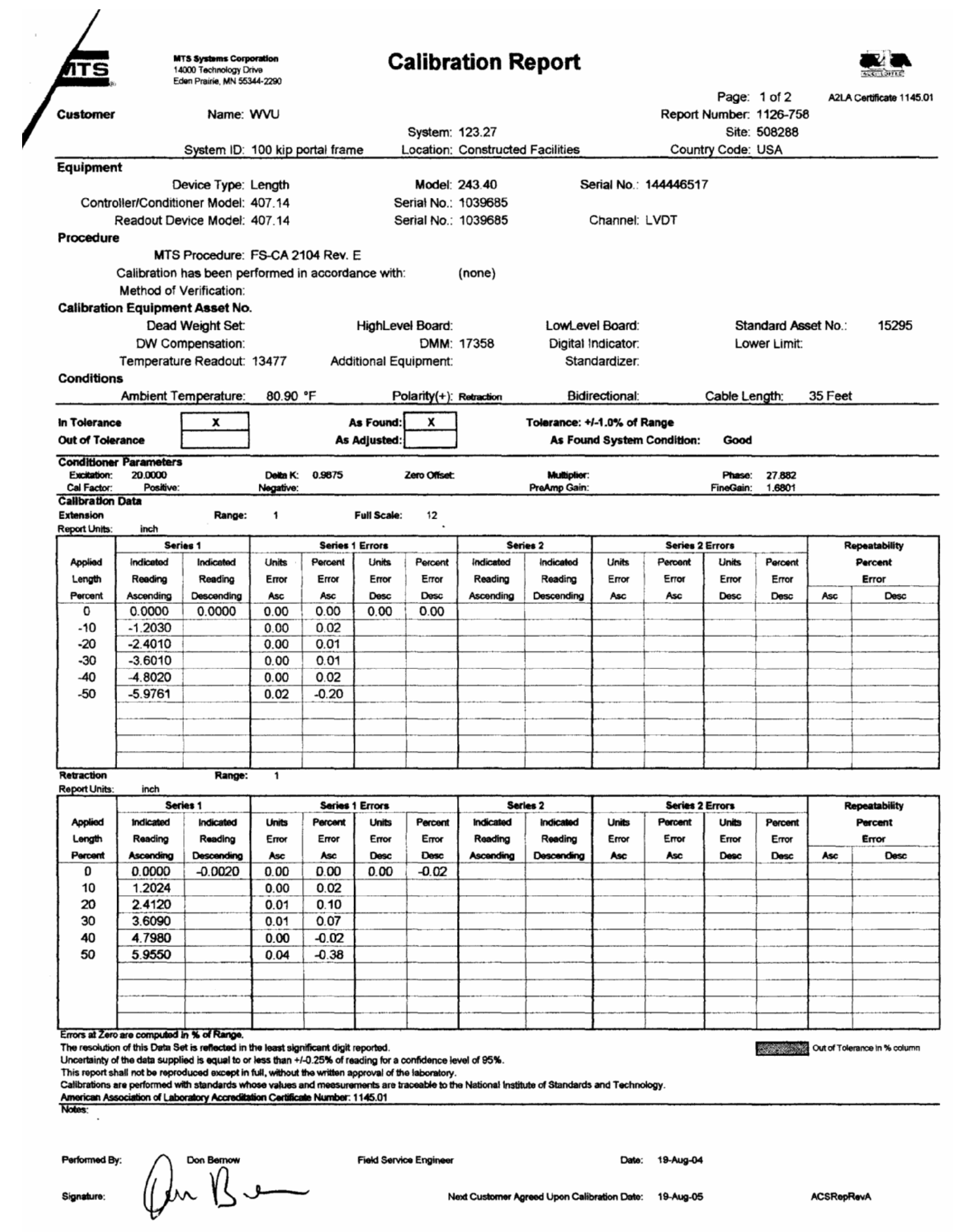




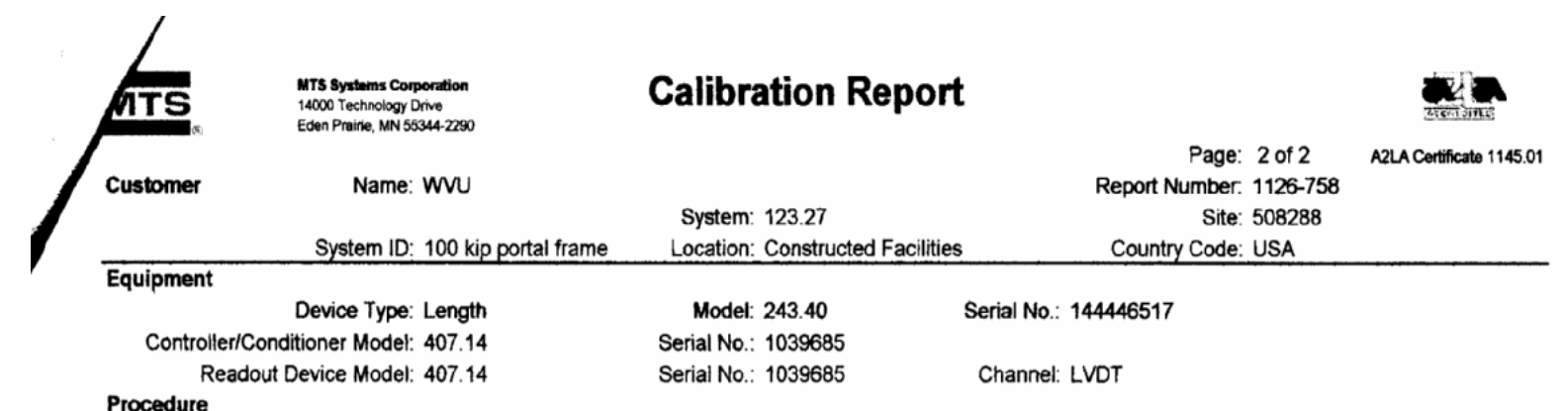

Procedure

MTS Procedure: FS-CA 2104 Rev. E

Calibration has been performed in accordance with: (none)

Method of Verification:

Calibration Equipment Asset No.

Dead Weight Set: $\quad$ HighLevel Board: $\quad$ Lowlevel Board: $\quad$ Standard Asset No.: 15295

DMM: 17358 Digital Indicator. Lower Limit

Conditions

Temperature Readout: 13477 Additional Equipment: Standardizer:

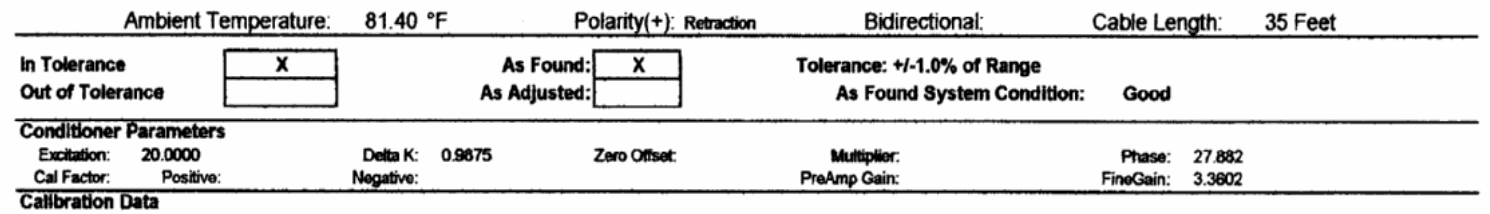

$\begin{array}{lllll}\text { Extension } & \text { Range: } & 2 & \text { Full Scale: } 6\end{array}$

\begin{tabular}{|c|c|c|c|c|c|c|c|c|c|c|c|c|c|c|}
\hline \multirow{4}{*}{$\begin{array}{l}\text { Applied } \\
\text { Length } \\
\text { Percent }\end{array}$} & \multirow{2}{*}{\multicolumn{2}{|c|}{$\begin{array}{l}\text { inch } \\
\text { Series } 1\end{array}$}} & \multirow{2}{*}{\multicolumn{4}{|c|}{ Series 1 Errors }} & \multirow{2}{*}{\multicolumn{2}{|c|}{ Series 2}} & & & & & & \\
\hline & & & & & & & & & \multicolumn{4}{|c|}{ Series 2 Errors } & \multirow{2}{*}{\multicolumn{2}{|c|}{$\begin{array}{c}\text { Repeatability } \\
\text { Percent } \\
\text { Error }\end{array}$}} \\
\hline & \multirow{2}{*}{$\begin{array}{l}\text { Indicated } \\
\text { Reading } \\
\text { Ascending }\end{array}$} & \multirow{2}{*}{$\begin{array}{l}\text { Indicatod } \\
\text { Reading } \\
\text { Descending }\end{array}$} & \multirow{2}{*}{$\begin{array}{l}\text { Units } \\
\text { Error } \\
\text { Asc }\end{array}$} & \multirow{2}{*}{$\begin{array}{l}\text { Percent } \\
\text { Error } \\
\text { Asc }\end{array}$} & \multirow{2}{*}{$\begin{array}{l}\text { Units } \\
\text { Error } \\
\text { Desc }\end{array}$} & \multirow{2}{*}{$\begin{array}{c}\text { Percent } \\
\text { Error } \\
\text { Desc }\end{array}$} & \multirow{2}{*}{$\begin{array}{l}\text { Indicatod } \\
\text { Reading } \\
\text { Ascending }\end{array}$} & \multirow{2}{*}{$\begin{array}{c}\text { Indicated } \\
\text { Roading } \\
\text { Descending }\end{array}$} & \multirow{2}{*}{$\begin{array}{l}\text { Units } \\
\text { Emor } \\
\text { Asc }\end{array}$} & \multirow{2}{*}{$\begin{array}{l}\text { Percent } \\
\text { Error } \\
\text { Asc }\end{array}$} & \multirow{2}{*}{$\begin{array}{l}\text { Units } \\
\text { Enror } \\
\text { Desc }\end{array}$} & \multirow{2}{*}{$\begin{array}{l}\text { Percont } \\
\text { Error } \\
\text { Desc }\end{array}$} & & \\
\hline & & & & & & & & & & & & & Asc & Dosc \\
\hline 0 & 0.00000 & -0.00160 & 0.00 & 0.00 & 0.00 & -0.03 & & & & & & & & \\
\hline-20 & -1.20340 & & 0.00 & 0.06 & & & & & & & & & & \\
\hline-40 & -2.40080 & & 0.00 & 0.01 & & & & & & & & & & \\
\hline-60 & -3.60130 & & 0.00 & 0.02 & & & & & & & & & & \\
\hline-80 & -4.80260 & & 0.00 & 0.04 & & & & & & & & & & \\
\hline \multirow[t]{5}{*}{-100} & -5.97470 & & 0.03 & -0.42 & & & & & & & & & & \\
\hline & & & & & & & & & & & & & & \\
\hline & & & & & & & & & & & & & & \\
\hline & & & & & & & & & & & & & & \\
\hline & & & & & & & & & & & & & & \\
\hline
\end{tabular}

Retraction Units: inch

\begin{tabular}{|c|c|c|c|c|c|c|c|c|c|c|c|c|c|c|}
\hline Report Units & inch & & & & & & & & & & & & & \\
\hline & Ser & & & Series & Errors & & & es 2 & & Series: & Errors & & & ability \\
\hline $\begin{array}{l}\text { Applied } \\
\text { Length }\end{array}$ & $\begin{array}{l}\text { Indicated } \\
\text { Reading }\end{array}$ & $\begin{array}{c}\text { Indicatod } \\
\text { Reading }\end{array}$ & $\begin{array}{l}\text { Units } \\
\text { Error }\end{array}$ & $\begin{array}{l}\text { Percent } \\
\text { Error }\end{array}$ & $\begin{array}{l}\text { Units } \\
\text { Error }\end{array}$ & $\begin{array}{l}\text { Percent } \\
\text { Error }\end{array}$ & $\begin{array}{l}\text { Indicated } \\
\text { Reading }\end{array}$ & $\begin{array}{l}\text { Indicated } \\
\text { Reading }\end{array}$ & $\begin{array}{l}\text { Units } \\
\text { Error }\end{array}$ & $\begin{array}{l}\text { Percent } \\
\text { Error }\end{array}$ & $\begin{array}{l}\text { Units } \\
\text { Emor }\end{array}$ & $\begin{array}{l}\text { Percent } \\
\text { Error }\end{array}$ & & $\begin{array}{l}\text { ort } \\
\text { or }\end{array}$ \\
\hline Porcent & Ascending & Descending & Asc & Asc & Desc & Desc & Ascending & Descending & Asc & Asc & Desc & Desc & Asc & Desc \\
\hline 0 & 0.00000 & -0.00190 & 0.00 & 0.00 & 0.00 & -0.03 & & & & & & & & \\
\hline 20 & 1.20360 & & 0.00 & 0.06 & & & & & & & & & & \\
\hline 40 & 2.40980 & & 0.01 & 0.16 & & & & & & & & & & \\
\hline 60 & 3.60950 & & 0.01 & 0.16 & & & & & & & & & & \\
\hline 80 & 4.79850 & & 0.00 & -0.02 & & & & & & & & & & \\
\hline 100 & 5.97670 & & 0.02 & -0.39 & & & & & & & & & & \\
\hline & & & & & & & & & & & & & & \\
\hline & & & & & & & & & & & & & & \\
\hline & & & & & & & & & & & & & & \\
\hline & & & & & & & & & & & & & & \\
\hline $\begin{array}{l}\text { Emors at Zen } \\
\text { The resolutio } \\
\text { Uncertainty } \\
\text { This report s } \\
\text { Calibrations } \\
\text { American As }\end{array}$ & $\begin{array}{l}\text { are oomputed } \\
\text { of this Datu S } \\
\text { the data suppli } \\
\text { all not be repro } \\
\text { ociation of Lab }\end{array}$ & $\begin{array}{l}\text { Wofkange. } \\
t \text { is reflected in } \\
\text { ed is equal to or } \\
\text { uced except in } \\
\text { th standands wh } \\
\text { ratory Accredita }\end{array}$ & $\begin{array}{l}\text { least sin } \\
\text { is than } \\
\text { ithou } \\
\text { in values } \\
\text { Cortific }\end{array}$ & $\begin{array}{l}\text { cant dig } \\
25 \% \text { of } \\
\text { i written } \\
\text { I measu } \\
\text { Numbe }\end{array}$ & $\begin{array}{l}\text { orted. } \\
\text { ing for a } \\
\text { roval of } \\
\text { nts are } \\
45.01\end{array}$ & elatal & $\begin{array}{l}\text { of } 95 \% \text {. } \\
\text { ational in }\end{array}$ & 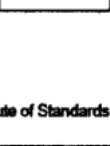 & 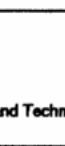 & & & 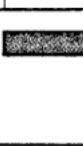 & Out of To & in $\mathbf{x}$ colum \\
\hline
\end{tabular}

Pertormed By: Don Bernow

Field Service Engineer

Date: 19-Aug-04

Signature:

Next Customer Agreed Upon Calibration Date: $\quad$ 19-Aug-05

ACSRepReve 


\title{
MTS Systems Corporation
}

14000 Technology Drive

Eden Prairie, MN 55344-2290

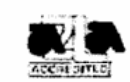

A2LA Certificate 1145.01

\author{
MTS Field Service
}

Certificate of Calibration

\begin{tabular}{|c|c|c|}
\hline \multirow[t]{2}{*}{ Name: WVU } & \multicolumn{2}{|c|}{$\begin{array}{c}\text { Page: } 1 \text { of } 1 \\
\text { Certificate Number: } 1126-757\end{array}$} \\
\hline & System: 123.27 & Site: $\mathbf{5 0 8 2 8 8}$ \\
\hline System ID: 100 kip portal frame & Location: Constructed Facilities & Country Code: USA \\
\hline \multicolumn{3}{|l|}{ Equipment } \\
\hline Device Type: Force & Model: 661.23E-01 & Serial No.: 1381914 \\
\hline Controller/Conditioner Model: 407.12 & Serial No.: 1038509 & \\
\hline Readout Device Model: 407.14 & Serial No.: 1038509 & Channel: Force \\
\hline
\end{tabular}

MTS Field Service is accredited by the American Association for Laboratory Accreditation (A2LA Cert. No. 1145.01).

The basis for this accreditation is the international standard for calibration laboratories, ISO/IEC 17025

"General Requirements for the Competence of Calibration and Testing Laboratories".

Defined and documented measurement assurance techniques or uncertainty analyses are used to verify the adequadicy of the measuitement processes. These techniques or analyses are available upon request.

Calibrations are performed with standards whose values and measurements are traceable to the National institute of Standards and Technology.

\section{CALIBRATION INFORMATION}

$\begin{array}{lllll}\text { As Found: } & \text { In Tolerance } \quad \text { Max. Error As Found: } & 0.67 \% & \text { Calibration Date: } & 19-A u g-04 \\ \text { As Left: In Tolerance } \quad \text { Max. Error As Left: } & 0.67 \% & \text { Calibration Due: } & 19-A u g-05 \\ \text { Tolerance: }+/-1.0 \% \text { of Applied Force } & & \\ \text { Calibration Procedure: } \quad \text { FS-CA 2103 Rev. E } & & \\ \text { Full Scale Ranges: } \quad 100000 \text { lbf, } 50000 \text { lbf } & & \\ \text { Note: } & & & \end{array}$

\section{STANDARDS USED FOR CALIBRATION}

\begin{tabular}{|c|c|}
\hline MTS Asset Number & Manufacturer \\
\hline 17333 & Interface Inc. \\
\hline 17358 & Fluke \\
\hline 13477 & Fluke \\
\hline 10559 & DJ \\
\hline 13824 & Revere \\
\hline
\end{tabular}

\begin{tabular}{llll} 
Model Number & Description & $\underline{\text { Cal. Date }}$ & \multicolumn{1}{c}{ Cal. Due } \\
\hline 9840 & Interface Indicator & 27-May-04 & 27-May-05 \\
189 & Fluke 189 & 4-Feb-04 & 4-Feb-05 \\
$80 T U 140$ & Temp Probe & $13-$ Nov-03 & $13-$ Nov-04 \\
STZ-2 & STZ & $13-$ Nov-03 & $13-$ Nov-04 \\
42U-D3-100K & Revere 100 kip cell & 13-Apr-04 & 13-Oct-05
\end{tabular}

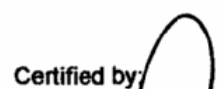

n

Issued on: 19-Aug-04 


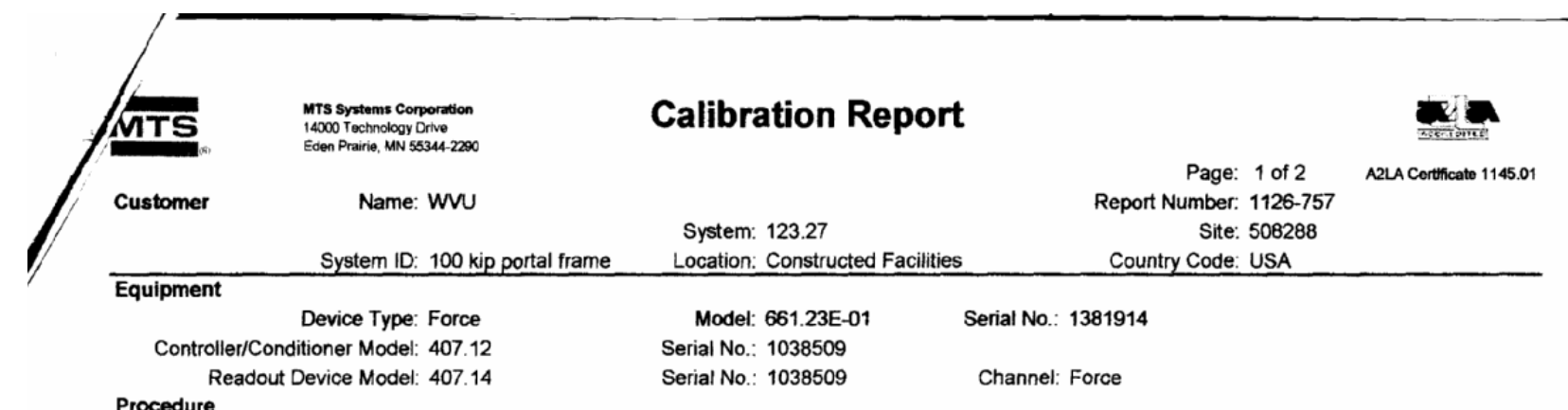

Procedure MTS Procedure: FS-CA 2103 Rev. E

Calibration has been performed in accordance with: $\quad$ ASTM E4-03

Method of Verification: Set-the-Force Method using Elastic Calibration Devices Calibration Equipment Asset No.

$\begin{array}{cccc}\text { Dead Weight Set: } & \text { HighLevel Board: } & \text { LowLevel Board: } & \text { Standard Asset No.: } 13824 \\ \text { DW Compensation: } & \text { DMM: } 17358 & \text { Digital Indicator: } 17333 & \text { Lower Limit: } 6422.7 \text { lbf }\end{array}$
Conditions

Temperature Readout: $13477 \quad$ Additional Equipment: $\quad$ Standardizer. 10559

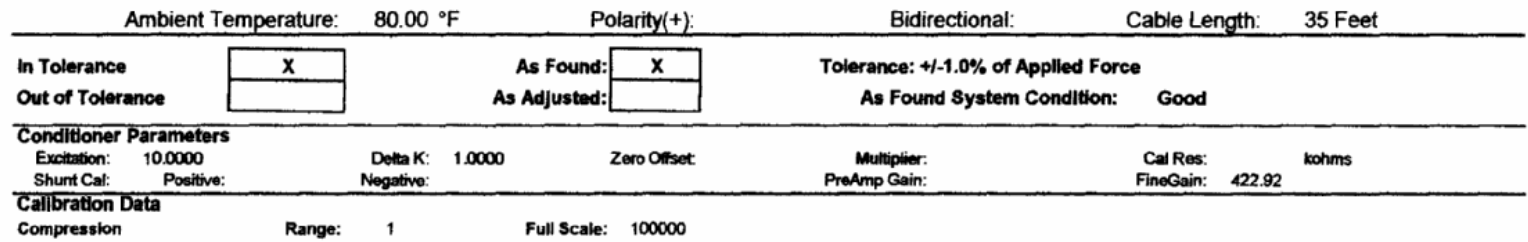

$\begin{array}{llll}\text { Compression Range: } & 1 & \text { Full Scale: } 100000\end{array}$

\begin{tabular}{|c|c|c|c|c|c|c|c|c|c|c|c|c|c|c|}
\hline \multirow{3}{*}{$\begin{array}{l}\text { Appliad } \\
\text { Force } \\
\text { Percent }\end{array}$} & \multicolumn{2}{|c|}{ Series 1} & \multicolumn{4}{|c|}{ Series 1 Errors } & \multicolumn{2}{|c|}{ Series 2} & \multicolumn{4}{|c|}{ Series 2 Errors } & \multirow{2}{*}{\multicolumn{2}{|c|}{$\begin{array}{l}\text { Repeatability } \\
\text { Percent } \\
\text { Error }\end{array}$}} \\
\hline & \multirow{2}{*}{$\begin{array}{l}\text { Indicated } \\
\text { Reading } \\
\text { Asconding }\end{array}$} & \multirow{2}{*}{$\begin{array}{c}\text { Indicated } \\
\text { Reading } \\
\text { Doscending }\end{array}$} & \multirow{2}{*}{$\begin{array}{l}\text { Units } \\
\text { Error } \\
\text { Asc }\end{array}$} & \multirow{2}{*}{$\begin{array}{l}\text { Percent } \\
\text { Error } \\
\text { Asc }\end{array}$} & \multirow{2}{*}{$\begin{array}{l}\text { Units } \\
\text { Error } \\
\text { Dosc }\end{array}$} & \multirow{2}{*}{$\begin{array}{l}\text { Percent } \\
\text { Eror } \\
\text { Desc }\end{array}$} & \multirow{2}{*}{$\begin{array}{l}\text { Indicatod } \\
\text { Reading } \\
\text { Asconding }\end{array}$} & \multirow{2}{*}{$\begin{array}{c}\text { Indicatod } \\
\text { Reading } \\
\text { Descending }\end{array}$} & \multirow{2}{*}{$\begin{array}{l}\text { Units } \\
\text { Error } \\
\text { Asc }\end{array}$} & \multirow{2}{*}{$\begin{array}{l}\text { Percont } \\
\text { Emor } \\
\text { Asc }\end{array}$} & \multirow{2}{*}{$\begin{array}{l}\text { Units } \\
\text { Error } \\
\text { Desc }\end{array}$} & \multirow{2}{*}{$\begin{array}{c}\text { Percont } \\
\text { Error } \\
\text { Dosc }\end{array}$} & & \\
\hline & & & & & & & & & & & & & Asc & Desc \\
\hline 0 & 0.0 & 0.5 & 0.00 & 0.00 & 0.50 & 0.00 & 0.0 & -3.5 & 0.00 & 0.00 & 3.50 & 0.00 & 0.00 & 0.00 \\
\hline-20 & -20117.0 & & 117.00 & 0.59 & & & -20110.0 & & 110.00 & 0.55 & & & 0.03 & \\
\hline-40 & -40132.0 & & 132.00 & 0.33 & & & -40129.0 & & 129.00 & 0.32 & & & 0.01 & \\
\hline-60 & -60084.0 & & 84.00 & 0.14 & & & -60087.0 & & 87.00 & 0.15 & & & 0.00 & \\
\hline-80 & -80002.0 & & 2.00 & 0.00 & & & -80007.0 & & 7.00 & 0.01 & & & 0.01 & \\
\hline \multirow[t]{5}{*}{-100} & -99896.0 & & 104.00 & -0.10 & & & -99925.0 & & 75.00 & -0.08 & & & 0.03 & \\
\hline & & & & & & & & & & & & & & \\
\hline & & & & & & & & & & & & & & \\
\hline & & & & & & & & & & & & & & \\
\hline & & & & & & & & & & & & & & \\
\hline
\end{tabular}

Tension

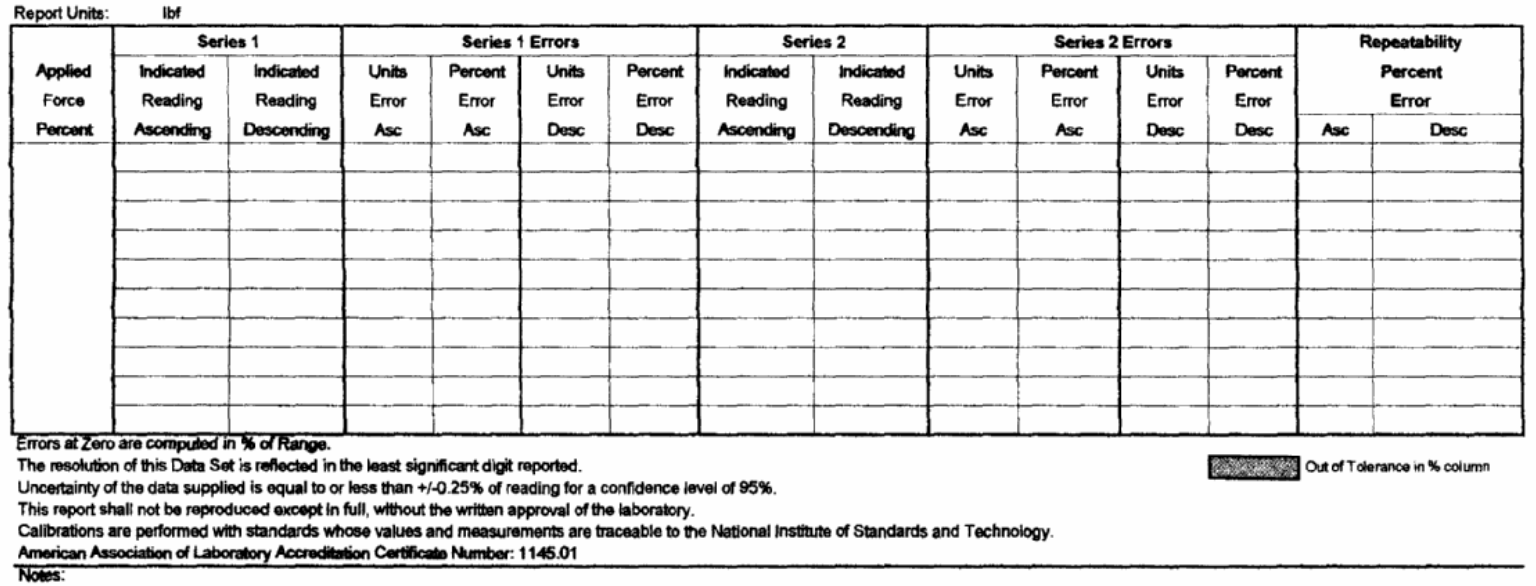

Pignetreared By: Don Bernow

Field Service Engineer

Dato: 19-Aug-04

Y

ACSRopReva 


\section{Calibration Report}

$\begin{array}{ll}\text { Customer Name: WVU } & \\ & \text { System: } 123.27\end{array}$

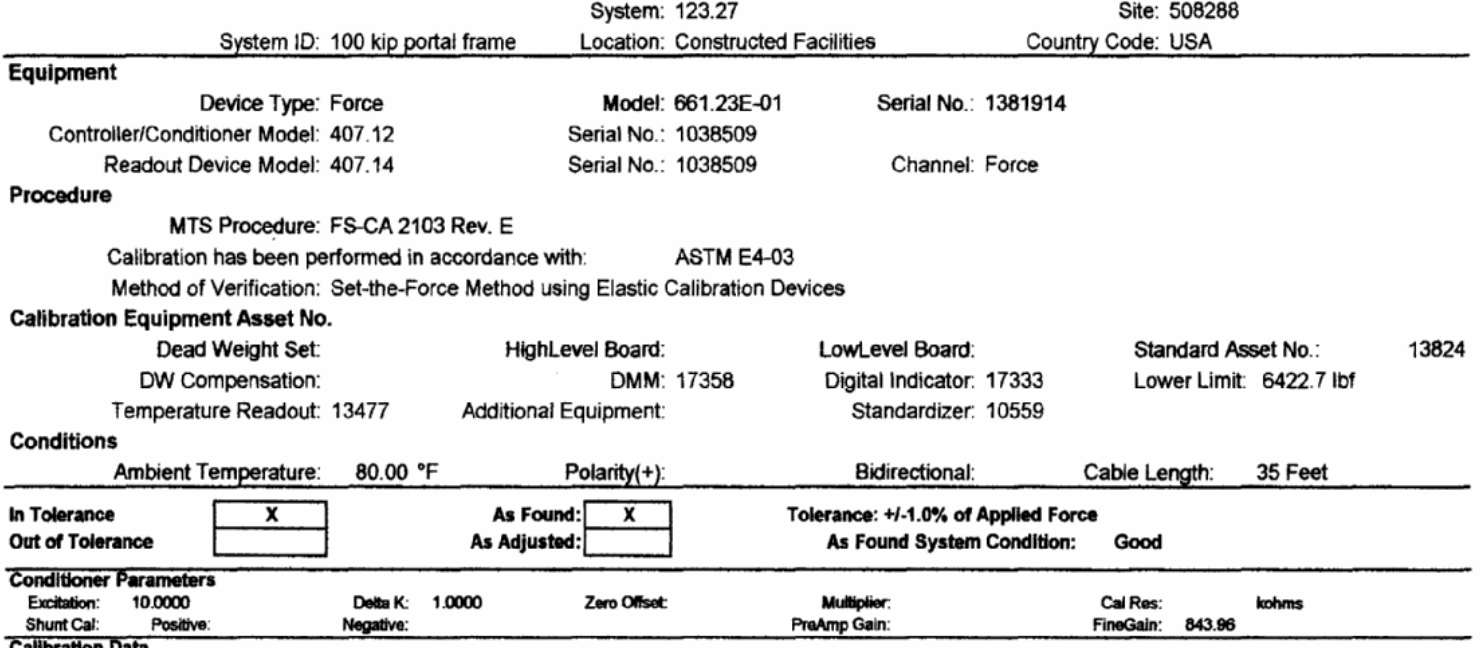

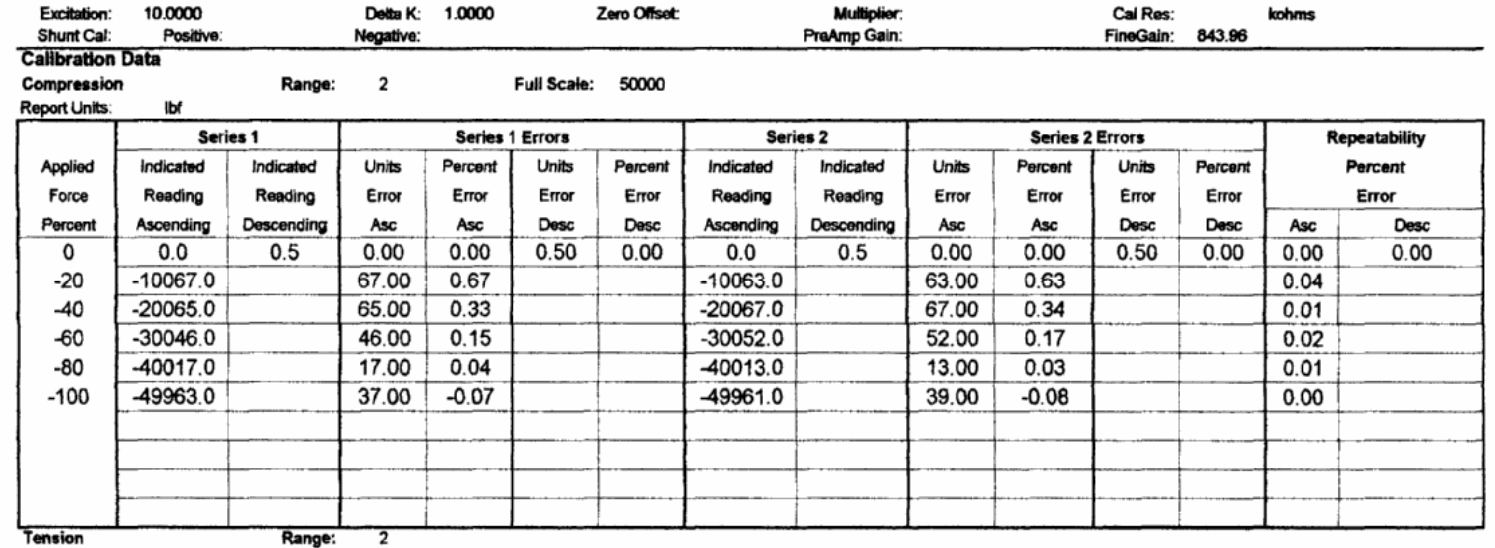

\section{Tension}

Report Units: It

\begin{tabular}{|c|c|c|c|c|c|c|c|c|c|c|c|c|c|c|}
\hline \multirow{2}{*}{\multicolumn{3}{|c|}{ Report Units: }} & \multirow{2}{*}{\multicolumn{4}{|c|}{ Series 1 Errors }} & \multirow{2}{*}{\multicolumn{2}{|c|}{ Series 2}} & \multirow{2}{*}{\multicolumn{4}{|c|}{ Series 2 Errors }} & \multirow{3}{*}{\multicolumn{2}{|c|}{$\begin{array}{c}\text { Repeatability } \\
\text { Percent } \\
\text { Error }\end{array}$}} \\
\hline & & & & & & & & & & & & & & \\
\hline \multirow{2}{*}{$\begin{array}{l}\text { Applied } \\
\text { Forco } \\
\text { Percent }\end{array}$} & \multirow{2}{*}{$\begin{array}{l}\text { Indicated } \\
\text { Reading } \\
\text { Ascending }\end{array}$} & \multirow{2}{*}{$\begin{array}{l}\text { Indicated } \\
\text { Reading } \\
\text { Descending }\end{array}$} & \multirow{2}{*}{$\begin{array}{l}\text { Units } \\
\text { Error } \\
\text { Asc }\end{array}$} & \multirow{2}{*}{$\begin{array}{l}\text { Percent } \\
\text { Error } \\
\text { Asc }\end{array}$} & \multirow{2}{*}{$\begin{array}{l}\text { Units } \\
\text { Error } \\
\text { Desc } \\
\end{array}$} & \multirow{2}{*}{$\begin{array}{l}\text { Percent } \\
\text { Emor } \\
\text { Desc }\end{array}$} & \multirow{2}{*}{$\begin{array}{l}\text { Indicated } \\
\text { Reading } \\
\text { Ascending }\end{array}$} & \multirow{2}{*}{$\begin{array}{l}\text { Indicated } \\
\text { Reading } \\
\text { Descending }\end{array}$} & \multirow{2}{*}{$\begin{array}{l}\text { Units } \\
\text { Error } \\
\text { Asc }\end{array}$} & \multirow{2}{*}{$\begin{array}{l}\text { Percent } \\
\text { Error } \\
\text { Asc }\end{array}$} & \multirow{2}{*}{$\begin{array}{l}\text { Units } \\
\text { Error } \\
\text { Desc }\end{array}$} & \multirow{2}{*}{$\begin{array}{l}\text { Percent } \\
\text { Error } \\
\text { Desc }\end{array}$} & & \\
\hline & & & & & & & & & & & & & Asc & Desc \\
\hline & & & & & & & & & & & & & & \\
\hline & & & & & & & & & & & & & & \\
\hline & & & & & & & & & & & & & & \\
\hline & & & & & & & & & & & & & & \\
\hline & & & & & & & & & & & & & & \\
\hline & & & & & & & & & & & & & & \\
\hline & & & & & & & & & & & & & & \\
\hline
\end{tabular}

Errors at Zero are computed in \$d Range

The resolution of this Data Set is reflectud in the least sionificant digit reported

Uncertainty of the data supplied is equal to or less than $+1-0.25 \%$ of roeding for a contidence level of $95 \%$.

This report shall not be reproduced except in full, without the writhen approval of the laboratory.

Calibrations are perfor

American Association of Laboratory Accreditation Cortificate Number: 1145.01

Notos:

Pertormed By: 1 Don Bernow

Field Servico Engineer Date: 19-Aug-04

Next Customer Agreed Upon Calibration Date: $19-A u g-05$

ACSRepReva 